\title{
REVISION OF THE INDO-PACIFIC SPECIES OF THE GENUS DISTICHOPORA
}

\author{
by
}

\author{
H. BOSCHMA
}

Rijksmuseum van Natuurlijke Historie, Leiden

\section{INTRODUCTION}

Twenty-one species of Distichopora have been described after specimens from various localities in the Indo-Pacific region, viz., D. violacea (Pallas, 1766) from "Mare Indicum", D. cinnabarina Nardo, 1844, from the Red Sea (?), D. gracilis Dana, 1848, from the Tuamotu Islands, $D$. coccinea Gray, 1860, from New Caledonia, $D$. fulvacea Michelin, 1862, from Réunion, D. nitida Verrill, 1864, from the Marshall Islands, $D$. rosea Kent, 1871, from the East coast of Australia, D. purpurea Schmeltz, 1875 (nomen nudum), from the Marshall Islands (?), D. irregularis Moseley, 1879 , from the Philippine Islands, $D$. livida Tenison-Woods, 1879 , from the Solomon Islands, $D$. brasseyi Wright, 1882, from the Gilbert Islands, $D$. allnutti Wright, 1882, from the Gilbert Islands (?), D. breviserialis Quelch, 1884, from unknown locality, D. milesii Quelch, 1884, from the Pacific (probably from the region of the Society and Tuamotu Islands), D. granulosa Quelch, 1885, from Rarotonga (?), $D$. conferta Quelch, 1885, from Rarotonga, $D$. ochracea Quelch, 1885, from the Solomon Islands, $D$. profunda Hickson \& England, 1909, from the Chagos Archipelago, $D$. borealis Fisher, 1938, from the Aleutian Islands, $D$. fisheri Broch, 1942, from the Fiji Islands, and $D$. serpens Broch, 1942, from the Philippine Islands. Most of the described species came from shallow water, only three species were collected from great depths, viz., $D$. profunda $(187-274 \mathrm{~m}), D$. borealis $(518-881 \mathrm{~m})$, and $D$. serpens $(91-183 \mathrm{~m})$. The type specimen of $D$. irregularis came from a depth of 10 fathoms $(18 \mathrm{~m})$.

To the species enumerated above should be added D. providentiae (Hickson \& England, 1909) from off Providence Island in the Western Indian Ocean, collected at a depth of 125 fathoms $(228 \mathrm{~m})$. This species was originally placed in the genus Sporadopora, but the manner of arrangement of the gastropores and the dactylopores indicate that it presents at least some affinity to the genus Distichopora, and accordingly it may provisionally find a place here.
Several attempts have been made to place the names of one or more of the described species of Distichopora into the synonymy of previously named species. Some of these proposed synonymies are accepted in the present paper, in many other instances a result has here been obtained that widely differs from the opinion of previous investigators. Of the twenty-one species of Distichopora described for the region, eight are here regarded as valid, eleven names are placed into the synonymy of earlier described species, while two of the described forms are considered species of uncertain standing. When including the species $D$. providentiae, this leads to the following arrangement (in chronological order of the original descriptions):

Distichopora violacea (Pallas) (synonyms cinnabarina Nardo, rosea Kent (?), and fisheri Broch).

Distichopora gracilis Dana (synonyms milesii Quelch, granulosa Quelch, and conferta Quelch).

Distichopora coccinea Gray (synonym purpurea Schmeltz, n. n.).

Distichopora fulvacea Michelin (species of uncertain standing).

Distichopora nitida Verrill (synonyms brasseyı Wright, allnutti Wright, breviserialis Quelch, and ochracea Quelch).

Distichopora irregularis Moseley.

Distichopora livida Tenison-Woods (species of uncertain standing).

Distichopora profunda Hickson \& England.

Distichopora providentiae (Hickson \& England) (specific characters well-defined, generic position uncertain).

Distichopora borealis Fisher.

Distichopora serpens Broch.

The most recent publication dealing with several species of the genus Distichopora is the valuable paper by ВRосн (1942), in which the characters of many different forms are accurately described. As 
far as the specific identification of the corals is concerned the views as laid down in the present paper differ in some respects from those of ВROCH, primarily owing to the fact that BrocH's conception of $D$. violacea does not correspond with the definition of the species in the present paper.

In the chapters dealing with the various species, the present paper contains references arranged in the manner of lists of synonyms. These lists consist of the different publications in which a certain name was found to occur; in many instances the data were too vague to determine whether the identification of the corals was correct or erroneous. When the true specific nature of the coral referred to could be ascertained, the reference has been recorded in its appropriate place, often in the synonymy of another species; numerous other references remain doubtful on account of insufficient characterization of the specimens in literature. The lists of references accordingly have an ambiguous character, partly consisting of real synonyms, partly of indications to corals recorded with the same name.

Attempts have been made to cover the literature on Stylasterine corals as complete as possible; it proved, however, an impossible task to collect all the references to these corals when more or less casually mentioned in publications containing faunal lists of a certain region, or published in works of a more general character. The manner in which more or less important data may escape detection may be illustrated with one example. When compiling a list of all the described species of the order Stylasterina with their apparent synonymies (Boschma, 1957), I was not aware of the existence of the works by Marllard (1862, 1863); when later I had occasion to consult these publications they proved to contain the description of Distichopora fulvacea Michelin. Fortunately this resurrection of a completely forgotten name (no references to this name were to be found in the literature of the group) did not give rise to nomenclatorial changes, as in all probability the described species is nothing else but a reddish-yellow colour variation of $D$. violacea, the type species of the genus. Some other data were puzzling on account of their lack of completeness. When I had come across the name "Distichopora purpurea Lütken" casually mentioned by SchmeLTz (1875) I tried in vain to find a description of this coral in LürkeN's papers. The question was solved when I received from Dr. F. Jensenius MAdSEN the specimens from the Copenhagen Museum indicated with this unpublished museum name (cf. Pl. VIII), leading to their identification with $D$. coccinea.

The notes on geographical distribution as they are given at the end of the chapters dealing with the various species do not contain all the data as they were published in the literature. A selection was made of the available data, keeping all those that seemed to be well-founded, and rejecting the dubious references or listing these with the indication "doubtful".

The measurements of the corals are always given in the same order of sequence, the first figure denoting the height, the second the greatest width of the colony. Sometimes there are slight differences between the measurements as given in the text and those to be obtained in the figures representing the corals in natural size. If this occurs the explanation is that the indication "natural size" should not be taken too literally, allowance to be made for a deviation of about 5 per cent.

For the privilege to examine specimens from the collections under their care I want to express my thanks to Dr. W. Adam (Brussels), Dr. F. M. Bayer (Washington, D.C.), Professor H. Graham Cannon (Manchester), Professor H. Engel (Amsterdam), Dr. J. W. Evans (Sydney), Dr. H. A. F. Gohar (Al Ghardaqa, Red Sea), Dr. F. Jensentus Madsen (Copenhagen), Mr. F. A. McNeill (Sydney), Dr. H. W. Parker (London), Dr. G. Ranson (Paris), Dr. W. J. ReEs (London), Mr. R. U. SAyce (Manchester), Mr. E. L. SEYD (Manchester), and Professor W. STEPHENSON (Brisbane).

\section{COMPARATIVE NOTES ON THE SPECIES OF DISTICHOPORA}

Like other sedentary organisms the species of Distichopora show considerable variation, apparently caused largely by the influence of the environment. In the following pages a review is given of the various structures that have been used to establish specific characters, and their variation in the species. Some of the data here presented are from previous publications, the greater part are based on the peculiarities of the specimens examined during the present investigation.

In the description of species of the genus $D i$ stichopora often much attention was paid to the condition of the sulci at the lateral borders of the branches (whether deep or shallow or absent), to the 
size of the gastropores (whether large or small), and to the configuration of the ampullae.

When taken in a general sense, the relative depth of the sulcus in many instances indeed furnishes a character of specific importance. In $D$. violacea and in $D$. gracilis the sulcus is as a rule very pronounced, rather deep. In certain colonies of $D$. violacea, however, the sulcus is very shallow, even vanishing in some parts, and in other colonies it is distinct in the smaller branches, very insignificant or even absent in the larger branches and the main stems. On the other hand in $D$. coccinea and $D$. nitida the sulcus is generally absent, the gastropores opening on the surface of the lateral margins of the branches. In some colonies of the two species, however, the smaller branches show a distinct sulcus, not as deep as in $D$. violacea, but forming a definite groove. Variation in the condition of the sulcus is very apparent in the corals that up to now have become known of the species $D$. irregularis; in the type specimen (MOSELEY, 1880, PI. 12 fig. 8a) the gastropores open in a fairly deep sulcus, while in the specimens described by ВRосн (1942) the sulcus is very shallow or absent.

The width of the sulcus also may show differences that to a certain degree seem to be of specific value. As the pore-rows do not always occur in a sulcus, a comparison of the condition in the various species may be based on the distance between the outer margins of the two rows of dactylopores. When this distance is indicated as the width of the pore-rows the following peculiarities are to be noted. In a $D$. violacea from Timor (PI. IV figs. 2 and 3 ) and in one from the Red Sea (Pl. IV fig. 11) the width of the pore-rows is $0.8 \mathrm{~mm}$; in specimens from the Torres Straits (Pl. IV figs. 6-9) and from the Marshall Islands (Pl. IV fig. 12) the pore-rows are about $1.0 \mathrm{~mm}$ wide. Judging by Broch's (1942) text-figure $2 \mathrm{~b}$ the specimen named by him $D$. fisheri (correct name $D$. violacea) has pore-rows of a width of about $0.8 \mathrm{~mm}$, corresponding with the values noted above for the specimen from Timor, which has the same form of growth. - Figures of pore-rows of $D$. gracilis (BosCHMA, 1956 a, Pl. 3 figs. 4 and 5) show that they have a width of 0.7-0.95 mm, corresponding with the values noted for $D$. violacea. - In $D$. coccinea the pore-rows are narrower, showing a width of about $0.55 \mathrm{~mm}$ in the specimen of Pl. IX fig. 1, a width of $0.6 \mathrm{~mm}$ in the specimen of Pl. IX figs. 2 and 3. The specimen supposed to be the type of $D$. fulvacea corresponds in its characters with $D$. violacea, the pore-rows having a width of about $0.8 \mathrm{~mm}$. - In $D$. nitida the width of the pore-rows is again somewhat smaller than in $D$. violacea, varying from $0.6 \mathrm{~mm}$
(Pl. IX figs. 4 and 6) over $0.7 \mathrm{~mm}$ (Pl. IX fig. 7) to $0.8 \mathrm{~mm}$ (Pl. IX fig. 5). In Broch's figured specimen of $D$. nitida (referred to with the name $D$. violacea forma typica, ВROCH, 1942, text-fig. $1 \mathrm{~b}$ ) the width of the pore-row is about $0.65 \mathrm{~mm}$, corresponding with the values noted above. - Judging by Moseley's figure $(1880, \mathrm{Pl} .12 \mathrm{fig} .8 \mathrm{a})$ the pore-rows of the type specimen of $D$. irregularis have a width of $0.6-0.7$ $\mathrm{mm}$; in BRoch's (1942, text-fig. 7 a) specimen of $D$. irregularis the pore-rows are about $0.6 \mathrm{~mm}$ wide. In the coral here tentatively identified with $D$. livida the pore-rows of the younger branches have a width of $1.0 \mathrm{~mm}$ (Pl. IV fig. 5), on the older parts of the colony they become narrower, about $0.6 \mathrm{~mm}$ (Pl. IV fig. 4). - In $D$. profunda the pore-rows are wider than in any other species of the genus, the figure (Hickson \& England, 1909, Pl. 44 fig. 6) showing a width of $2.8 \mathrm{~mm}$ (judging by the measurements of the pores as given by the cited authors the figure here referred to is about 10 times enlarged). - In D. providentiae (Pl. IX figs. 1-3) there are no distinct pore-rows; in parts where there is a single row of gastropores the width between the dactylopores of the two opposite rows is about $1.3 \mathrm{~mm}$. - For $D$. borealis forma japonica BROCH (1942, p. 21) records that the sulcus is astonishingly wide (generally $0.7-$ $0.8 \mathrm{~mm}$ ). When measuring the distance between the two opposite rows of dactylopores in Broch's figure (l. c., text-fig. $5 \mathrm{~b}$ ) values are obtained of about 1.0 $\mathrm{mm}$, corresponding with the condition in the specimens from the Sagami Sea dealt with in the present paper. Here the width of the pore-rows is 1.0$1.2 \mathrm{~mm}$ (Pl. XV figs. 4, 5, and 10). The same width of the pore-rows occurs in the fragment of the type lot of $D$. borealis (PI. XV figs. 7 and 8). - Finally in $D$. serpens the width of the pore-rows is about 0.75 $\mathrm{mm}$, judging by the figure of $\mathrm{BROCH}(1942$, textfig. $3 \mathrm{~b}$ ).

Within certain limits the width of the gastropores is a character for the discrimination of the species in the genus Distichopora. It is interesting to note that $D$. violacea, a species that as a rule does not grow to a large size, has much wider gastropores than $D$. coccinea and $D$. nitida, two species in which the colonies may attain a much larger size. Hickson \& ENGLAND (1909, p. 348) state that the gastropores of $D$. violacea are rarely more than $0.3 \mathrm{~mm}$ in diameter; BROCH (1942, p. 14) remarks that in $D$. fisheri (correct name $D$. violacea) the diameter of the apertures of the larger gastropores is $0.35 \mathrm{~mm}$. Some specimens of $D$. violacea have gastropores of an even larger size. In a specimen from Timor (Pl. IV figs. 2 and 3) the gastropores have a width of $0.3-0.4 \mathrm{~mm}$ 
in specimens from Torres Straits (PI. IV figs. 6-9) the larger gastropores are up to $0.5 \mathrm{~mm}$ wide. For the type specimen of $D$. gracilis, Fisher (1938) mentions a width of the gastropores of $0.1-0.12 \mathrm{~mm}$; in the larger colonies from the Passe du Hao in the Tuamotu Islands the gastropores have a width of up to $0.3 \mathrm{~mm}$ (Boschma, 1956 a). - In $D$. coccinea the gastropores are as a rule not wider than $0.2 \mathrm{~mm}$, they rarely show a diameter of $0.28 \mathrm{~mm}$ (Pl. IX fig. 2). - The specimen supposed to be the type of $D$. fulvacea has the typical characters of $D$. violacea, its gastropores having a width of $0.3 \mathrm{~mm}$ or being slightly wider. - Generally in $D$. nitida the gastropores are still smaller than those of $D$. coccinea (PI. IX figs. 4-7), as a rule $0.24 \mathrm{~mm}$ being the greatest width. Brock (1942) states that, when fully developed, the gastropores may have a diameter of $0.2-$ $0.3 \mathrm{~mm}$ in $D$. nitida (referred to as $D$. violacea forma typica). - Judging by the figure of Moseley (1880, PI. 12 fig. 8 a) the larger gastropores of the type specimen of $D$. irregularis are about $0.3 \mathrm{~mm}$ wide; in the specimen described by Broch (1942) they have a diameter of $0.30-0.35 \mathrm{~mm}$. - Of $D$. livida, Tenison-Woods (1879 a) remarks that the gastropores are large, irregular. In the specimen from the Brussels Museum that is here tentatively identified with D. livida the gastropores have a width of up to 0.4 $\mathrm{mm}$ (Pl. IV fig. 5), corresponding with the values obtained in $D$. violacea. - The gastropores of $D$. profunda are varying in size, the larger ones are $0.5 \mathrm{~mm}$ in diameter (Hickson \& ENGLAND, 1909), a size only exceptionally occurring in $D$. violacea. The gastropores of $D$. providentiae (PI. XV figs. 1-3) have a width of about $0.3 \mathrm{~mm}$. - In the description of $D$. borealis, Fisher (1938) records the width of the gastropores as $0.25-0.425 \mathrm{~mm}$; ВRoch (1942) states that in $D$. borealis forma japonica the diameter of the gastropores at the opening is about $0.53 \mathrm{~mm}$. These measurements at least partly refer to the funnelshaped widened distal part of the gastropores. In the specimens from the Sagami Sea dealt with in the present paper the cylindrical tubes of the gastropores have a width of 0.25 to $0.35 \mathrm{~mm}$, the funnel-shaped top parts of the gastropores being 0.5 to $0.8 \mathrm{~mm}$ wide (Pl. XV figs. 4, 5, and 10). About the same dimensions occur in the fragment from the type lot of $D$. borealis; here the tubes of the gastropores have a width of up to $0.35 \mathrm{~mm}$, while the funnel-shaped end parts vary in width from 0.4 to $0.6 \mathrm{~mm}$ (Pl. XV figs. 7 and 8). - In D. serpens the diameter of the gastropores is $0.25-0.30 \mathrm{~mm}$ (ВвосH, 1942, p. 17).

There is some variation in the shape of the gastropores at least in some of the species of Distichopora; this is especially apparent in D. violacea. On the older parts of the colonies the gastropores as a rule have a circular opening (Pl. IV fig. 10). In the smaller branches there are often next to circular gastropores many of quadrangular or triangular shape, a condition obviously caused by their crowded position (Pl. IV figs. 2 and 3). In the four top parts of another specimen of $D$. violacea (Pl. IV figs. 6-9) again next to round gastropores there are some with an angular contour. An altogether similar variation is to be observed in the top parts of two other specimens of D. violacea (Pl. IV figs. 11 and 12). - In $D$. gracilis the young branches as a rule have gastropores with a circular or slightly oval opening, not showing angular contours (Boschma, 1956 a, Pl. 3 figs. 4 and 5). - The gastropores of $D$. coccinea, even those in the youngest branches, have a circular or slightly oval opening (PI. IX figs. 1-3). - The specimen supposed to be the type of $D$. fulvacea belongs to the species $D$. violacea; it has many gastropores with an angular contour. - In $D$. nitida the gastropores invariably have a circular opening (Pl. IX figs. 4-7). - In the two figured specimens of $D$. irregularis (Moseley, 1880, Pl. 12 fig. 8 a; В восH, 1942, text-fig 7 a) the gastropores have a circular opening. - Of D. livida, Tenison-Woods (1879a, p. 302) remarks: "Gastropores large, irregular", which seems to indicate that they did not all have a circular shape. In the specimen here tentatively identified with $D$. livida the gastropores are round to polygonal in the top branches (Pl. IV fig. 5), while they show a strong tendency to become circular in the larger branches (Pl. IV fig. 4). - The figure representing an enlarged view of a part of a pore-row of $D$. profunda (HICKson \& ENGland, 1909, Pl. 44 fig. 6) shows gastropores of a generally polygonal shape; the less strongly enlarged view of a pore-row (1. c., fig. 5) has gastropores of a circular contour; the text (l.c., p. 348) does not mention particulars of the shape of the gastropores. - The gastropores of $D$. providentiae (PI. XV figs. 1-3) have a circular or slightly oval opening. In $D$. borealis there is some variation in the shape of the funnel-shaped top part of the gastropores, which may be more or less evenly rounded (Pl. XV figs. 7, 8 , and 10 ) or may become somewhat polygonal ( $\mathrm{Pl}$. $\mathrm{XV}$ fig. 4) or very pronouncedly polygonal owing to the development of distinct ridges at the margins of the funnel-shaped parts (Pl. XV fig. 5). - Judging by the text-figure $3 \mathrm{~b}$ in BRoch (1942) the gastropores of $D$. serpens have a circular opening.

On account of their extreme length the gastrostyles of Distichopora differ from those of most of the other genera of Stylasterina, with the exception of Spora- 
dopora. As a rule there is very little variation in the gastrostyles of the different species of Distichopora; only in the species $D$. serpens they seem to show a peculiarity deserving special attention; of this species Вrосн $(1942$, p. 17) remarks: "The gastropores ... have a comparatively short, feebly conical gastrostyle." The figure (1. c., text-fig. $3 \mathrm{c}, \mathrm{d})$ shows that the gastrostyles in this species bear a strong likeness to those of several species of the genus Stylaster, extending for a very short distance from the bottom of the gastropore. - In all other species of the genus the gastrostyles are of a rather uniform shape, very long, with sharp top, and covered with spines all over the surface. In the literature some differences have been mentioned concerning the manner of spinulation of the gastrostyles, which perhaps might point to specific differences. In the following notes observations on the specimens dealt with in the present paper are recorded together with data from previous papers. - Of a specimen of $D$. violacea from the Fiji Islands (named $D$. fisheri by Broch, 1942) the gastrostyle is described as "needle-shaped, but comparatively compact and robust; the distal half of it is closely covered with spicules which, however, are not bristling", the condition as described appears also from the figure (l. c., text-fig. $2 \mathrm{c}$ ). The gastrostyles of some specimens in the materials dealt with in the present paper proved to be densely beset with small spines often extending sideways at a distinct angle to the long axis of the gastrostyle. They present a striking similarity to the gastrostyles of $D$. gracilis mentioned below. - When describing the gastrostyles of $D$. gracilis (BoschмA, 1956 a) I noted that their shape and spinulation is largely similar to the corresponding structures in other species of the genus, meaning $D$. violacea, $D$. coccinea, and $D$. nitida. In $D$. gracilis (ï. c., text-tig. 2) the gastrostyles are very long and slender, the parts distally of the tabulae being densely covered with spinules chiefly extending sideways. The figured gastrostyles have a transverse diameter of up to $0.1 \mathrm{~mm}$. - Moseley (1880, Pl. 2 fig. 6) represents a "View of one of the inner surfaces of a fragment of the coenosteum of Distichopora coccinea, which has been split in half through the line formed by the pores of the gastrozooids; showing the arrangement of these pores, and their very long styles" (l. c., p. 211). The figure is very instructive as it shows the very long and slender gastrostyles of the older gastropores and the gradual development of these structures in the younger gastropores; here the spines of the gastrostyles are not drawn. The gastrostyles of some specimens of $D$. coccinea in the materials dealt with in the present paper correspond closely with those of $D$. violacea, having the same slender shape and a similar manner of spinulation. The gastrostyles of the specimen supposed to represent the type of $D$. fulvacea were not examined, the specimen showing the typical characters of $D$. violacea. - Examination of the gastrostyles of a few specimens of $D$. nitida in the collections dealt with in the present paper proved that these present the same peculiarities as those of $D$. violacea, completely corresponding in shape and in spinulation. - The gastrostyles of $D$. irregularis seem to differ from those of $D$. violacea in their manner of spinulation, BRoch (1942, p. 26) describing them as follows: "The gastrostyle is slenderly needle-shaped, its outer parts are covered with spicules which, however, do not bristle, but cover the style almost scale-like"; these statements are confirmed by the figure (l. c., text-fig. $7 \mathrm{~b}$ ). - In his description of $D$. livida, Tenison-Woods (1879a) characterizes the gastrostyle as long and spinous. His figure (cf. text-fig. $4 \mathrm{c}$ in the present paper) shows that in its shape and spinulation it bears a strong resemblance to the gastrostyle of $D$. violacea. - Of D. profunda, Hickson \& ENGLand (1909, p. 348 ) note that the long gastrostyle is brush-like at the tip; the figure (1. c., Pl. 44 fig. 7) shows that the gastrostyle is not strikingly different from that of $D$. violacea, the top part only being somewhat swollen. - According to Hickson \& England (1909, p. 349) the gastropore of $D$. providentiae (referred to with the name Sporadopora providentiae) "bears a long gastrostyle, similar to that of Distichopora but not quite so slender, tapering to a point near the gastropore". The cited authors did not give a figure of the gastrostyle, and I did not examine it in the small branch that I have on loan from the Manchester Museum, not wanting to damage the specimen. The remarks quoted above support the view that the species providentiae should be incorporated in the genus Distichopora. - The gastrostyle of $D$. borealis has been described by FisHer (1938, p. 543) as "very slender, usually long, and bristling with oblique sharp delicate spicules". Вкосн (1942, p. 21) describes the gastrostyle of $D$. borealis forma japonica as "long and slender, needle-shaped, and armed with extraordinarily long, bristling spicules"; the figure (l. c., textfig. $5 \mathrm{c}$ ) showing the top of a gastrostyle with rather long spines extending distinctly sideways. The gastrostyles of specimens of $D$. borealis from the Sagami Sea dealt with in the present paper (text-fig. 5) do not present striking differences from those of $D$. violacea, though the spines give the impression of being somewhat larger and having a stronger tendency to extend sideways. The thickest part of the gastrostyles 
in the cited figure is about $0.1 \mathrm{~mm}$ (excluding the spines), just as in $D$. gracilis referred to above. Summarizing the notes as given above there seems to be only one species of Distichopora (D. serpens) with gastrostyles of a peculiar shape in the genus, rather short conical, in contradistinction to the other species, which all have long slender gastrostyles with a dense spinulation all over the surface except on the lower portions when they are partitioned off from the top part by tabulae.

The ampullae of the shallow-water species of $D i$ stichopora show among each other rather insignificant differences, not sufficing for the establishment of definite specific characters, though in $D$. violacea they usually show much more pronounced ridges than in the other species. The diameter of the female ampullae of $D$. violacea is slightly variable, $0.6 \mathrm{~mm}$ (Pl. V fig. 4), $0.6-0.8 \mathrm{~mm}$ (Pl. V figs. 1-3, Pl. VI fig. 4), or $0.8-1.0 \mathrm{~mm}$ (Pl. IV fig. 1, Pl. VI fig. 1). In $D$. coccinea the diameter of the female ampullae generally does not differ noticeably from $0.8 \mathrm{~mm}$ (Pl. IX figs. 2 and 3, Pl. X figs. 1 and 2), in one specimen being slightly smaller (about $0.7 \mathrm{~mm}, \mathrm{Pl}$. $X$ fig. 3). In $D$. nitida the female ampullae vary in diameter from 0.6 to $0.7 \mathrm{~mm}(\mathrm{Pl}$. X fig. 4, Pl. XIII figs. 1 and 3), sometimes being slightly larger (up to $0.8 \mathrm{~mm}, \mathrm{Pl}$. XIII figs. 2 and 5). The male ampullae usually have a diameter of $0.4-0.5 \mathrm{~mm}$ (violacea, Pl. VI fig. 2; nitida, Pl. XIII fig. 4).

In a colony of $D$. violacea from the Red Sea (Pl. V fig. 1) most of the ampullae have a comparatively smooth surface, being covered with minute tubercles, similar to those on the surface of the branches. Each ampulla is surrounded by about six or eight distinct pits, the ridges between these pits giving the ampullae a slightly stellate appearance. On some of the ampullae the ridges are continued centrally over the surface as elevated crests, then the ampullae become still more star-shaped. In a specimen from the Fiji Islands one patch of ampullae (Pl. VI fig. 4, lower part) shows the condition as found in the coral from the Red Sea, while in the upper part of the figure some ampullae are to be seen of a slightly more hemispherical shape, more distinctly rising over the surface of the corallum. - The ampullae of a specimen of D. coccinea (Pl. X fig. 1) are arranged in rows or small patches next to the pore-rows. Here the ampullae are of a circular shape, the pits surrounding them being of very small size, not leading to a stellate appearance. The surface of the ampullae is very smooth, presenting an even finer granulation than the surface of the branches. - In a branch of $D$. nitida (Pl. XIII fig. 2) the ampullae again have a smooth surface, their granulation being finer than that of the surface of the branches. Here the ampullae are surrounded by 6 to 8 large pits giving the structures a slightly stellate shape. It is interesting to note that in another branch of the same colony the surface of the ampullae has a much coarser granulation (Pl. XIII fig. 3). - A comparison of the four specimens here dealt with shows that in one of these (coccinea) the pores surrounding the ampullae are very small, while they are much larger in the other three. It is further of interest that the ampullae generally have a comparatively smooth surface, while in one specimen of violacea some of them have distinctly elevated ridges radiating from the centre to the periphery.

In the specimens referred to above the ampullae show more or less similar characters. Some more specimens may be here dealt with to illustrate the variation in the shape of the ampullae. In a colony of $D$. violacea from the Gulf of Suez (Pl. V fig. 4) the ampullae are not as closely packed as generally in the species; here they appear as circular bodies with crenulated margins, the pits surrounding the ampullae being very small. The surface of the ampullae is finely granulated, not presenting ridges radiating from the centre. - In another colony of $D$. violacea (Pl. V fig. 2) the ampullae form crowded patches with rather deep pits between the individual ampullae, while their surface presents well-developed elevated ridges radiating from the centre. - A specimen of $D$. violacea from the Red Sea in the collection of the Leiden Museum (Pl. V fig. 3) shows a patch of ampullae of a similar shape, though less distinct because the ampullae are combined into a continuous mass, irregularly presenting numerous pits, and ridges running over the surface. - In specimens of $D$. violacea from Torres Straits (Pl. IV figs. 1 and 9, Pl. VI fig. 1) the ampullae have obtained a very irregular shape, being covered with strong blunt spines, sometimes developing into thick ridges more or less radially arranged on the surface. Ampullae of a similar shape were observed by Tenison-Woons (1879 b) in a colony of $D$. violacea (cf. fig. $4 \mathrm{~d}$ in the present paper). - In a colony of $D$. coccinea, differing from other specimens by its very light colour, there are patches of more or less confluent ampullae (Pl. X fig. 2), the large pits vaguely indicating the margins, the granulation corresponding with that of the surface of the branches. - In another colony of $D$. coccinea ( $\mathrm{Pl}$. X fig. 3) the ampullae are also strongly confluent, the circular rows of pits determining the borders of the individual ampullae are, however, more distinct. Here the surface again shows a granu- 
lation completely corresponding with that of the surface of the branches. - A colony of D. nitida (Pl. XIII fig. 1) is interesting because the surface of the branches is much more coarsely granular than usual in the species; the surface of the ampullae has the same coarse granulation. - In a colony of $D$. nitida of very large size, corresponding with the form described as D. brasseyi Wright (Pl. XIII fig. 5), the patches of ampullae consist of rather confluent masses showing a number of large pits indicating the borders of the ampullae; the granulation corresponds with that of the surface of the branches. - In another colony of $D$ : nitida ( $\mathrm{Pl}$. X fig. 4) some of the ampullae have rather well-developed ridges leading to a more or less stellate appearance.

Male ampullae are to be observed in a colony of D. nitida (PI. XIII fig. 4); here they occur in patches in which the individual ampullae are rather indistinctly separated; the granulation corresponds exactly with that of the surface of the branches. - In a colony of $D$. violacea from the Fiji Islands (PI. VI fig. 2) the male ampullae are very indistinct; they occur in large patches, which apparently are covered with a thin layer of calcareous matter. This colony is interesting as next to the patches of male ampullae there occur a few of larger size, apparently female.

The data given above show that the ampullae of $D$. violacea, $D$. coccinea, and $D$. nitida do not present definite specific characters. In $D$. coccinea the ampullae never seem to have the elevated ridges radiating from the centre as they occur in many specimens of $D$. violacea, while they only exceptionally occur in $D$. nitida; on the other hand these ridges do not always occur in $D$. violacea, for in many specimens at least the majority of the ampullae have a smooth surface (leaving the granulation out of account).

In $D$. gracilis the ampullae are as a rule more strongly hemispherical than those of $D$. violacea; in their further peculiarities they present a similar amount of variation as occurs in this species. In a previous paper (Boschma, 1956a) there are several photographs of branches of $D$. gracilis with ampullae, their surface varying from comparatively smooth to distinctly stellate on account of radiating elevated ridges. In this species again the male ampullae form much more confluent masses than the female.

A few notes may be added concerning the ampullae of the other species of the genus. The specimen supposed to be the type of $D$. fulvacea has some patches of male ampullae. - In the specimens of $D$. irregularis described by Ввосн (1942, pp. 24-27, text-fig. 7) the female ampullae occur in closely pack- ed groups below the surface of the younger branches; judging by the figure they have a diameter of about $0.6 \mathrm{~mm}$. - According to TeNison-Woods (1879 a, p. 302) the ampullae of $D$. livida occur "in slightly swollen, pale, livid masses, in which the separate cells are not easily distinguished", a condition similar to that of many specimens of $D$. violacea. - In the description of $D$. profunda by Hrckson \& ENGLAND (1909) the ampullae are not mentioned; they are, however, represented in the figure of a branch in natural size (1. c., Pl. 44 fig. 4); here they appear as scattered hemispherical bodies of a size of about $0.5 \mathrm{~mm}$. - The female ampullae of $D$. providentiae are visible from the exterior as slight swellings (HickSON \& ENGLAND, 1909); in the branch of this species in the collection of the Manchester Museum (PI. XV figs. 1-3) the ampullae are also faintly visible as insignificant little protuberances, the part rising over the surface having a diameter of about $0.5 \mathrm{~mm}$. Fisher (1938, p. 544) describes the male ampullae of $D$. borealis as superficial, convex, with a ridged or corrugated surface; diameter about $0.5 \mathrm{~mm}$; the female ampullae as strongly convex, the surface traversed by prominent, interrupted or continuous, often sharp ridges or crests; or surface irregularly corrugated with occasional tubercles; diameter 1 to $1.25 \mathrm{~mm}$. The male ampullae of a fragment from the type lot are represented in figs. 6-9 of $\mathrm{Pl}$. XV; female ampullae of specimens of $D$. borealis from the Sagami Sea (Pl. XVI figs. 3-6) show the dimensions as noted by FrsHer, but have a rather indistinct shape owing to their being covered with a layer of calcareous matter. - ВRосн $(1942$, p. 18) notes that in $D$. serpens the female ampullae have a rather coarsely warty surface, as a rule being radially grooved. Judging by the figure (l. c., text-fig. $3 \mathrm{e}$ ) they have a diameter of about $1.0 \mathrm{~mm}$. In their general appearance they are similar to those of many specimens of $D$. violacea.

The structure of the coenosteum, particularly that of the young branches, furnishes a character to divide the four well-defined Indo-Pacific species of Distichopora from shallow water into two groups, the one (violacea and gracilis) showing small tubercles of 0.15 to $0.20 \mathrm{~mm}$, the other (coccinea and nitida) having a finer granulation (diameter of the granules $0.05-0.10 \mathrm{~mm}$ ).

Already Ellis \& Solander (1786, p. 140) remarked that in Distichopora violacea the surface, when magnified, is rough like chagreen; the structure of the coenosteum indeed could not be characterized in a better manner. At least in the tops of the branches the surface shows evenly distributed, roundish or 
oval, rather flat-topped tubercles, which at their margins often have a row of minute pits or pores. This structure has been mentioned by BRoch (1942, p. 14) for the specimens named by him $D$. fisheri (correct name $D$. violacea); his drawing of a 19 times enlarged top of a branch (l. c., text-fig. 2 a) gives an excellent view of the occurrence of the tubercles, which vary in diameter from 0.15 to $0.20 \mathrm{~mm}$. Most of the figures in the present paper representing parts of $D$. violacea 5 times enlarged show the small tubercles; a few examples may be here noted. The tubercles occur rather crowdedly in the specimens of Pl. V figs. 1 and 3; they are more widely spaced in the specimen of Pl. VI fig. 4. The tubercles vary in diameter from 0.15 to $0.20 \mathrm{~mm}$. - In $D$. gracilis the tubercles are of the same shape as those of $D$. violacea; they also occur in the same arrangement on the smaller branches, and, occasionally, on the larger branches (cf. Boschma, 1956 a, Pls. 2-4). - The tops of the branches of $D$. coccinea and of $D$. nitida do not have the tubercles as mentioned above, they show a fine granulation only (diameter of the granules 0.05 to $0.10 \mathrm{~mm}$ ). In some parts of the surface the granules remain isolated; more often, however, they unite to form ridges, which generally together develop into a vermiculated pattern. A rather fine granulation occurs in the specimen of $D$. coccinea of Pl. X fig. 1, a somewhat coarser granulation is to be observed in the specimen of D. coccinea of Pl. X fig. 3. - In D. nitida the granulation is as a rule of a very fine character (Pl. XIII figs. 2 and 3); rarely the granules become coarser (Pl. XIII fig. 1). Especially the larger branches of $D$. nitida have a fine granulation (Pl. IX fig. 7). - In their microscopic structure the granules of $D$. coccinea have a slightly coarser appearance than those of $D$. nitida, the corals of the last-mentioned species thereby obtaining a much more shiny appearance, $D$. coccinea lacking the gloss that is characteristic of $D$. nitida. - In the structure of its surface the specimen supposed to be the type of $D$. fulvacea has the characters of $D$. violacea, the specimen actually belonging to this species. - The specimen here tentatively identified with D. livida shows in its top branches (PI. IV fig. 5 ) the surface characters of $D$. violacea, on the main stem the characters of the surface bear a strong resemblance to $D$. nitida (Pl. IV fig. 4).

The chief peculiarities of the structure of the coenosteum of the species of Distichopora from deeper water are the following. - Of $D$. profunda the surface is described as very rough, while "the pits and furrows of the coenenchym-canals can be easily seen without magnification" (HiCKSON \& ENGLAND, 1909, p. 348). Judging by the figure (1. c., Pl. 44 fig. 4) the granules of the surface have a diameter of at least $0.5 \mathrm{~mm}$. - In D. providentiae the surface of the coenosteum is rather coarsely granular, the granules often uniting into ridges forming a vermiculated pattern (Pl. XV figs. 1-3). - According to FISHER (1938, p. 543) the surface of the coenosteum of $D$. borealis is "minutely spiculated rather than uneven and glossy", while BrOCH (1942, p. 22) notes for specimens from the Sagami Sea $(D$. borealis forma japonica) that "the surface of the coenosteum lacks the microscopic small spicules which are characteristic of Fisher's specimens." In the specimens of $D$. borealis from the Sagami Sea dealt with in the present paper the surface is on the whole finely granular, on the topmost parts of the branches the granules being united to longitudinal ridges. Besides the finer granulation, FisHer's female colonies show comparatively large spines scattered over the surface and uniting into ridges on the distal parts of the branches. - BRoch (1942, p. 17) remarks of D. serpens: "The surface of the coenosteum is distinctly and rather coarsely warty, but no pores are seen between the warts at lower magnification, and neither vermiculation nor veins have been observed." The structure as described, and as illustrated in text-fig. $3 \mathrm{a}$, e in the cited paper, shows a strong resemblance to the small tubercles as they occur in $D$. violacea and $D$. gracilis, though the tubercles appear to be somewhat smaller than in these two species.

The colour of the coenosteum of the species of Distichopora is not always sufficiently constant to be of use as a specific character. Though in the majority of instances the corals of $D$. violacea are violet, of $D$. coccinea crimson, and of $D$. nitida vermilion turning to orange, these colours are not definitely fixed, as of all the three species corals are known of a colour altogether different from the usual. - Since Hickson (1892) remarked that in D. violacea from the Torres Straits the immature specimens are orange, the male brown, and the female violet, and in a later paper (Hickson in Hickson \& ENGLAND, 1909) stated that in the Indian Ocean $D$. violacea may occur in white, yellow, orange, violet and purple colour varieties, it is beyond doubt that in this species the colour is far from constant. Of the two specimens of $D$. violacea described by ВRосн (1942, under the name $D$. fisheri) the one was greyish blue with a faint lilac hue, the other light brown or yellowish. On the other hand in the list of specimens of $D$. violacea of the present paper in 18 of the 23 lots the corals have a violet colour in various gradations from dark to light, sometimes so strongly intermixed with red that the 
latter colour predominates; in only 5 of the 23 lots the corals do not show any trace of a violet colour. The corals of each of these five lots with an aberrant colour show some peculiarities different from the general characters of $D$. violacea; these differences are here briefly mentioned. The specimens from the Australian Museum with the localities New Hebrides (Pl. XIV figs. 3 and 4) and China Strait, characterized by their vermilion colour, in the figured specimen slightly turning to orange, show in their larger branches peculiarly constricted regions as they are to be found in the specimen here tentatively identified with $D$. livida, while also their general shape is similar to this specimen. The corals from the Gilbert Islands in the collection of the Australian Museum (Pl. I figs. 3 and 4), in which the colour is ochreyellow to orange, present in their form of growth a certain similarity to $D$. gracilis, while their fine granulation is similar to that in $D$. nitida; the welldeveloped sulci and the flattened end-branches lead, however, to a provisional identification with $D$. violacea. The type specimen of $D$. rosea, with its bright rose-pink colour (KENT, 1871), has in some respects peculiarities giving it a more or less intermediate position between the species $D$. violacea and $D$. gracilis. Finally the specimen from New Zealand in the collection of the Manchester Museum (Pl. I fig. 2) has a light orange colour; it is very much possible that on account of its living in a comparatively great depth $(122 \mathrm{~m})$ the colour has remained much lighter than that of shallow-water specimens of $D$. violacea. - According to DANA (1848) the type specimen of D. gracilis is reddish; Fisher (1938) describes the same specimen as pale rose (perhaps faded in the course of time?). The colour of specimens from the Passe du Hao in the Tuamotu Islands is generally brick red, sometimes turning to a purplish tint, and rather often lighter, dull orange or yellowish orange (Boschмa, 1956a). Of the three species described by QUELCH, here regarded as synonyms of $D$. gracilis, the cited author notes as their colour: milesii, dull lake-red; granulosa, rich scarlet red; and conferta, a delicate carmine red. - The colour of $D$. coccinea is bright crimson (GRAY, 1860), a deep blood-red (Tenison-Woods, 1879 b), crimson (Wright, 1882) or intense carmine (BRoch, 1942, the specimens being referred to with the name $D$. violacea forma cornuta). The specimens of $D$. coccinea dealt with in the present paper generally correspond in colour with those previously described, being of a crimson tint of varying intensity. One specimen (with the museum name $D$. sanguinea) is a dirty dull red; another specimen is exceptionally light for the species, being a light yellowish orange, the coral, moreover, differing from the other specimens by its comparatively robust branches that are very little divided into side branches (Pl. VII fig. 2). - In the description of $D$. fulvacea (Michelin, 1862) the colour was noted as fulvous (reddish yellow), in the specimen supposed to be the type of the species (Pl. I figs. 12 and 13) the colour is now ochre-yellow (faded in the course of time?). - Verrill (1864) described the colour of $D$. nitida as "bright red with the tips of the branches yellowish white, other specimens are light orange"; Quelch (1885) characterizes $D$. nitida as "bright red to light orange." Of the species here regarded as synonyms of $D$. nitida the following notes were given of the colour. D. brasseyi (Wrught, 1882): a deep red, tinted or slightly mottled with orange at the extremities of the stems and adult branches, paling off into white and pale orange-yellow; $D$. allnutti (WRIGHT, 1882): fuscous orange-red, paling towards the extremities; D. breviserialis (QUELCH, 1884 a): rather deep fleshred or pale aurora-red: D. ochracea (QUELCH, 1885): of a dull ochre-yellow colour, sometimes becoming white at the tips; D. brasseyae (BоscнмA, 1951): brick red, the smaller branches often being of a lighter colour, sometimes towards their tips changing into a yellowish grey. Among the specimens dealt with in the present paper there are two colonies from unknown locality, in the collection of the Amsterdam Museum (one figured on $\mathrm{Pl}$. XI), with an exceptional colour, the two colonies being light reddish purple. The other specimens examined range from ochreyellow to vermilion, corresponding with the notes on the colour as mentioned in previous papers. - The type specimen of $D$. irregularis had a light pinkish colour (Moseley, 1880). The specimen described by Broch (1942) was yellowish with a distinct lilac hue. - Tenison-Woods (1879 a) described the colour of D. livida as "livid, tips of branches sometimes yellow or white, lateral furrows and tips of smaller branches bright red or orange." The colour of specimens, which according to Quelch (1884 a) seem to belong to $D$. livida, varies from dull or pale purplish red to dull reddish or brownish orange, the lateral furrows and the incipient branches being red or orange. The specimen from the Brussels Museum here tentatively identified with D. livida (PI. XIV figs. 1 and 2) has a dark greyish violet colour all over the surface, including the sulci and the tops of the branches. It is interesting to note that the corals from the Australian Museum that in their form of growth present a strong likeness to the specimen of the Brussels Museum (e.g., the specimen of Pl. XIV figs. 3 and 4) have a vermilion red colour, corresponding in this respect 
with the specimens mentioned by QuELCH. - The colour of $D$. profunda is brownish white; that of $D$. providentiae is yellowish white (Hickson \& ENGLAND, 1909). - Fisher (1938) describes the colour of the type specimens of $D$. borealis as cartridge buff, warm buff, and capucine buff, tints varying from yellowish white to light orange or ochre-yellow. The specimens of $D$. borealis forma japonica have a light yellow colour in alcohol, when dried they become almost white, in most parts with a distinct lilac hue (Broch, 1942). The specimens from the Sagami Sea dealt with in the present paper have a white colour. - Of D. serpens, Broch (1942) states that the colour (in alcohol) is a yellowish orange. - The data compiled above show that the species of Distichopora living in rather deep water have a white, yellowish, or light brownish colour; different shades of orange and red to violet occurring in the shallow-water specimens only. It must be noted that in the data mentioned above no attention has been paid to the fact that corals of a red or violet colour very often have the tips of the branches much paler, often white, in a sharp contrast to the more proximal parts.

In their form of growth all the species of the genus Distichopora of which a fairly large number of specimens have become known present a considerable amount of variation. In some species, e.g., $D$. violacea, the variety in shape is almost bewildering; even if the species is divided into three formae (violacea s. s., fisheri, and tenella) many specimens do not easily fit into one of these. As a general characterization of the form of growth is to be observed that as a rule the species does not grow to a size larger than about $8 \mathrm{~cm}$ high, that the branches have a strong tendency to develop fan-wise in such a way as to fill rather densely the flabellar plane of branching, leaving less space between the branches than the thickness of the branches themselves. The branches have a tendency to become flattened anteroposteriorly; this is especially apparent in the ends of the branches, which as a rule are about half as thick as broad. The characters of the three formae may be here briefly mentioned. In the forma violacea s. s. the branches remain of the same breadth for comparatively long distances; they are not conspicuously divided into main branches and those of secondary importance. An ideal example of the forma violacea s. $s$. is the specimen of Ellis \& Solander's figure (cf. text-fig. 1 a in the present paper); specimens in the collections here dealt with are the corals of PI. I figs. 16 and 17 and Pl. III fig. 3. In the forma fisheri there is a greater tendency for an upward growth of one or a few main branches, though in their general aspect these corals do not strikingly differ from the first mentioned. An example of the forma fisheri is the specimen of PI. I fig. 11; the coral of Pl. I fig. 2 has an altogether similar form of growth. The third variety of $D$. violacea may be indicated with the name forma tenella; it is branching in a manner to completely fill the flabellar plane with larger and smaller branches; in this forma the larger branches are gradually tapering from a thick base to a narrow top, all the terminal branches being considerably slenderer than in the forma violacea s. s. Examples of the forma tenella are the corals of Pl. III figs. 1 and 2. - Thirteen colonies of $D$. gracilis from one locality, the Passe du Hao in the Tuamotu Islands, are represented on $\mathrm{Pl} .1$ of a previous paper (Boschma, 1956 a). They show a striking conformity in their form of growth, the branches rather widely spreading in the flabellar plane, leaving between them a space much wider than the thickness of the branches. In contradistinction to $D$. violacea the smaller branches of $D$. gracilis have a strong tendency to remain cylindrical. The shape of the type specimen of D. gracilis (FisHer, 1938, Pl. 75) has the same form of growth. The two specimens figured in the present paper (the one from the Passe du Hao, PI. II fig. 2; the other the type specimen of $D$. milesii, a synonym of $D$. gracilis) again show the spreading form of growth distinguishing the species from most of the corals belonging to $D$. violacea. There are, however, some specimens of $D$. violacea that have an entirely similar manner of growth, as the corals of figs. 3 and 4 of Pl. II. A large specimen of $D$. gracilis with a very vigorous manner of growth (Pl. III fig. 5) shows a certain likeness to specimens of $D$. violacea forma tenella. $-D$. coccinea is per. haps the only species of the genus that unmistakably can be identified on its form of growth only, the coral always presenting on the flabellar surfaces of the larger branches (anteriorly as well as posteriorly, though often more pronouncedly on the anterior surface) distinct longitudinal rows of small tubercles with incipient pore-rows, constituting the adumbrations of young branches extending perpendicular to the general plane; in many specimens these tubercles have grown out to branches of a length of sometimes over $10 \mathrm{~mm}$. These peculiar characters were already clearly noted in the original description (Gray, 1860), the small branchlets here referred to are represented in the original figures (cf. text-figs. 2 and 3 in the present paper). The characters of the species were again emphasized in the description of the specimen examined by Broch (1942, referred to with the name D. violacea forma cornuta), while the figure (l. c., 
Pl. 1 fig. 2) distinctly shows the small branchlets as they occur on the anterior surface of the coral. The figured specimens from the collections dealt with in the present paper all show the peculiar branchlets that are characteristic of the species (PI. III fig. 4, Pl. VII figs. 1 and 3 , Pl. VIII, Pl. X fig. 1 ; less distinctly in Pl. VII fig. 2 but in the enlarged part of this specimen, PI. X fig. 2, they are clearly to be seen). A further peculiarity of the form of growth of $D$. coccinea is that as a rule the branches are strongly compressed antero-posteriorly, the smaller branches even having a rather sharp edge. - The indication of the height of 3 to 4 centimeters is the only peculiarity concerning the form of growth in the original description of $D$. fulvacea (Michelin, 1862). The coral supposed to be the type specimen (Pl. I figs. 12 and 13) belongs to the typical form of $D$. violacea. Colonies of $D$. nitida, even when comparatively small, as a rule have a very robust appearance. The colonies possess one or a few main branches, which are divided into side branches to rather completely fill up the flabellar space. The branches have a more or less cylindrical shape, only at their tops becoming flattened antero-posteriorly. A specimen with the typical form of growth of $D$. nitida was described and figured by BROCH (1942, Pl. 1 fig. 1) under the name $D$. violacea forma typica. Other specimens of the usual growth form are the large colony of $\mathrm{Pl}$. XI and the smaller specimen of Pl. XIV fig. 5. D. nitida is known sometimes to grow out to a very large size, specimens of this excessive growth were described by WRIGHT (1882) as D. brasseyi; a coral of a similar form of growth is the one represented on Pl. XII; here the vigorously developed main branches leave very little space for the growth of side branches. Though the corals of $D$. nitida as a rule develop as regular flabellar colonies, some specimens have become known in which part of the side branches grow out in a rather wide angle to the flabellar plane; one of these was described by Quelch $(1884$ a) as $D$. breviserialis, another is the specimen of Pl. I fig. 1 in the present paper. - The two specimens that have become known of the species $D$. irregularis (MOSELEY, 1880, Pl. 12 fig. 8; Broch, 1942, Pl. 2 fig. 4) closely correspond in their form of growth, both consisting of a branch with a few side branches, which together are not contained exactly in the same plane. The growth form is similar to that of $D$. violacea forma fisheri. - The original figure of $D$. livida (cf. text-fig. $4 \mathrm{a}$ in the present paper) represents a coral of very robust shape, consisting of a thick main stem and several side branches. Though having a slenderer shape, the coral from the Brussels. Museum here tentatively identified with $D$. livida (Pl. XIV figs. I and 2) is of a similar manner of growth. In its general shape the specimen presents a strong likeness to colonies of $D$. nitida, the lower part also in its finer structures showing a similarity to this species; the smaller branches of the specimen here concerned have, however, the typical characters of $D$. violacea. The characters of genuine specimens not being known the form of growth does not furnish sufficient evidence for the specific status of this coral. - A definite description of the form of growth of $D$. profunda cannot be given, as the available specimens consisted of a few very small branches only (Hickson \& England, 1909). - Of D. providentiae, Hickson \& ENGLAND (1909) characterize the form of growth as flabelliform and dichotomous. The figured type specimen (1. c., Pl. 44 fig. 1) consists of three branches united at the base, somewhat spreading fan-wise; the branches are compressed antero-posteriorly. The one branch in the collection of the Manchester Museum (Pl. XV figs. 1-3) corresponds in its form of growth with the previously figured coral. $-D$. borealis may grow to a fairly large size, one of the colonies figured by Fisher (1938, Pl. 71 fig. 4) having a main stem with a diameter of $17 \mathrm{~mm}$. In the type specimens the branches are growing rather close together, the space between the smaller branches being narrower than the thickness of the branches (FISHER, 1938, Pls. 71-73). Broch (1942), who gave the name $D$. borealis forma japonica to specimens from the Sagami Sea, has a figure of a specimen with very widely spreading branches (1. c., Pl. 2 fig. 5). The specimens from the Sagami Sea dealt with in the present paper (Pl. XVI figs. 1 and 2) have a form of growth more or less intermediate between the corals of FISHER and those of BROCH, the branches not widely spreading but being less closely arranged than in the type specimens from the Aleutian Islands. - The corals on which the description of $D$. serpens was based according to Broch (1942) display a distinctly dichotomic ramification, the figured specimen (l. c., Pl. 2 fig. 8) consists of a branch bifurcating at half its length, each secondary branch with a few incipient side branchlets.

The comparative notes given above, partly taken from the existing literature, partly based on specimens from the collections dealt with in the present paper, lead to the here following diagnoses of the Indo-Pacific species of Distichopora. Because the gastrostyles of the various species among each other do not show easily definable differences, the peculiarities of these structures are as a rule not mentioned below. Data on the male ampullae have been omit- 
ted because their shape is generally little distinctly defined, while, moreover, they are of rather uncommon occurrence in the specimens of the collections dealt with in the present paper, and are rarely referred to in the literature.

D. violacea (Pallas). Corallum of small to moderate size, not exceeding a height of about $8 \mathrm{~cm}$, flabelliform, with several branches generally of about equal shape and size. Branches compressed antero-posteriorly, with blunt distinctly compressed tops, the branches generally growing close together, leaving less space between them than their own breadth. Surface of the coenosteum, particularly in the top parts of the branches, rather rough, showing minute round or oval flat tubercles with a diameter of 0.15 to $0.20 \mathrm{~mm}$. Lateral sulcus deep, pore-rows wide (0.8-1.0 mm), gastropores large (up to $0.5 \mathrm{~mm}$ wide), often of polygonal shape. Female ampullae flat hemispherical, diameter on an average $0.8 \mathrm{~mm}$, with granulated surface or (as in most instances) with radiating ridges. The colour of the colonies is usually violet in various shades or violet intermixed with red of different intensities; rather exceptionally the colour is white, yellow, orange, or brown.

$D$. gracilis Dana. Corallum generally of small size, exceptionally height up to $7 \mathrm{~cm}$, flabelliform, with several branches generally of about equal size. Branches more or less eylindrical, tops of the branches not noticeably compressed, the branches as a rule rather widely spreading. Surface of the coenosteum, particularly in the top parts of the branches, rather rough, with minute round or oval flat tubercles with a diameter of 0.15 to $0.20 \mathrm{~mm}$. Lateral sulcus deep, pore-rows wide (about $0.8 \mathrm{~mm}$ ), gastropores comparatively large (up to about $0.3 \mathrm{~mm}$ ), with a round opening. Female ampullae hemispherical, their surface granulated or with radiating ridges. The colour of the colonies is reddish of various shades, sometimes orange or purplish.

D. coccinea Gray. Corallum often of fairly large size, a height of $15 \mathrm{~cm}$ not being exceptional, flabelliform, with several branches generally of equal size. Branches strongly compressed antero-posteriorly, the smaller branches presenting a rather sharp lateral edge. At the flabellar surfaces of the larger branches there are median rows of tubercles with incipient pore-rows that may grow out to branchlets of a length of about $10 \mathrm{~mm}$ or longer, extending perpendicular to the flabellar plane. Surface of the coenosteum granular (diameter of the granules 0.05 to $0.10 \mathrm{~mm}$ ), rather opaque, not shiny. Lateral sulcus absent or occurring as a shallow groove in the younger branchlets only; pore-rows rather narrow (up to $0.6 \mathrm{~mm}$ ), gastropores as a rule not wider than $0.25 \mathrm{~mm}$, with round or oval opening. Female ampullae flat hemispherical, diameter generally $0.8 \mathrm{~mm}$, their surface granular, not presenting radiating ridges. The colour of the colonies is crimson of various shades from light to dark, rarely yellowish-orange.

D. fulvacea Michelin. The specimen supposed to be the type of the species has the characters of $D$. violacea; the colour is ochraceous (probably faded from fulvous or reddish-yellow).

D. nitida Verrill. Corallum of moderate to very large size (height up to $40 \mathrm{~cm}$ ), flabelliform, with a number of branches of about equal size dividing into several side branches. Branches more or less cylindrical, the top branches compressed anteroposteriorly. Surface of the coenosteum granular (diameter of the granules 0.05 to $0.10 \mathrm{~mm}$ ), glossy. Lateral sulcus absent, pore-rows comparatively narrow $(0.6$ to $0.8 \mathrm{~mm})$, gastropores rarely wider than $0.2 \mathrm{~mm}$, with a circular opening. Female ampullae flat hemispherical, diameter up to $0.8 \mathrm{~mm}$, their surface granular, in exceptional instances only showing faint radiating ridges. The colour of the colonies is generally vermilion with an orange shade, sometimes ochre-yellow or purplish red.

D. irregularis Moseley. The two existing colonies each consist of a single branch with some side branches not exactly extending in a flabellar plane. The branches are cylindrical with rounded tops. The surface of the coenosteum is finely granular. Porerows in a sulcus (MOSELEY's specimen) or on the surface (BRoch's specimen), width of the pore-rows $0.6-0.7 \mathrm{~mm}$. Pore-rows partly on the lateral margins of the branches, partly on the flabellar surfaces. Gastropores with round opening, up to $0.35 \mathrm{~mm}$ wide. Female ampullae deeply imbedded in the coenosteum, diameter about $0.6 \mathrm{~mm}$. The colour of the specimens is described as light pinkish (MOsELEY, $1880)$ and yellowish with a distinct lilac hue (BROCH, 1942).

D. livida Tenison-Woods. The species being of uncertain standing no attempt is here being made to define the characters. Notes on the peculiarities of the specimen of the Brussels Museum tentatively identified with $D$. livida are recorded on a previous page; here it may suffice to note that in its finer structures the specimen is similar to $D$. violacea, while in its form of growth it bears a certain likeness to $D$. nitida.

D. profunda Hickson \& England. In the original description the form of growth is defined as flabellate, the branches being very stout, obtuse, and flattened in the plane of the flabellum. The surface 
of the coenosteum is described as very rough; the granules appear to have a diameter of at least 0.5 $\mathrm{mm}$. The pore-rows have a width of $2.8 \mathrm{~mm}$, wider than in any other species of Distichopora. The gastropores are up to $0.5 \mathrm{~mm}$ in diameter; in one of the original figures they have a polygonal shape, in the other they are circular. The female ampullae are figured as scattered hemispherical bodies with a size of about $0.5 \mathrm{~mm}$. The colour of the specimens is brownish white.

D. providentiae (Hickson \& England). The largest specimen consists of three branches united at the base, gradually spreading to form a flabellum. The branches have blunt tops, they are distinctly compressed antero-posteriorly. The surface of the coenosteum is rather coarsely granular (size of the granules about $0.15 \mathrm{~mm}$ ), the granules as a rule uniting to ridges forming a vermiculated pattern. Gastropores in indistinct rows, surrounded by scattered dactylopores, the pores not arranged in definite pore-rows. Gastropores with round or slightly oval opening, about $0.3 \mathrm{~mm}$ wide. Female ampullae imbedded in the coenosteum, rising as slight swellings over the surface. The colour of the colonies is yellowish white.

$D$. borealis Fisher. Corallum of fairly large size (one colony of the type specimens has a main stem of $17 \mathrm{~mm}$ diameter), flabelliform, some branches often twisted or bent. Branches rather densely filling the flabellar plane (specimens from the Aleutian Islands, Fisher, 1938, Pls. 71-73) or more widely spaced (specimens from the Sagami Sea, Pl. XVI figs. 1 and 2) to widely spreading (specimen from the Sagami Sea, Brocr, 1942, Pl. 2 fig. 5). The surface of the coenosteum is finely granular, the granules at the tops of the branches uniting into ridges; in female colonies often larger spines among the granules. Sulcus deep, pore-rows wide, $1.0-1.2 \mathrm{~mm}$. Gastropores with-a funnel-shaped terminal part, the round tubular parts of the gastropores having a width of 0.25 to $0.35 \mathrm{~mm}$, the often polygonal funnelshaped part being 0.4 to $0.8 \mathrm{~mm}$ wide. Female ampullae "strongly convex, the surface traversed by prominent, interrupted or continuous, often sharp ridges or crests; or surface irregularly corrugated with occasional tubercles; diameter 1 to $1.25 \mathrm{~mm}$ " (Fisher, 1938). Colour of the colonies varying from white to light orange or ochre-yellow.

$D$. serpens Broch. Corallum of small size (the type specimen has a height of $25 \mathrm{~mm}$ ), branching in one plane, rather strongly compressed antero-posteriorly. The surface of the coenosteum is covered with small tubercles, about as in $D$. violacea and $D$. gracilis, but of somewhat smaller size. Sulci confined to the lateral margins of the branches, deep. Pore-rows comparatively wide, about $0.75 \mathrm{~mm}$. Gastropores with round openings, 0.25 to $0.30 \mathrm{~mm}$ wide. The gastrostyles are not long and slender as in all other species of Distichopora but are comparatively short, feebly conical. Female ampullae with a rather coarsely warty surface, often radially grooved, diameter about $1.0 \mathrm{~mm}$. The colour of the colonies (in alcohol) is a yellowish orange.

The well-defined Indo-Pacific species of the genus Distichopora can be distinguished with the following key:

1. Gastropores and dactylopores arranged in distinct rows . . . . . . . . . . . . 2

- Gastropores and dactylopores not arranged in welldefined rows . D. providentiae (Hickson \& England)

2. Pore-rows of moderate width (up to $1.2 \mathrm{~mm}$ ) . . 3

- Pore-rows exceptionally wide (about $2.8 \mathrm{~mm}$ )

D. profunda Hickson \& England

3. Pore-rows on the lateral margins of the branches (rarely a few additional short pore-rows on the flabellar surfaces . . . . . . . . . . . . . . 4

- Pore-rows of irregular course, partly on the flabellar surfaces, partly on the lateral margins

D. irregularis Moseley

4. Gastrostyles long and slender. . . . . . . 5

- Gastrostyles short and feebly conical, not elongated D. serpens Broch

5. Colour of the colony as a rule orange-red to violet . 6

- Colour of the colony yellowish (buff) or white

D. borealis Fisher

6. Surface of the coenosteum of the small branches with tubercles with a diameter of 0.15 to $0.20 \mathrm{~mm}$. .7

- Surface of the coenosteum of the small branches with fine granules with a diameter of 0.05 to $0.10 \mathrm{~mm}$. 8

7. Tops of the branches flattened antero-posteriorly; branches as a rule narrowly joining . $D$. violacea (Pallas)

- Tops of the branches more or less cylindrical; branches as a rule rather widely spreading - D. gracilis Dana

8. Flabellar surface of the larger branches with a median row of incipient branchlets . . . D. coccinea Gray

- No rows of tubercles or small branches on the flabellar surface of the larger branches . . D. nitida Verrill.

The geographical distribution of the Indo-Pacific species of Distichopora is recorded at the ends of the chapters dealing with each of the species. Here some remarks may be given concerning the occurrence of species of Distichopora (and other Stylasterine corals) in the Hawaiian Islands. Though the data referring to the occurrence of Stylasterina in this locality seem to be extremely doubtful, it is a remarkable fact that a great number of corals of the group in the collection of the Paris Museum have on their labels the indication "Iles Sandwich", the corals labelled as such being: Distichopora coccinea (under the name $D$. miniacea Michelin), 5 colonies and 5 fairly large fragments; $D$. violacea, 2 colonies; $D$. nitida, 2 colo- 
nies; Stylaster sanguineus Valenciennes in Milne Edwards \& Haime, 19 colonies. Most of these were received from Mr. BALLIEU in the years 1875 to 1879 .

In the literature there are the following data on the occurrence of Stylasterina in the Hawaiian Islands.

MOSELEY (1877, p. 101) remarks: "Immense quantities of a large flabellate red Distichopora brought from the Marquesas group, are sold to tourists at Honolulu. The corals are said to come from deep water." This statement may explain the supposed occurrence of Stylasterina in the Hawaiian Islands; the characterization of the Distichopora as "large flabellate red" indicates that in all probability the specimens referred to were $D$. coccinea.

Perrier (1881, p. 303), who mentioned the occurrence of the "Distichopore violet" and of Stylaster roseus (correct name Stylaster sanguineus) in the Hawaiian Islands, obviously referred to corals in the collection of the Paris Museum; the same holds for the remarks by FruHoL $(1885$, p. 268) concerning "Stylaster roseus" from the same locality. Hickson (in Hickson \& England, 1909, p. 347) mentions "beautiful rose-coloured Distichoporas from Hawaii."

Fisher (1938, p. 495) remarks: "As a parenthetic observation on the distribution of the Stylasterina, the only species known to inhabit the Hawaiian pla- teau is Stylaster sanguineus. Probably Distichopora violacea also occurs, although I can find no record." It has to be kept in mind that Fisher includes the two species $D$. coccinea and $D$. nitida in his conception of $D$. violacea. WeLLs (1954, p. 476) records a specimen from Johnston Island among his materials of D. violacea (sensu Brocr, the correct name being that of one of the two species coccinea and nitida, erroneously placed into the synonymy of violacea).

EDMONDSON, who has made thorough studies of the marine fauna of the Hawaiian Islands, observes (1928, p. 6): “On Hawaiian reefs few alcyonarians and no hydroid corals such as Millepora and Stylaster have been reported although they exist at Johnston Island." In a later publication (EDMONDSON, 1946, p. 27) he states: "No hydroid corals are known to occur in Hawaiian shallow waters. The locality nearest to Hawaii where they have been observed is Johnston Island, 750 miles southwest of Oahu."

Taking these data into consideration it seems fairly conclusive that Stylasterine corals do not occur in the Hawaiian Islands; the numerous specimens in the Paris Museum labelled with this locality apparently were obtained in the Hawaiian Islands but came originally from other localities in the Pacific.

\section{DISTICHOPORA VIOLACEA (PALLAS, 1766)}

Millepora violacea Pallas, 1766, p. 258; Boddaert, 1768, p. 321; Ellis \& Solander, 1786, p. 140; Wilkens, 1787, p. 328 ; Gmelin, 1789 , p. 3785 ; Herbst, 1789 , p. 60 ; Boddaert, 1798, p. 321; Bosc, 1802, p. 289; Oken, 1815, p. 62; Cuvier, 1830, p. 316; Cuvier, 1836, p. 386; Milne Edwards, 1836-1849, p. 141; Nardo, 1845, p. 637; Milne Edwards, 1860 , p. 450; Tenison-Woods, 1879 b, p. 50; Hickson in Hickson \& England, 1909, p. 346; Hickson, 1924, p. 152; Kühn, 1959, p. A 31; Boschma, 1956a, p. 140; Boschma, $1956 \mathrm{~b}, \mathrm{p} . \mathrm{F} 100$.

Distichopora violacea Lamarck, 1816a, p. 198; Lamarck, 1816b, Pl. 481 fig. 1a, b; Schweigger, 1819, Pl. VI fig. 61; Schweigger, 1820, p. 413; Lamouroux, 1821, p. 46; Deslongchamps, 1824, p. 256; Defrance, 1826, p. 394; De Blainville, 1830, p. 381; Henschel, 1833, p. 199; De Blainville, 1834, p. 416; Deshayes \& Milne Edwards, 1836, p. 305; Milne Edwards, 1836-1849, Atlas, Pl. 85; Nardo, $1844 a$, p. 68 ; Nardo, 1844 b, p. 435 ; Dana, 1848, p. 703; Milne Edwards \& Haime, 1850-1854, p. lix; Dana, 1859, p. 151; Gray, 1860, p. 245; Milne Edwards, 1860, p. 451; Schmeltz in Gräffe, 1866, p. 592; Schmeltz, 1875, p. 21; Tenison-Woods, 1879a, p. 303; Tenison-Woods, $1879 \mathrm{~b}$, p. 61 ; Klunzinger, 1879 , p. 89 ; Moseley, 1879 , p. 482 ; Moseley, 1880, p. 84; Wright, 1882, p. 73; Quelch, 1885, p. 16; Von Lendenfeld, 1885, p. 614; Ludwig, 1886, p. 1021; Von Lendenfeld, 1887, p. 46; Kirkpatrick, 1890, p. 12; Hickson, 1892, p. 501; Ortmann, 1892, p. 668; Ward, 1892 , p. 53; Hickson, 1893, p. 129; Von Martens, 1902, p. 135; Kirkpatrick, 1902, p. 54; Hickson \& England, 1905, p. 19; Hickson in Hickson \& England, 1909, p. 346; England, 1926, p. 267; Hoffmeister, 1929, p. 365; Fisher, 1938, p. 544; Broch, 1950, p. 40; Boschma, 1951, p. 459; Tokioka, 1953, p. 130; Boschma, 1953, p. 167; Utinomi, 1956a, p. 4; Utinomi, 1956b, p. 345; Boschma, 1956a, p. 139; Boschma, 1956b, p. F 100; Boschma, 1957, p. 47; Boschma, 1959, p. 247.

Distichopora cinabarina Nardo, 1844a, p. 62.

Dictichopora cinnabarina Nardo, 1844b, p. 435.

Madrepora violacea Nardo, 1844a, p. 68; Milne Edwards, 1860, p. 451; Fisher, 1938, p. 543; Broch, 1942, p. 9.

Distichopora cinnabarina Nardo, 1845, p. 637; Boschma, 1957, p. 42.

? Distichopora rosea Kent, 1871, p. 281; Tenison-Woods, 1879 a, p. 303 ; Tenison-Woods, 1879b, p. 61; Moseley, 1879 , p. 482 ; Moseley, 1880 , p. 85 ; Wright, 1882 , p. 74 ; Quelch, 1884a, p. 114; Quelch, 1885, p. 17; Von Lendenfeld, 1887, p. 46; Hickson, 1892, p. 502; Fisher, 1938 , p. 544; Boschma, 1953, p. 167; Boschma, 1956a, p. 138; Boschma, 1957, p. 46.

Distichophora violacea Tenison-Woods, $1879 \mathrm{~b}$, p. 58; Knauer, 1887, p. 216; Broch, 1942, p. 16.

Stylaster violaceus Ortmann, 1892, p. 636.

Distichopora (Millepora) violacea Kühn, 1928, p. 103.

Madreporaria violacea Broch, 1942, p. 7.

Distichopora fisheri Broch, 1942, p. 14; Boschma, 1953, 
p. 167; Wells, 1954, p. 476; Boschma, 1957, p. 43. Dystichopora violacea Dawydoff, 1952, p. 56. Distichopora fisheri form $\alpha$ Wells, 1954, p. 476. Distichopora fisheri form $\beta$ Wells, 1954 , p. 476 . Distichopora Hickson, 1889, p. 52; Crossland, 1928, p. 581; Gardiner, 1936, p. 412.

Distichopora benhami (?) MS.

Pallas (1766, p. 258) described the species Millepora violacea as follows:

"Massulae corallinae in rupibus diffusae, assurgentes ramulis teretibus, obtusis, subflexuosis, passim ramosis verrucosisve, sesquipollicaribus. Substantia intus tubulis vasculosa, violaceo albida, in superficie tenerrime scabra \& saepe pulcherrimo florum sambuci colore tincta. Per ramulos extus suturae vulgo binae, plerumque oppositae, longitudinales, cellulosae seu ex poris concatenatae decurrunt. In quibusdam speciminibus observavi passim crebras in superficie bullulas, quales in adusto glutine fere surgunt; quae confractae cellulositatem latentem prodiderunt, efflorescentiumque polyporum quasi gemmulae esse videntur."

Next to characters common to most of the species of Distichopora (the marginal sulci with the pores

and the ampullae) this description contains important data for a specific identification, viz., the blunt ending slightly compressed branches (oval in cross section), the indication of the height as one and a half inches, the violet colour, and the slightly rough surface.

It is interesting to note that the description of Millepora violacea by Ellis \& Solander (1786, p. 140) contains data closely corresponding to those mentioned by Pallas; their description reads:

"Millepora in plano ramosa, ramulis ascendentibus flexuosis tereti-compressis, suturâ porosa marginem ambiente.
This flat branching Millepore has round, erect branches, a little compressed, and waved; there is a suture with a line of pores encompassing the margin.

This Coral is of a fine violet-blue; it rises from a spread base about three inches high: besides the line of large pores that surrounds the margin, there are two rows of small pores, one on each side of it. The surface, when magnified, is rough like chagreen, and here and there upon it are clusters of little warts, like studs or bullulae, which may probably be its ovaries. When the branches

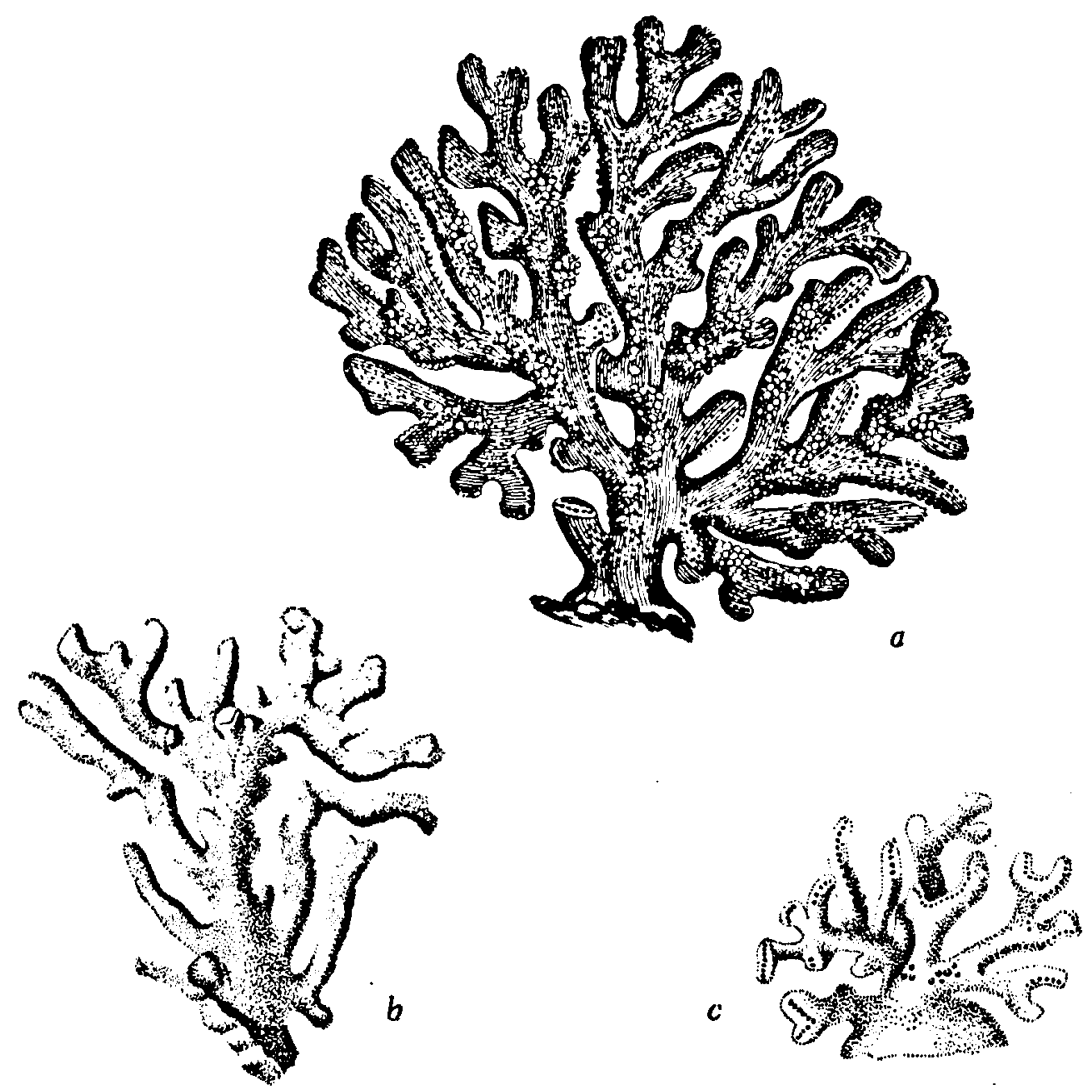

Fig. 1. Distichopora violacea (Pallas). a, after Ellis \& Solander (1786, PI. 26 fig. 3); b, after Milne Edwards (1849, Pl. 85 fig. 4); c, after De Blainville (1830, Pl. 35 fig. 2). Original (natural) size. 
are broken across, there appears in the middle a row of three or four large pores, surrounded by small ones. I had formerly a specimen of this Coral from W. Webber, Esq. F. R. S. and very lately some compleat ones from Mr. Banks and Dr. Solander, that the divers had fished up about the islands in the South Sea."

Pl. 26 fig. 3 of the cited work (copied in fig. 1 a of the present paper) undoubtedly represents Millepora violacea, though no explanation of this plate was found in Mr. Ellis's papers (1. c., p. 202).

The following diagnosis of Distichopora violacea is based on the peculiarities mentioned by Pallas (1766) and by Ellis \& Solander (1786), on the figure in the last mentioned work, and on an examination of specimens showing an external appearance similar to this figure.

Corallum flabelliform, up to about $8 \mathrm{~cm}$ high, with several branches generally of approximately equal size. Branches compressed antero-posteriorly, with blunt tops, generally growing close together so that the space between the branches is smaller than the branches themselves. Surface of the coenosteum, especially in the top parts of the branches, rather rough, showing minute round or oval flat tubercles. Sulcus at the sides of the branches rather deep; gastropores comparatively large (diameter 0.3--0.5 $\mathrm{mm}$ ); dactylopores with prominent dactylopore projections. Ampullae in groups on the flabellar surfaces of the colony, low hemispherical, their surface covered with tubercles of the same appearance as those of the surface of the branches, or showing elevated ridges radiating from the centre to the periphery. Colour violet, pink, brown, or orange, the tips of the branches often white.

The characters as noted in this description are those of the typical form of Distichopora violacea. Unfortunately the typical locality cannot be determined, Pallas giving "Mare Indicum" as the place of origin, while Ellis \& Solander noted that their specimen was "fished up about the islands in the South Sea." Specimens with the typical characters, as here understood, have been recorded from various localities in the Indo-Pacific region, from the Red Sea to the Fiji Islands and Tahiti, proving that the species is widely distributed in the area.

LAMARCX (1816 a, p. 198) characterizes the species Distichopora violacea as " $D$. ramosa; ramulis ascendentibus flexuosis, tereticompressis" and cites as references the works of Pallas and of Ellis \& Solander; in another publication (LAmarck, $1816 \mathrm{~b}, \mathrm{Pl} .481$ fig. 1) there is a copy of the figure of Ellis \& SoLANDER. This proves that LAMARCK's $D$. violacea corresponds with the data referred to above. The same holds for the coral of this name mentioned by Lamouroux (1821, Pl. 26 fig. 3), the figure again being copied from Ellis \& Solander.

The specific identification of the coral figured by Schweigger (1819, Pl. 6 fig. 61), and named by him Distichopora violacea, is uncertain. The figure may have been made after a specimen of $D$. violacea, but the form of growth and the shape of the branchlets point to a strong similarity to $D$. nitida, the very small pores also indicating a possible identification with the last mentioned species.

Deslongchamps (1824, p. 256) has the following remark on the distribution of Distichopora violacea: "Il habite la mer des Indes, les côtes de l'Australie; il n'est pas rare à l'île de Timor." The first two localities are copied from LAMARCK's data, the locality Timor was apparently based on specimens collected on this island by PÉRoN \& LEsueur in 1801 or 1803 (cf. Milne Edwards, 1849, and list of specimens in the Paris Museum).

The figure of Distichopora violacea in DE BLAINVILle (1830, PI. 35 fig. 2, copied in text-fig. 1c of the present paper) represents a colony with slender branches, closely corresponding with the specimens from the Red Sea in the collection of the Paris Museum (cf. Pl. III figs. 1 and 2 in the present paper). The same figure appeared in a later publication by De Blainville (1834, Pl. 55 fig. 2). This figure was also cited by Deshayes \& Milne EDWARDS (1836) in their synonymy of the species.

DaNA (1848, p. 703) characterizes Distichopora violacea as: "Violet, with the tips a little yellowish; 2 to $2 \frac{1}{2}$ inches high, and ramose; branches somewhat compressed, dichotomous, 1 to $1 \frac{1}{2}$ lines broad." $\mathrm{He}$ examined specimens collected in the Tuamotu Archipelago, the figures (1. c., Pl. 60 figs. 3, 3 a) represent a coral in natural size with rather slender branches and an enlarged view of a marginal sulcus with the row of pores. The identification with $D$. violacea is in all probability correct.

In the "Disciples' Edition" of the "Règne Animal" (MILNE Edwards, 1849) there are very distinct figures of a colony of Distichopora violacea (Pl. 85 figs. $4,4 \mathrm{a}-\mathrm{c})$, representing the coral in natural size and enlarged views of a marginal sulcus with the three rows of pores, of a longitudinal section of a branch, and of a transverse section of a branch. The figure of the coral in natural size is copied in fig. $1 \mathrm{~b}$ of the present paper. It represents the specimen of a height of $50 \mathrm{~mm}$ and a breadth of $35 \mathrm{~mm}$ collected at Timor by Péron \& Lesueur in 1801 (Pl. I fig. 11). The original dimensions of the specimen were 50 by 43 $\mathrm{mm}$ (cf. fig. $1 \mathrm{~b}$ ), some of the branches have broken 
off so that the specimen now is slightly smaller; the growth form shows that the two figures represent the same colony. The general appearance of this coral is slightly different from that of the specimen figured by ElLis \& Solander, in the latter the branches are spreading much more fan-wise, while in the former there is one large main stem with several side branches. In its growth form the colony here dealt with shows a strong resemblance to the type specimen of Distichopora fisheri figured by Ввосн (1942, Pl. 2 fig. 3).

The specific description of Distichopora violacea by MiLNe EDwards (1860) is rather vague, the remark that the species seems to occur on the coasts of the island Timor indicates that the author referred to specimens from this. locality which undoubtedly belong to the species.

KLUNZINGER ( 1879 , p. 89 ) gives a detailed description of Distichopora violacea from the Red Sea, he remarks that here the colonies are not exceeding 2 to $3 \mathrm{~cm}$ in height and breadth, in contradistinction to specimens from other localities, which grow to a larger size. He mentions the small tubercles occurring on the surface of the corallum and states that the colour is always blue or violet, as a rule with white tops of the branches. KLunzinger remarks that the species is new for the Red Sea, overlooking the fact that DE Blainville (1834, p. 416) already recorded it from this locality.

The specimens identified by Tenison-Woons $(1879 \mathrm{~b})$ with Distichopora violacea indeed belong to this species, for he gives as maximum height two inches, and notes that the surface is finely granular, the granules being larger than in any other species dealt with in the cited paper. He further states (l. c., p. 61): "At each side the lateral furrow is broad, deep, and undulating. Margins of furrow very prominent-irregularly and finely dentate, sometimes extending in lobes on the face of the branches." The ampullae are described as roughly stellate excrescences. The figure (1. c., Pl. 1 fig. 1) shows a specimen with the typical characters, the branches arranged fan-wise, height of the colony about $35 \mathrm{~mm}$, breadth about $50 \mathrm{~mm}$.

Rather aberrant specimens of Distichopora violacea were reported upon by Hickson (1892); the specimens were obtained in shallow water off Murray Island (Torres Straits). In the first place they were remarkable on account of their variation in colour: "Some of the smaller colonies are bright orange in colour, others vandyke brown, and the larger ones are deep purple with pale yellowish white tips. Many intermediate varieties of colour are to be met with in the collection." (HICkson, 1892, p. 501). According to Hickson the difference in colour does not point to specific differences, but depends upon the age and the sexual maturity of the colonies (immature colonies having an orange colour, male colonies a brown colour, and female colonies a violet colour). In this connexion Hickson remarks that the status of $D$. coccinea and of $D$. rosea must be considered provisional until information on the anatomy of the soft parts will become available. (It may be here noted that in the present paper $D$. coccinea is considered a well-defined species, while $D$. rosea is tentatively placed in the synonymy of $D$. violacea).

Hickson further remarks that Moseley (1880, p. 95) already drew attention to the fact that in species of Distichopora sometimes the rows of pores are not confined to the lateral margins of the branches but also occur on the flabellar surfaces of the colony. This aberrant occurrence of rows of pores was strongly pronounced in the specimens from Torres Straits, as shown in the figures on Pl. 18 of Hickson's paper; here several short rows of pores are to be seen on the flabellar surfaces of the corals. The same condition was to be observed in a still more striking manner in a fragment of a Distichopora from Lembeh Island near North Celebes, presenting on the flabellar surface of the corallum not only numerous short rows of pores but also a number of pores arranged in isolated cyclosystems similar to those of Stylaster and Allopora (Hickson, 1892, Pl. 19 fig. 1). Notwithstanding the aberrant position of the pore-rows Hickson's conclusion as far as concerns the specific determination of the specimens as Distichopora violacea seems to be correct. I could examine two colonies from the collection of the Manchester Museum, locality Torres Straits, which to all appearances formed part of the specimens examined by Hickson, and which show all the salient characters of the species (cf. notes on a following page).

The following sentence from a later paper by Hickson (1898, p. 256) may be here quoted to show that this author gradually became convinced of the lack of specific characters in the genus Distichopora: "It would be premature to propose to extend my remarks to other genera of corals, but I have already pointed out that there are some reasons for believing that there is not more than one species in the Alcyonarian genus Tubipora and the Hydrocoralline Distichopora." In a similar manner KIRKPatrick (1.902, p. 54) wrote: "Probably the various supposed species of Distichopora (D. coccinea, violacea, livida) are colour variations of one species."

A more elaborate account of the species problem 
in Distichopora was given by Hicxson in Hickson \& ENGLAND (1909, pp. 346-348). Here he stated that all the shallow water specimens of the genus examined by him, from Torres Straits, the Malay Archipelago, the coasts of Fiji, and from other islands of the S. Pacific and the Indian Ocean belong to the one species, Distichopora violacea. Hrckson added that he had not yet examined with sufficient care "the beautiful rose-coloured Distichoporas from Hawaii" nor any specimens from the West Indies to warrant the conclusion that they also belong to the same widespread species. After examination of the shallow-water specimens from the Indian Ocean Hickson became more firmly convinced that the colour is no guide to specific distinction. In a manner similar to the specimens from Torres Straits the corals from the Indian Ocean proved to occur in white, yellow, orange, violet, and purple varieties, in general the colour of large colonies being more pronounced than that of small specimens. Hickson is inclined to believe that $D$. violacea is protandrous and that the purple colour is the last of a series of colourchanges during growth.

Fisher (1938) made some remarks on certain species of the genus Distichopora that have given rise to considerable confusion. After having described the new species Distichopora borealis he remarked: "I have compared specimens with examples of $D$. violacea (Pallas) Lamarck, D. coccinea Gray, and $D$. nitida Verrill - color variations of one reef and shallow-water Indo-Pacific tropical species, $D$. violacea. This species does not have dactylotome projections and has a smooth, purple, violet, rose, red, or deep apricot corallum." (1. c., p. 544). It is surprising that Fisher, whose work on the Stylasterina of the North Pacific is of the highest quality, came to this insufficiently founded conclusion. It appears that he did not examine specimens of the typical form of $D$. violacea, which have well-developed dactylotome projections. He noted that "some specimens of $D$. violacea forma coccinea" show one or a few gastropores surrounded by a number of dactylopores, usually on a slight convexity, the first appearance of a new branchlet, proving that at least some of the specimens examined by him were $D$. coccinea. As these convexities were present in some specimens only, and as the corallum is described as smooth, a fairly large number of his specimens must have been $D$. nitida.

When dealing with his extensive material of $D i$ stichopora from shallow water of various localities in the Pacific, Вroch (1942) took for granted that Fisher was correct in placing the species $D$. coccinea and $D$. nitida in the synonymy of $D$. violacea. He arranged his specimens in three units (two species, the one composed of two formae), and made elaborate descriptions of each of the three forms in such an admirable manner that the correct specific identification is to be established without any doubt, as shown in the following list:
Names of units
in BROCH (1942)

violacea forma typica Broch violacea forma cornuta Broch fisheri Broch
Names of the same units in the present paper nitida Verrill coccinea Gray violacea Pallas
Leaving aside here Broch's "violacea" with its two formae, it must be noted that fisheri Broch in reality is a synonym of violacea Pallas. The growth form of the type specimen of $D$. fisheri (ВRосн, 1942, Pl. 2 fig. 3) closely corresponds with that of the specimen of $D$. violacea from Timor figured by MiLNE EDwards (PI. I fig. 11 and text-fig. $1 \mathrm{~b}$ in the present paper). Broch's elaborate description of the peculiarities of his specimens and his text-figure 2, showing a side view of a top of a branch, a part of a sulcus, and a longitudinal section of a fragment, prove that the corals present all the characters of $D$. violacea, the surface showing the minute flat rounded tubercles, the sulcus being deep, the dactylopores having distinct dactylotome projections giving a serrate appearance to the branches in side view.

The identification of specimens of Distichopora from the Marshall Islands by WeLLs (1954) was based on Broch's (1942) revision of the genus. Accordingly one of the species was identified with $D$. violacea sensu Ввосн, the appropriate name being D. nitida Verrill (Wells, 1954, p. 476, Pl. 185 fig. 3). The other species (1. c., p. 476, Pl. 185 figs. 1 and 2), showing relatively deep sulci at the sides of the branches, was identified with $D$. fisheri Broch, the correct name therefore being $D$. violacea (Pallas). WeLls divides his specimens in two groups, the one (type $\alpha$ ) closely corresponding with the type specimen of Broch's $D$. fisheri, the other (type $\beta$ ) with relatively broad and stubby branches. In many respects this type $\beta$ bears a resemblance to the specimen figured by Ellis \& Solander (1786), representing the typical form of $D$. violacea.

In a previous paper (Boschma, $1956 \mathrm{a}$, p. 140) I pointed to the desirability to restrict the name $D i$ stichopora violacea (Pallas) to corals of comparatively small size corresponding in form of growth with the figure of Ellis \& Solander, leading to the con- 
clusion that $D$. coccinea Gray and D. nitida Verrill are specifically distinct from $D$. violacea. In this paper I further noted that Broch's violacea forma typica in reality is $D$. nitida, while his violacea forma cornuta has all the salient characters of the species $D$. coccinea. In another paper (Boschma, $1956 \mathrm{~b}$, p. F 102) there is a figure of $D$. violacea drawn after the original figure of the species in ElLIS \& SOLANDER (1786). Recently I remarked again that each of the three species $D$. violacea, $D$. coccinea, and $D$. nitida has its own well-defined specific characters (BoschмA, 1959).

ToxroxA (1953, p. 130) mentioned a "small but very pretty violet hydrocoral, Distichopora violacea (Pallas)" as occurring in the Tokara Islands, south of Kyûsyû, Japan. The specimens were later examined by UTiNOMI (1956 b), who noted that they exactly agree with Hickson's coloured figures of $D$. violacea from Murray Island (Torres Straits). He adds that the species was up to now unknown to occur in Japanese waters. The largest specimen had a height of $17 \mathrm{~mm}$ and a width of $25 \mathrm{~mm}$. A coral of approximately the same dimensions is figured in another publication (Utinomi, $1956 \mathrm{a}, \mathrm{Pl} .2$ fig. 9), its form of growth corresponding with the specimens from Torres Straits referred to above.

Some remarks must be added concerning certain names placed in the synonymy of $D$. violacea.

NArDo (1844 a, b, 1845) made some vague and indefinite remarks on a coral named by him Distichopora cinnabarina. The species is stated to differ from $D$. violacea by its smaller dimensions and slenderer branches, and by its cinnabar (vermilion) colour, the tops of the branches being white. NARDo further remarks that in contradistinction to $D$. violacea, which has a row of large pores flanked at each side by a row of smaller pores, $D$. cinnabarina has but a single row of pores. He states that the verrucae (ampullae) of his new species are round, not stellate as in $D$. violacea. In all probability the coral came from the Red Sea. The available data concerning $D$. cinnabarina do not suffice to identify the coral with one of the known species of the genus. The size, smaller than $D$. violacea, indicates that in all probability it represented a form of this species with very slender branches, as they occur in the Red Sea. The bright red colour, and especially the single row of pores, make the identification with this species problematical. In the account of the specimens examined, at the end of the present chapter, however, notes are given on specimens from the Red Sea, in the collection of the Paris Museum, in which the colour is predominantly red, though intermixed with some violet; this gives some support to the opinion that NARDo's coral had the characters of the specimens referred to, and accordingly belonged to the species $D$. violacea.

The important characters in the description of Distichopora rosea (KeNT, 1871, p. 281) are: "Corallum arborescent, branches nearly cylindrical. Calices occupying deep and occasionally irregularly interrupted lateral furrows; margins of the furrows very prominent." The colour of the coenenchyma is noted as bright rose-pink. During a visit to the British Museum in 1957, I had occasion to examine the type specimen, and noted that the surface shows the flat rounded tubercles as they occur in $D$. violacea and in D. gracilis. In its form of growth the coral is more or less intermediate between the two species here mentioned, the branches being very little compressed and not broadening at the tops. The attempt to identify the coral with $D$. violacea must remain provisional. It is interesting to note that Fisher (1938, p. 544) remarked that $D$. rosea Kent is probably the same species as $D$. gracilis Dana.

The name Distichopora fulvacea Michelin is in all probability a synonym of $D$. violacea (Pallas). The peculiarities of the coral supposed to be the type specimen of $D$. fulvacea are dealt with in a following chapter.

Although Distichopora violacea generally does not grow to a size exceeding 7 or $8 \mathrm{~cm}$, its gastropores are wider than those of $D$. coccinea and $D$. nitida, in which the colonies often become much larger. The gastropores of $D$. coccinea have a diameter of up to $0.2 \mathrm{~mm}$, rarely developing to a width of $0.3 \mathrm{~mm}$. In D. nitida $0.2 \mathrm{~mm}$ is usually the maximum width of the gastropores, ВRосн (1942) mentions a diameter of $0.2-0.3 \mathrm{~mm}$ for the gastropores of $D$. nitida (referred to as $D$. violacea forma typica). Hickson (in Hickson \& ENGLaNd, 1909) remarks that in $D$. violacea the gastropores are rarely more than $0.3 \mathrm{~mm}$ in diameter; Broch (1942) gives as the diameter of the apertures of the larger gastropores $0.35 \mathrm{~mm}$ in this species (referred to with the name $D$. fisheri). In specimens of $D$. violacea from Timor (PI. IV figs. 2 and 3) the width of the larger gastropores is 0.3$0.4 \mathrm{~mm}$, in specimens from Torres Straits (PI. IV figs. 6-9) they are even larger, with a diameter of up to $0.5 \mathrm{~mm}$.

In their manner of growth the colonies of Distichopora violacea present considerable variation. WeLLS (1954) stated that his specimens from the Marshall Islands (named by him $D$. fisheri) fall into two forms: " $\alpha$ in which the branches are narrow ( $2.5 \mathrm{~mm}$ or less) and slender, and $\beta$ in which the branches are relatively broad (3.5 $\mathrm{mm}$ ) and stubby." WeLls (l. c., p. 
476) further remarks: "Although Broch does not give dimensions of the branches, comparison with his figures indicates that $a$ is closest to his type. Type $\beta$ may be a geographical variant." A comparison of Broch's figure of $D$. fisheri with the two colonies figured by WeLLs shows that while the latter both are distinctly flabellate with a pronouncedly radiating growth of the main branches, the former tends to develop into a few upstanding branches with side branches remaining in the flabellar plane; this form of growth leads to corals of a decidedly different shape. The three forms are here indicated with Latin names; they should, however, not be considered distinct subspecies, for they are not geographically separated. The forms violacea s. s. and tenella, e.g., both occur in the Red Sea. The three forms may be characterized as follows:

Forma violacea s. s.: Colony flabellate, consisting of several main branches of about equal size, the terminal branchlets relatively broad (about $3.5 \mathrm{~mm}$ ) and stubby. The branches have a tendency for keeping the same thickness for rather long distances. Examples of this form are the coral of the form $\beta$ of Wells (1954, Pl. 185 fig. 1), the specimen figured by Ellis \& Solander (cf. text-fig. 1 a), and the specimens from Murray Island in Torres Straits (Pl. I fig. 17). This form may be considered the typical form of growth of the species as it corresponds with the oldest figure of $D$. violacea (Ellis \& Solander, 1786).

Forma fisheri: Colony consisting of one or a few main stems, each with several side branches, the terminal branchlets relatively broad ( 3 to $4 \mathrm{~mm}$ ) and blunt. Examples of this form are the coral figured by Milne Edwards (cf. text-fig. $1 \mathrm{~b}$ ) and the type specimen of $D$. fisheri (Broch, 1942, Pl. 2 fig. 3). The colony tentatively identified with $D$. livida ( $\mathrm{PI}$. XIV figs. 1 and 2) may represent a vigourously developed specimen of this form.

Forma tenella: Colony flabellate, consisting of several main branches of about equal size, the terminal branchlets narrow (about 2.0-2.5 $\mathrm{mm}$ ) and slender. The branches are distinctly tapering from the base towards the top. Examples of this form are the coral of the form $a$ of WeLLS (1954, Pl. $185 \mathrm{fig}$. 2) and the majority of the specimens from the Red Sea in the collection of the Paris Museum (PI. III figs. 1 and 2). In all probability the coral figured by De Blainville (cf. text-fig. 1 c) also belongs to this form.

\section{Specimens examined}

Australian Museum, Sydney: Distichopora, Marshall
Islands (?), reg. no. G 6241 (partim), 1 colony, 30 by $16 \mathrm{~mm}$ (Pl. II fig. 8). The specimen consists of a thick basal part and a few branches; the largest having five side branches. The branches are strongly compressed antero-posteriorly. The gastropores are rather wide (up to $0.5 \mathrm{~mm}, \mathrm{Pl}$. IV fig. 12). In the basal part of the colony there are numerous short pore-rows on the flabellar region of both sides (Pl. IV fig. 13). Some of the branches have a patch of confluent male ampullae. The colour is a dull greyish purple. The colony is too young to definitely determine the forma; the manner of growth shows a certain likeness to DE Blainville's figure (cf. textfig. 1c).

Australian Museum, Sydney: Distichopora rosea, Bougainville Strait, New Hebrides, Capt. BraithwAITE, reg. no. G 7261 (partim), 1 colony, 45 by $59 \mathrm{~mm}$ (Pl. XIV figs. 3 and 4). The specimen is rather puzzling as its form of growth differs from all of the three forms defined above, the shape of the colony strongly corresponding with that of the specimen tentatively identified with D. livida (Pl. XIV figs. 1 and 2). Like this specimen the coral here dealt with has the posterior surface of the normal shape, while on the anterior surface parts of the larger branches are more or less gouged out, leaving a broad ridge in the middle of the branches. The lateral sulci are deep in the smaller branches, while on the larger branches they may become very shallow or even absent. The gastropores are large. The tips of the branches distinctly show the small round or oval tubercles as they are peculiar to $D$. violacea. On several of the branches there are large patches of male ampullae forming narrowly confluent masses. The colour of the colony is vermilion, faintly turning to orange.

Australian Museum, Sydney: China Strait, near Samarai, East of Papua, J. B. Norkis, reg. no. G 13282 (partim), 1 fragment, 70 by $24 \mathrm{~mm}$. A single branch with side branches, some of which are extending next to the flabellar plane. The growth form is similar to that of $D$. nitida, the larger branches are compressed sideways in a manner reminiscent of the structure of the specimen tentatively identified with D. livida. The lateral sulci are deep, the gastropores are large, leading to an identification of the specimen with $D$. violacea, a conclusion strengthened by the fact that the surface of the branchlets' has the flattopped minute tubercles which are characteristic of the species. The colony has some dense patches of male ampullae. The colour is vermilion, some of the tops of the branches are a dirty white. The specimen bears a certain likeness to the coral from the New 
Hebrides dealt with above; the two specimens have, however, a different form of growth, the coral from China Strait having a tendency for upward growth, the coral from the New Hebrides spreading more pronouncedly in a lateral direction.

Australian Museum, Sydney: Distichopora nitida, Gilbert Islands, no reg. no., 2 fragments, 39 by 33 $\mathrm{mm}$ and 28 by $22 \mathrm{~mm}$ (Pl. I figs. 3 and 4, Pl. II fig. 3). The two fragments are more or less regularly spreading in one plane, only some of the branches being curved anteriorly. In the larger fragment the base of the main branch has a diameter of about $4 \mathrm{~mm}$, the branchlets are $2 \mathrm{~mm}$ or less in thickness. The larger branches are more or less cylindrical, the smaller branches are strongly flattened antero-posteriorly. The surface of the coenosteum is finely granular, while most of the branchlets distinctly show the characteristic minute flat-topped tubercles, though these are smaller than generally in the species. In the smaller branches the lateral sulcus is deep, in some of the larger branches the sulcus becomes very shallow. The gastropores are rather narrow, up to $0.2 \mathrm{~mm}$ in diameter; the dactylopores have dactylotome projections, which especially in the tops of the branchlets are well-developed, giving these parts a slightly serrate margin. There are a few small patches of male ampullae. The colour of the colonies is ochre-yellow to orange, the tops of the branchlets often being somewhat paler. In their form of growth these corals present a similarity to the specimens of $D$. gracilis from the Tuamotu Islands (cf. Pl. II fig. 2); the pronouncedly flattened branchlets exclude, however, an identification with this species. The fine granulation of the surface might indicate an affinity with $D$. nitida, the well-developed lateral sulci point against an identification with this species. Provisionally the specimens may find a place in the species $D$. violacea, though they cannot easily be brought to one of the three formae to be recognized in this species.

British Museum (Natural History): Distichopora rosea, Type, East coast of Australia, F. M. Rayner, Esq., 62. 2. 4. 22, 1 colony, 38 by $45 \mathrm{~mm}$. For notes on this specimen see a previous page.

Leiden Museum: Distichopora violacea, Menado, Celebes, L. DE Priester, 1930, 1 colony, 32 by 25 $\mathrm{mm}$. The basal parts of a colony with three branches of a breadth of $5 \mathrm{~mm}$, all the top parts broken off. Numerous female ampullae in large patches, especially on one of the flabellar surfaces. Several short pore-rows next to and between the ampullae. Colour pale violet. The specimen belongs to one of the two formae violacea s. s. or fisheri, being not sufficiently developed to show the definite manner of branching.

Leiden Museum: Distichopora violacea, Mer Rouge, Ruyssenaers, 6 colonies, up to 28 by $38 \mathrm{~mm}$ (Pl. I figs. 8-10, Pl. II fig. 5). The very small colonies have slender branches (diameter $2 \mathrm{~mm}$ or slightly more) spreading more or less radially from the base. The branches are distinctly compressed, at their tops they often show the small tuberches of the surface in a very pronounced manner (Pl. V fig. 3). The gastropores are comparatively wide (up to $0.45 \mathrm{~mm}, \mathrm{Pl}$. IV fig. 11). Most of the colonies bear numerous female ampullae, sometimes showing well-developed radiating ridges ( $\mathrm{Pl} . \mathrm{V}$ fig. 3 ); in one colony there are some female ampullae next to patches of male. The colour is greyish violet, the tops of the branches are often whitish. To all appearances the colonies are young stages of the forma tenella.

Leiden Museum: Distichopora violacea, Tjilaoet Eureum, South Java, L. De Priester, 1931, 1 colony, 40 by $37 \mathrm{~mm}$ (Pl. I fig. 16). Most of the tops of the branches have broken off, the remaining parts are more or less radially spreading from the base. The larger branches have a diameter of about $5 \mathrm{~mm}$. The flabellar surfaces of the branches have large patches of female ampullae, they also show some short porerows. The colour is a light violet. The form of growth is nearest to violacea $\mathbf{s}$. s.

Leiden Museum: Snellius Expedition, Bone Tamboeng near Macassar, diving helmet, depth 6-7 m, March 2, 1930, 2 colonies, 18 by $14 \mathrm{~mm}$ and 14 by $8 \mathrm{~mm}$ (Pl. I fig. 5). The very small colonies bear already numerous female ampullae with rather strongly developed radiating ridges. There are some small pore-rows on the flabellar surfaces of the larger specimen. The colour is a light violet, the tops of the branchlets are white. The colonies are too small to determine the forma.

Leiden Museum: Snellius Expedition, Binongko, March 7-10, 1930, depth $3 \mathrm{~m}$, Distichopora violacea, det. W. Vervoort, IX. 1931, 2 colonies, 38 by 28 $\mathrm{mm}$ (Pl. I fig. 6) and 24 by $43 \mathrm{~mm}$. In the figured specimen there is one stem with a broad basal part; towards the top it gradually diminishes in thickness. Most of the side branches are round, a few only showing a flattened shape. On the flabellar surfaces there are several confluent patches of male ampullae. The other colony consists of two main branches each with a number of side branches, which at their tops are compressed. Here again there are patches of male ampullae. In the two colonies the colour is violet, the tops of the branches being slightly paler. Though in their form of growth the two colonies show some resemblance to $D$. gracilis, they undoubt- 
edly belong to $D$. violacea forma tenella.

Leiden Museum: Sha'b Abu Melana at entrance of Gulf of Suez, depth L W S, from under stones, windward edge of reef, 19. VIII. 1954, received from Dr. H. A. F. Gohar, Biological Station Al Ghardaqa, Red Sea, 5 colonies, height up to $22 \mathrm{~mm}$, breadth up to $35 \mathrm{~mm}$ (Pl. I fig. 7, Pl. II fig. 6), and some smaller colonies and fragments. The specimens are young or dwarfed; in some the corallum is spreading fan-wise in one plane, in others there are parts of the colony growing next to the first upstanding growth, while sometimes the basal region shows an irregular mass of incipient branches. The small tubercles of the surface are very distinct, especially in the tops of the branches, while numerous female ampullae occur on the anterior and posterior surfaces ( $\mathrm{Pl}$. V fig. 4), the ampullae as a rule being more or less flat-hemispherical, without pronounced radiating ridges. The colour of the colonies is violet; often comparatively large parts of the tops are white. The form of growth indicates that to all appearances the colonies are young stages of the forma tenella.

Leiden Museum: Storm Island, Fiji Islands, $\mathrm{H}$. Boschma, March 5, 1949, 2 colonies, 25 by $18 \mathrm{~mm}$ (Pl. II fig. 4) and 26 by $15 \mathrm{~mm}$. The two very small colonies were collected in one locality on the same spot, they undoubtedly belong to the same species. Especially the figured specimen shows a strong resemblance to $D$. gracilis as the branches are round. In the other colony, however, the branches are distinctly compressed, pointing to an identity with $D$. violacea. The two colonies have rather large patches of confluent male ampullae (Pl. VI fig. 2). They have a deep violet colour. The specimens bear some resemblance to the figure of $D$. violacea in $D E$ Blainville (cf. text-fig. $1 \mathrm{c}$ ), and probably belong to this species, though the similarity with $D$. gracilis, at least in the figured specimen, is rather striking.

Leiden Museum: Suva reef, Fiji Islands, H. BoschMA, March 16, 1949, 2 colonies, 21 by $28 \mathrm{~mm}$ and 15 by $12 \mathrm{~mm}$, and some fragments. The colonies are of irregular shape, in the larger the branches are developing in two planes more or less perpendicular to each other, in the smaller there are a few incipient stems without apparent order of orientation. In the very much smaller colony the branchlets are rather round, in the larger colony they are distinctly compressed. The two colonies bear female ampullae, in the larger of the two these are hemispherical, in the smaller stellate, having radially arranged ridges ( $\mathrm{Pl}$. VI fig. 4). The colour is violet, the tops of the branches are slightly paler. The specimens show a certain similarity to the figure of DE BLAINviLLE (cf. text-fig. 1c); they also present a superficial likeness to $D$. gracilis, the compressed branchlets, however, pointing to an identity with $D$. violacea forma tenella.

Manchester Museum: Distichopora violacea, Torres Straits; Royal College of Science, Dublin, Zoological Department, C A 26, 2 colonies, 33 by $44 \mathrm{~mm}$ (Pl. I fig. 17) and 20 by $27 \mathrm{~mm}$. The colonies spread more or less fan-wise in one plane, the larger branches have a diameter of about $5 \mathrm{~mm}$. The surface of the coenosteum is rather rough, the tubercles covering the branches being larger than generally in the species (PI. VI fig. 1). The colonies bear numerous female ampullae, which are covered with irregular blunt spines and often show a radial arrangement of exceptionally thick ridges (Pl. IV fig. 1). The lateral sulcus is deep, the gastropores are wide, up to 0.5 $\mathrm{mm}$, the dactylopores are surrounded by well-developed ridges (Pl. IV figs. 6-9). Irregular short pore-rows occur here and there on the flabellar surfaces. The colour is a dark grey-violet. The manner of growth of the colonies indicates that they belong to the forma violacea s. s. - The corals in the collection of the Manchester Museum evidently form part of the specimens examined by Hickson (1892). They do not show colour variations, being uniformly dark violet; they have, however, the irregularities in the distribution of the pore-rows as described by Hickson.

Manchester Museum: Distichopora benhami (?), Mouth of Rangitiki River, North Island, New Zealand, 67 fathoms, 1 colony, 45 by $27 \mathrm{~mm}$ (PI. I fig. 2). The specimen consists of a fairly large branch with some side branches. The large branch is roundish, slightly compressed laterally (dimensions at the base 4 by $5 \mathrm{~mm}$ ); the side branches are slightly flattened antero-posteriorly. The surface of the coenosteum is densely covered with round flat-topped minute tubercles, which are especially distinct on the tops of the branches. The lateral sulci are deep, in the tops of the branches as well as in the older parts of the colony; the gastropores are comparatively wide (about $0.4 \mathrm{~mm}$, cf. Pl. IV fig. 10), the dactylopores have well-developed dactylotome projections, giving the tops of the branches a finely serrate appearance. On the flabellar surfaces there are some patches of male ampullae in confluent masses, while here and there some female ampullae occur; their exact shape is not to be determined as they are covered with a thin layer of calcareous matter. The colour of the colony is a light orange. The form of growth presents a strong likeness to the forma fisheri. - The coral comes from a depth of $122 \mathrm{~m}$, which is exceptional for the species. It shows the typical charac- 
ters of $D$. violacea, especially in the structure of the surface and in the condition of the pore-rows. The colour, light orange without any trace of violaceous, is of very rare occurrence in the species.

Paris Museum: Distichopora violacea, Timor, PÉRON et Lesueur, 1801, 1 colony, 50 by $35 \mathrm{~mm}$ (PI. I fig. 11), 1 colony, 60 by $53 \mathrm{~mm}$. The figured specimen is the coral of Pl. 85 fig. 4 in Milne Edwards (1849, cf. text-fig. $1 \mathrm{~b}$ in the present paper); a comparison of the two figures shows that in the course of time the coral has lost some of its branches. The colony has one large main stem with a number of branches of a thickness of about $3 \mathrm{~mm}$, some of the smaller branchlets grow out perpendicular to the flabellar plane. The surface of the coenosteum has the small tubercles as they are characteristic of the species, the lateral sulci are fairly deep, the gastropores are comparatively large (up to $0.4 \mathrm{~mm}$ in diameter), the dactylopores are surrounded by a well-developed ridge (PI. IV figs. 2 and 3). There are a few short pore-rows on the flabellar surfaces of the colony; the patches of male ampullae have become rather indistinct, being covered with a layer of calcareous matter of rather rough appearance. The colony is greyish with faint remains of the faded, apparently violet original colour. The coral has the typical characters of the forma fisheri. - In its general aspect the coral with a height of $60 \mathrm{~mm}$ closely corresponds with the other specimen, though having a broader base with several large branches, all but one of which are broken off. The colour is greyish violet, apparently faded in the course of time.

Paris Museum: Distichopora violacea, Timor, PERON et Lesueur, 1803, 1 colony, 71 by $54 \mathrm{~mm} ; 1$ colony, 60 by $70 \mathrm{~mm}$. The colony with a height of $71 \mathrm{~mm}$ consists of a broad main stem (thickness about $10 \mathrm{~mm}$ ) and several side branches; the colony with a height of $70 \mathrm{~mm}$ has several large branches spreading fan-wise from a common basal part, the branches distinctly tapering from the base towards the top. The colour of the two colonies is violet, in the one $71 \mathrm{~mm}$ high with a reddish tint, most pronouncedly on the smaller branches. The colonies represent the forma tenella, especially the specimen with the reddish violet tint showing the typical characters of this form of growth.

Paris Museum: Distichopora violacea, Timor, QuoY et Gaimard, 1829, I colony, 35 by $48 \mathrm{~mm}$. The specimen consists of a large basal part and several short, rather thick branches divided into short side branches. The surface of the coenosteum is rough, distinctly showing minute tubercles; the lateral sulci are deep, the gastropores comparatively wide. There are several small pore-rows on the flabellar surfaces. The female ampullae are stellate, with radiating ridges. The colour of the colony is greyish violet (faded). The shape indicates that it belongs to the forma violacea s. s.

Paris Museum: Distichopora violacea, Mer Rouge, 1 colony, 35 by $46 \mathrm{~mm}$ (Pl. III fig. 3). The greater part of the colony is spreading fan-wise in one slightly bent plane, the concave surface showing the larger branches only, the convex surface presenting numerous side branches growing perpendicular to the general plane of growth. The branches are round or slightly compressed, with a diameter of 3-4 mm. There are several short irregular pore-rows on the flabellar surface. The female ampullae have distinct ridges running from the centre to the margin. The colour is a greyish violet. In its form of growth the colony comes nearest to the forma violacea $\mathbf{s}$. $\mathbf{s}$. though in some respects it shows a likeness to the forma fisheri.

Paris Museum: Distichopora violacea, Mer Rouge, 11 colonies, 45 by $62 \mathrm{~mm}, 45$ by $50 \mathrm{~mm}, 50$ by 55 mm (Pl. III fig. 2), 62 by $64 \mathrm{~mm}, 55$ by $63 \mathrm{~mm}, 62$ by $45 \mathrm{~mm}, 40$ by $72 \mathrm{~mm}$ (Pl. II fig. 7), 98 by $61 \mathrm{~mm}$, 70 by $103 \mathrm{~mm}$ (Pl. III fig. 1), 50 by $60 \mathrm{~mm}$, and 32 by $38 \mathrm{~mm}$. All the colonies have a similar form of growth, the branches rather regularly spreading fanwise. The larger branches are strongly tapering from the broad base to the top, the branches with their side branchlets fill about the whole of the plane of growth, generally leaving a space between them smaller than the thickness of the branches themselves. Especially the top parts of the branches are strongly flattened antero-posteriorly. In one specimen there are three flabellar growths parallel to each other, in other specimens (e.g., the one of Pl. III fig. 1) small parts of the corallum entend perpendicular to the main plane. The lateral sulci are fairly deep, the gastropores are rather wide. Most of the colonies bear female ampullae, varying in shape from low hemispherical with granular surface to pronouncedly stellate with ridges radiating from the centre $(\mathrm{Pl}$. V figs. 1 and 2). Some colonies have male ampullae in crowded masses without pronounced borders of the individual ampullae. Ten of the eleven colonies are of an altogether similar colour, changing from reddish violet to crimson. The stems and the larger branches are red with a distinct intermixture of light violet, in the end branches the colour is almost purely red, while the groups of ampullae generally are distinctly marked off from their surroundings by their bright crimson tint, the same colour as a rule appearing in the pore-rows. The tops of the branches are often a 
very pale pink, often white. One of the colonies has a lighter colour; here the red has changed to a light orange. The specimens here dealt with have the typical characters of the forma tenella. - The predominantly red colour of these colonies from the Red Sea possibly leads to an explanation of the notes by NArDo (1844 a, b; 1845) concerning a coral of cinnabar (vermilion) colour, named by him Distichopora cinnabarina and supposed to come from the Red Sea (cf. notes on a previous page).

Paris Museum: Distichopora violacea, Iles Sandwich, Ballieu, 1875, 1 colony, 50 by $65 \mathrm{~mm}$; idem, 1879,1 colony, 70 by $68 \mathrm{~mm}$. In their form of growth and in their manner of branching the two colonies closely correspond with the specimens from the Red Sea dealt with above; they also have a similar colour. The colony with a height of $50 \mathrm{~mm}$ consists of a single flabellum, in the other colony there are a few flabellar growths extending parallel to each other from the common basal parts, the larger having the dimensions as noted above. The specimens belong to the forma tenella. - It is interesting that on the dead basal parts of the larger colony there are two very small colonies of a species of the genus Allopora corresponding with larger specimens in the collection of the Paris Museum, which came from the Tuamotu Islands (to all appearances representing an up to now undescribed species). If the specimens of $D$. violacea forma tenella really were collected in the Hawaiian Islands the Allopora spec. here referred to also must occur in this locality.

Paris Museum: Distichopora violacea, Océan Pacifique, Hickson, 1912, 1 colony, 35 by $35 \mathrm{~mm}$. The small specimen has rather spreading branches with a tendency for upward growth; it may be placed in the forma fisheri.

Paris Museum: Tahiti, G. Ranson, juillet 1952, 5 colonies, height up to $23 \mathrm{~mm}$, breadth up to $43 \mathrm{~mm}$ (Pl. I figs. 14 and 15). The specimens are young colonies consisting of a broad base and a varying number of short branches, which have a thickness of about $4 \mathrm{~mm}$. Most of the branches have stubby, blunt tops, sometimes the end branchlets are of a more slender shape. As a rule the growth form is irregular, the colonies consisting of two or three incipient parts next to each other, parallel or forming a wide angle. The pore-rows occur in rather deep sulci; often irregular pore-rows are to be found on the flabellar surfaces. Four of the colonies have patches of male ampullae, forming confluent masses; on the other colony there are no ampullae. The colour of the specimens is violet in shades from light to rather dark, in some of them the tops of the branches are white or very faintly purple. Though the young colonies as yet have a rather indefinite shape they should be ranged with the forma violacea s. s. They show a certain likeness to the specimens from Torres Straits dealt with above but have a surface of smoother appearance, presenting only the small flat tubercles as they are characteristic of the species. The colonies being young and having ampullae of the male sex only, they support Hickson's ideas of protandry in the species.

\section{Geographical distribution}

Seychelles, Chagos Archipelago, Western Indian Ocean (Hickson in Hickson \& ENGLAND, 1909); Dares-Salaam (Ortmann, 1892); Red Sea (De Blainville, 1834; Nardo, 1844 a, b; Klunzinger, 1879; present paper); Gulf of Suez (present paper); Sumatra (Broch, 1942); South Java (present paper); Menado, Celebes (present paper); Lembeh Island near Celebes (Hickson, 1892); Binongko (present paper); New Guinea (Tenison-Woods, 1879 b); China Strait, East of Papua (present paper); Timor (Deslongchamps, 1824; Milne Edwards, 1860; present paper); Murray Island, Torres Straits (Hickson, 1892; present paper); New Hebrides (Tenison-Woods, 1879 b; present paper); North East Australia or East coast of Australia (Tenison-Woods, $1879 \mathrm{~b}$; present paper); New Zealand (present paper); Garvan Reef, China Sea (KIrxPatrick, 1890); Tokara Islands, South of Kyûsyû, Japan (TокіохA, 1953; UtiNomI, 1956 b); Marshall Islands (WARD, 1892; WeLLs, 1954; present paper); Gilbert Islands (present paper); Fiji Islands (Schmeltz in GrÄFFe, 1866; Schmeltz, 1875; Wright, 1882; OrtmanN, 1892; Вroch, 1942; present paper); Tahiti (HoffmeIster, 1929; present paper); Tuamotu Islands (DANA, 1848); Hawaiian Islands (doubtful record, Perrier, 1881; Filmol. 1885; present paper).

\section{DISTICHOPORA GRACILIS DANA, 1848}

Distichopora gracilis Dana, 1848, p. 704; Dana, 1859, p. 151; Tenison-Woods, 1879a, p. 303; Tenison-Woods, 1879 b, p. 61; Wright, 1884, p. 218; Quelch, 1884b, p. 267; Quelch, 1885, p. 18; Von Lendenfeld, 1885, p. 615; Von
Lendenfeld, 1887, p. 46; Fisher, 1938, p. 544; Boschma, 1953, p. 167; Boschma, 1956a, p. 137; Boschma, 1957, p. 44.

Distichopora fragilis Quelch, 1884a, p. 114; Wright, 
1884, p. 218; Quelch, 1884b, p. 267; Boschma, 1956a, p. 137.

Distichopora milesii Quelch, 1884a, p. 114; Quelch, 1885, p. 16; Boschma, 1953, p. 172; Boschma, 1957, p. 45.

Distichopora granulosa Quelch, 1885, p. 14; Boschma, 1953, p. 167; Wells, 1954, p. 476; Boschma, 1957, p. 44.

Distichopora conferta Quelch, 1885, p. 15; Boschma, 1953, p. 167; Boschma, 1957, p. 43.

DANA (1848, p. 704) gave the following description of the species Distichopora gracilis:

“D. rubida; gracilior, ramulosa; ramulis triplo angustior (apice $1 / \mathbf{s}^{\prime \prime \prime}$ ).

Reddish; more slender than the violacea, ramulous; branchlets one third as broad, at summit about a third of a line.

Plate 60 , fig. 4 , corallum, natural size; fig. 5 , a variety? natural size; $5 a, 5 b$, views, enlarged.

Paumotu Archipelago. Exp. Exp.

The delicate corallum is about an inch high."

Fisher (1938, p. 544), who examined the type specimen, remarked:

“D. gracilis Dana (1846, p. 704, pl. 60, figs. 4, 5-5b), from Tuamotu Archipelago, is very small, the pale rose corallum being only $23 \mathrm{~mm}$ high. The gastropores $(0.1 \mathrm{~mm}$ to $0.12 \mathrm{~mm}$ ) are one-fourth to one-third the diameter of average pores of borealis. They open in a shallow sulcus, and the dactylotomes have a slightly elevated lip. The relatively broad and low female ampullae sometimes occupy the entire breadth of a branch (pl. 75) and are not corrugated but are covered like the rest of corallum with microscopic convexities or bosses. D. rosea Kent (1871), from the east coast of Australia, is probably the same species. As Dana's figure of the type is very small, a photograph, enlarged five times, is given (pl. 75). Type of D. gracilis Dana is Mus. Comp. Zool. no. 5507."

The notes published by Fisher are the only data of any significance on the species during the ninety years following the original description. The only other remark worth noting is the one by QUELCH (1885, p. 18), reading: “ $D$. gracilis is distinguished by its regularly flabellate and extremely slender habit; by its fainter or reddish coloration; and by its compressed branches", adding that a more complete description is needed. The "compressed branches" in Quelch's notes are not mentioned in the original description of the species; perhaps this remark is based on the fact that in a very young colony (DANA, $1849, \mathrm{Pl} .60$ fig. 5) one of the branches has a flattened extremity, probably indicating a beginning division of this branch.

More than 30 colonies from the Passe du Hao in the Tuamotu Islands, in the collection of the Paris Museum, were identified with Distichopora gracilis Dana. The following description is condensed from the detailed notes on these corals in a previous paper (Boschma, 1956a): Colonies of a height of up to 40 $\mathrm{mm}$, consisting of several stems or branches of approximately equal size, each divided into a number of side branchlets. The stems and the branches are slender, of roundish contour (the basal parts of the stems often compressed antero-posteriorly). As a rule the colonies are rather spreadingly divided in one plane, the space between the branches being wider than the branches themselves. The surface of the coenosteum is closely covered with minute roundish flat tubercles, which are especially distinct on the top parts of the branches but may remain visible in the lower parts of the colonies too. Sulcus containing the gastropores and the dactylopores on the lateral margins of the branches, distinct, deep in the topmost parts of the branches, often shallower in the lower parts. Dactylopores with a distinct outer wall, especially well-developed in the tops of the branches, giving these parts a definite serrate appearance when seen from the flabellar surfaces. Gastrostyles long and slender, with numerous spines. Gastropores up to $0.3 \mathrm{~mm}$ wide, with numerous ridges giving the inner surface a honeycombed appearance. Ampullae in smaller or larger groups on the flabellar surfaces of the corallum, rounded to slightly stellate, covered with minute tubercles. The female ampullae have a diameter of $0.8 \mathrm{~mm}$, the male ampullae vary from 0.4 to $0.6 \mathrm{~mm}$. The colour of the colonies is generally brick red, sometimes slightly turning to a purplish tint, and rather often lighter, dull orange or yellowish orange. The tips of the branches have a much lighter colour than the rest of the colony, they are often almost white.

When compared with the original description by DANA and the additional notes by Fisher it seems safe to conclude that the specimens from the Passe du Hao are typical representatives of the species Distichopora gracilis, the figure of the type specimen (Fisher, 1938, Pl. 75) also closely corresponding with figured specimens from the Passe du Hao (Boschma, 1956 a, Pls. 1-4). Moreover, the localities of the specimens referred to correspond completely, the Passe du Hao being in the Tuamotu Islands, the locality of the type specimen.

The name Distichopora fragilis, which was used in a number of papers, is nothing else but an error for D. gracilis.

Distichopora milesii was described by Quelch (1884a, p. 114) as a separate species but all the characters as noted in this description correspond with those of $D$. gracilis as they are given above. The colour of $D$. milesii is described as dull lake-red; the exact locality is unknown, but as the specimen was growing on one piece of rock with a colony of 
Allopora stellulata (Stewart), a species only known from the Society Islands (Tahiti) and the Tuamotu Islands, QUELCH remarks that it probably came from this region, which is also the type locality of $D$. gracilis. QueLCH remarks that $D$. milesii seems to be closely related to " $D$. fragilis Dana" (meaning $D$. gracilis), the specific characters of which are not distinctly noted in the description. Examination of the type specimen of $D$. milesii in the British Museum (Pl. II fig. 1) proved that the coral corresponds in every respect with the specimens of $D$. gracilis from the Passe du Hao in the Tuamotu Islands (Pl. II fig. 2).

The elaborate description of Distichopora granulosa by Quelch $(1885$, p. 14) shows that this coral has all the salient characters of $D$. gracilis, though rather differing in its growth form from specimens from the Tuamotu Islands. There are three colonies of $D$. granulosa in the collection of the British Museum, with a height of 58,47 , and $69 \mathrm{~mm}$, accordingly of much larger size than the specimens from the Tuamotu Islands, which have a height of 35 to 40 $\mathrm{mm}$ (Bоsснма, 1956 a, Pl. 1). The main stems of the specimens of $D$. granulosa are stouter than those of the corals from the Tuamotu Islands, while the smaller branches are more densely filling the whole of the flabellum, not as widely spreading as in the specimens from the Tuamotu Islands (cf. QUELCH, 1885, Pl. 1 fig. 1). Quelch describes the colour as a rich scarlet-red, some regenerating young branchlets being very pale reddish. On account of their larger size and thicker main stems the specimens of $D$. granulosa show a certain resemblance to the large colony of $D$. gracilis from the Gambier Islands in the collection of the Paris Museum (Pl. III fig. 5).

Wells (1954, p. 476) mentioned Distichopora granulosa (British Museum no. 85.5.4.4) in the synonymy of $D$. violacea sensu Broch (correct name D. nitida Verrill).

The careful, detailed description of Distichopora conferta (QueLCH, 1885, pp. 15/16) again contains all the important data for an identification of this coral with D. gracilis. QueLCH describes the colour as a delicate carmine-red, with whitish tips. The type specimen, in the collection of the British Museum, consists of a number of flabellar growths parallel next to each other, the whole giving a crowded appearance to the mass of branches, which are rather closely arranged (QueLCH, 1885, Pl. 1 fig. 3), not widely spreading as in the colonies from the Tuamotu Islands (Boschma, 1956 a, Pl. 1). Quelch remarks that $D$. conferta is close to $D$. granulosa, but differs from it in mode of growth, in coloration, the smaller and more slender habit, and in peculiarities of finer structures.

After examination of the three species described by Quelch (D. milesii, $D$. granulosa, and $D$. conferta) in the collection of the British Museum I became fully convinced that they belong to the species $D$. gracilis. Of the three described species $D$. milesii corresponds in every respect with specimens of $D$. gracilis from the Tuamotu Islands, the two other described species differ from these specimens in their form of growth only.

\section{Specimens examined}

British Museum (Natural History): Distichopora milesii, Type, South Sea Islands, 84. 1.5.2, 1 colony, 28 by $23 \mathrm{~mm}$ (Pl. II fig. 1). See notes on a previous page.

British Museum (Natural History): Distichopora granulosa, Type, Raratonga, V. A. Flower, Esq., 85. 5. 4.4 (pt.), 2 colonies, 58 by $61 \mathrm{~mm}$ and 47 by $45 \mathrm{~mm}$ (Quelch, 1885, Pl. 1 fig. 1); Distichopora granulosa, Type, Raratonga, Mast. V. A. Flower, 85. 5. 4. 4, 1 colony, 69 by $54 \mathrm{~mm}$. See notes on a previous page.

British Museum (Natural History): Distichopora conferta, Type, Raratonga, Sir W. H. Flower, 84. 12. 26. 1,1 colony, 50 by $45 \mathrm{~mm}$ (QueLch, 1885, Pl. 1 fig. 3). See notes on a previous page.

Paris Museum: Iles Touamotou, Passe du Hao, L. G. Seurat, 28 novembre 1904, more than 30 colonies of a height of up to $40 \mathrm{~mm}$ and a breadth of up to $70 \mathrm{~mm}$ (Distichopora gracilis, Boschмa, $1956 \mathrm{a}, \mathrm{Pl}$. 1). See the condensed description on a previous page. One specimen from the Passe du Hao is here figured in twice the natural size (Pl. II fig. 2) to show the striking resemblance to the type of $D$. milesii enlarged on the same scale (Pl. II fig. 1).

Paris Museum: Iles Gambier, L. G. Seurat, 1906, 1 colony, 68 by $71 \mathrm{~mm}$ (Pl. III fig. 5), 1 colony, 22 by $28 \mathrm{~mm}$. In its manner of branching, in the structure of the surface, and in the shape and the arrangement of the female ampullae the smaller of the two colonies corresponds with the specimens from the Passe du Hao in the Tuamotu Islands. The larger specimen from the Gambier Islands forms a much more vigorously developed colony. The specimen has a flabellar form of growth with a triangularly pointed top, one of the branches being larger than the other. In their basal parts the larger branches are strongly broadened in the flabellar plane, towards their tops they divide into smaller branches of a more or less cylindrical shape. On the flabellar surfaces there are numerous female ampullae, usually in crowded 
masses; they are, however, not as closely packed as generally in specimens of $D$. violacea; as a rule they do not possess ridges leading to a stellate appearance, but are low hemispherical with a granular structure corresponding with that of the surface of the branches. When examining the specimen in the Paris Museum I unfortunately omitted to make notes on the colour. The specimen undoubtedly belongs to $D$. gracilis though showing some resemblance to certain colonies of $D$. violacea, particularly to those of the forma tenella. The large specimen of $D$. gracilis is, how- ever, of a more spreading form of growth, while the tops of the branches are rounded, not flattened. It is further of interest that the locality, Gambier Islands, is in the neighbourhood of the Tuamotu Islands, the type locality of $D$. gracilis.

\section{Geographical distribution}

Rarotonga (QUeLch, 1885); Gambier Islands (present paper); Tuamotu Islands (DanA, 1848; Boschma, 1956 a; present paper).

\section{DISTICHOPORA COCCINEA GRAY, 1860}

Lithodendrum saccharaceum rubrum Rumphius, 1750 , p. 243; Henschel, 1833, p. 199; Tenison-Woods, $1879 \mathrm{~b}$, p. 50; Hickson, 1892, p. 502; Boschma, 1956a, p. 140 .

Distichopora coccinea Gray, 1860, p. 244; Verrill, 1864, p. 46; Schmeltz, 1875, p. 21; Tenison-Woods, 1879a, p. 301; Tenison-Woods, 1879b, p. 62; Moseley, 1879, p. 482; Moseley, 1880, p. 85; Schmeltz, 1882, p. 9; Wright, 1882, p. 76; Quelch, 1884a, p. 117; Von Lendenfeld, 1887, p. 46; Moseley, 1892, p. 461; Ward, 1892, p. 53; Hickson, 1892, p. 502; Kent, 1893, p. 105; Hall, 1898, p. 179; Fowler, 1900, fig. 43b 7; Delage \& Hérouard, 1901, fig. 249; Kirkpatrick, 1902, p. 54; Von Martens, 1902, p. 135; Grobben, 1917, p. 307; Dehorne, 1920, p. 129; Pax, 1928, p. 31; Fisher, 1938, p. 544; Broch, 1942, p. 10; Boschma, 1951, p. 459; Boschma, 1953, p. 167; Wells, 1954, p. 476; Boschma, 1956a, p. 140; Boschma, 1957, p. 42; Boschma, 1959, p. 247.

Distichopora purpurea Schmeltz, 1875, p. 21; Boschma, 1953, p. 167; Boschma, 1957, p. 46.

Lithodendrum saccharatum rubrum Von Martens, 1902, p. 135.

Distichopora violacea forma coccinea Fisher, 1938, p. 543.

Distichopora violacea var. coccinea Broch, 1942, p. 13. Distichopora violacea forma cornuta Broch, 1942, p. 13; Boschma, 1953, p. 167; Boschma, 1959, p. 247.

Distichopora miniacea Michelin MS.

Distichopora sanguinea Lütken MS.

The original description of Distichopora coccinea (GRAY, 1860, pp. 244/245) reads:

"Coral bright crimson, much branched, compressed; branches rather fan-shaped, expanded, placed on each side of the stem; the sides of the branches rather compressed; the main branches with a subcentral series of small compressed tubercles, like the commencement of new branches; lateral pores narrow, cells small.

Var. The upper surface of the stem with many short furcate branches.

$H a b$. Pacific Ocean, near New Caledonia, in deep water.

This species differs from the only other recent species of the genus known, viz. D. violacea, not only in the beautiful bright crimson colour, but also in the form of the stem and branches, which in this coral is much more compress- ed, broader, and with shelving edges, giving it a rather sword-like appearance. The lateral grooves containing the cells are much narrower, and the polypiferous cells much smaller. In one specimen the small oblong compressed tubercles on the middle of the upper side of the branches are produced into simple, forked, or sometimes more subdivided short branches. The apices of the branches, which have been broken and reproduced, are whitish.

The surface of many of the branchlets, as in $D$. violacea, is more or less covered with more or less crowded, convex, circular elevations or slight tubercles, which appear to be hollow and blister-like, with rather thick parietes."

This description of Distichopora coccinea contains all the characters peculiar to the species; it is astonishing that later authors could come to the conclusion that coccinea is a synonym of violacea. The compressed shape of the branches, with shelving edges, leading to a sword-like appearance, combined with the presence of tubercles on the flabellar surface of the corallum, which form the commencement of new branchlets, are characters unlike to those of the other species of the genus, while in this species the colour seems to be subject to very little variation, the colonies almost invariably being bright crimson.

Gray's figures show a colony with rows of small incipient branches on the flabellar surface (copied in text-fig. 2) and a colony in which these branches are considerably larger, often with forked tops (copied in text-fig. 3 ), this colony evidently is the variety mentioned in the description. The locality of the type specimens is given as New Caledonia, in deep water; the last remark is perhaps not altogether correct, for generally the species seems to occur in shallow water.

Tenison-Woods $(1879 \mathrm{~b}, \mathrm{p} .62)$ gives an account of the characters of Distichopora coccinea, recording the height as five to six inches and the colour as "a deep blood red, the distal ends often lighter in colour 


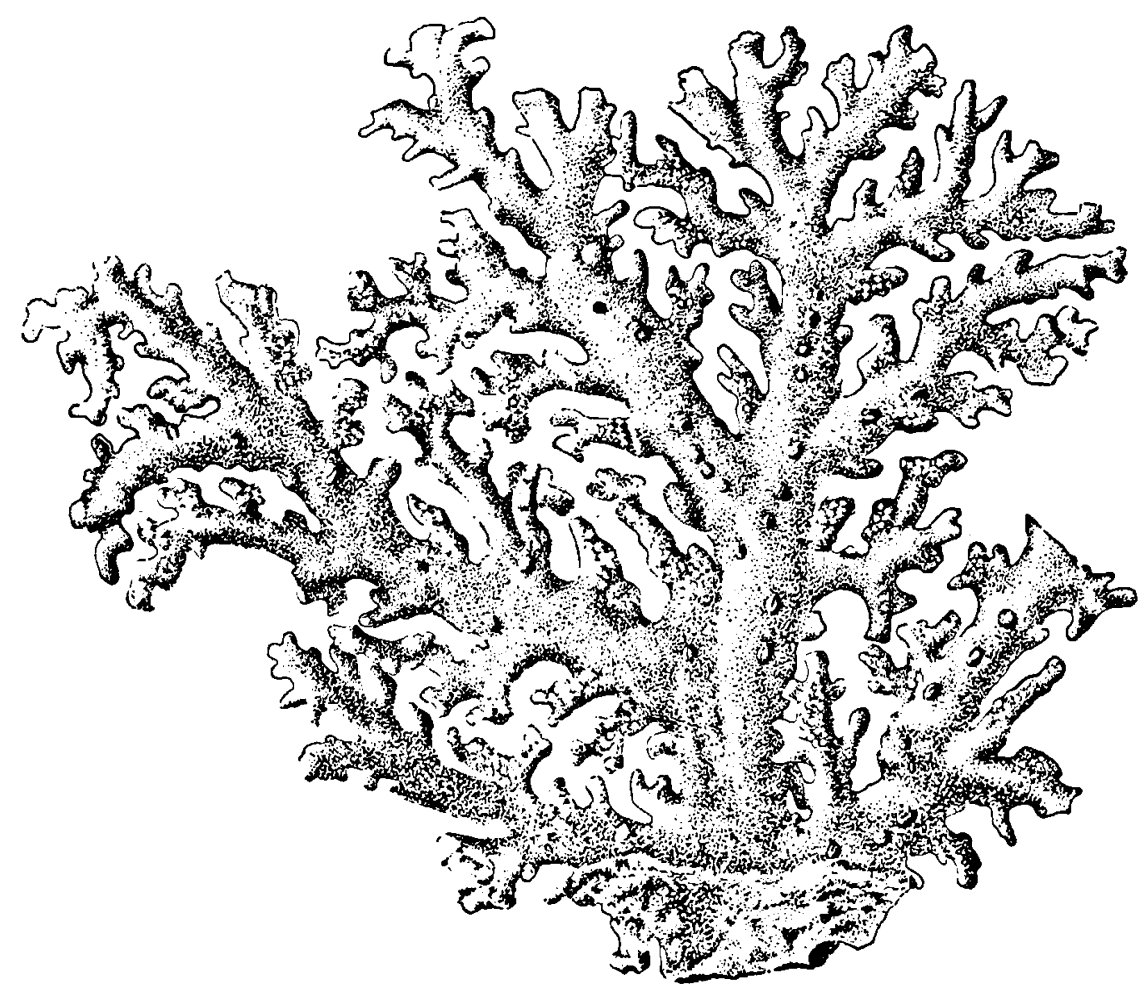

Fig. 2. Distichopora coccinea Gray, copy of the figure of a type specimen (Gray, 1860, Pl. Radiata 17, lower figure). Original (natural) size.

and fading into pale yellow." He mentions the incipient branchlets on the flabellar surfaces ("branches studded all over with little wart-like branchlets, seldom more than two millim. high"), and has a figure of a specimen, $7 \mathrm{~cm}$ high and $12 \mathrm{~cm}$ broad, closely corresponding with Gray's figures, and showing like these numerous small branchlets in the middle of the larger branches.

Moseley (1879, Pl. 35 figs. 6 and 16; 1880, Pl. 2 figs. 6 and 16) published more or less diagrammatic figures of a section of a branch showing the gasiropores and the slender gastrostyles, and of a row of gastropores (showing the tops of the gastrostyles) flanked by rows of dactylopores. These figures occur again in Moseley (1892) and Fowler (1900), the section of a branch in Delage \& Hérouard (1901).

WrIGHT (1882) remarks that in the two species Distichopora brasseyi and D. allnutti (regarded by QUeLCH, 1884 a, as synonyms of $D$. nitida Verrill) the branches are rounded, while in $D$. violacea and in $D$. coccinea they are compressed, somewhat broad, with shelving edges. Wricht (l. c., Pl. 4 fig. 7) gives a figure of a fairly large fragment of $D$. coccinea
( 55 by $56 \mathrm{~mm}$ ) showing a crimson colour with white terminal parts of the branches, and presenting a row of small tubercular branchlets in the middle of the flabellar surface of the larger branches.

While arguing that the colour is not a safe criterion for an identification of species of the genus Distichopora, Hickson (1892, p. 502) remarks that it is quite possible that both $D$. coccinea and $D$. rosea should be considered to be distinct species, but that this opinion must remain provisional until information on the anatomy of the soft parts becomes available, hereby overlooking the fact that already in the original description $D$. coccinea was characterized by well-defined specific data. KIrKPatrick (1902) was apparently influenced by Hickson's views when remarking that $D$. coccinea is a colour variation of $D$. violacea.

The definite identification of the coral mentioned by KENT (1893) with the name Distichopora coccinea remains uncertain. Its colour is noted as brilliant vermilion red or crimson, its shape (l. c., Chromo $\mathrm{Pl}$. 11 fig. 6) points against an identification with $D$. coccinea; the figure may represent a slender form of 


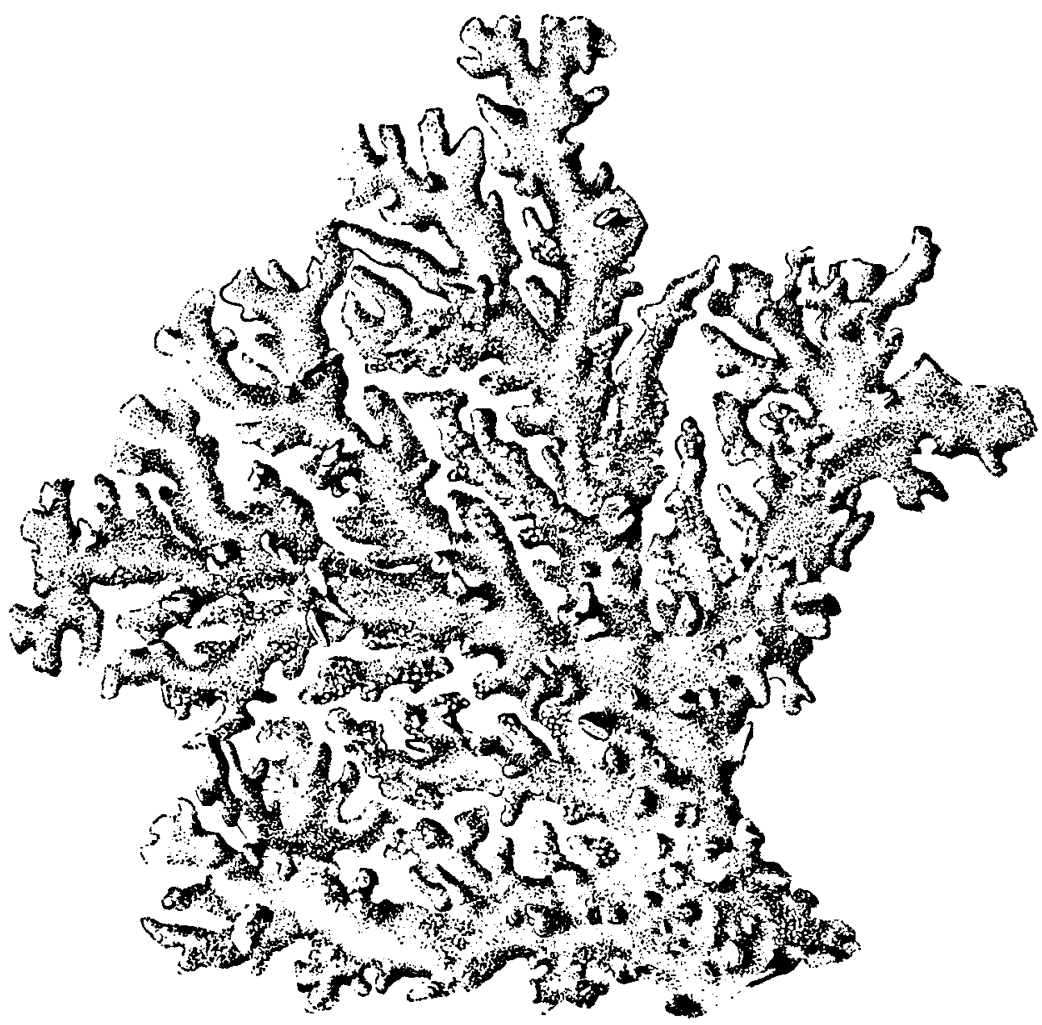

Fig. 3. Distichopora coccinea Gray, copy of the figure of a type specimen representing the variety with short furcate branches (Gray, 1860, Pl. Radiata 17, upper figure). Original (natural) size.

$D$. nitida, or perhaps a colony of $D$. gracilis.

Von Martens (1902) used the name Distichopora coccinea as the most probable determination of a coral mentioned by Rumphius (1750) with the following peculiarities: not over a hand (about $10 \mathrm{~cm}$ ) high, with round branches ending in blunt tops, of a light red colour, the tops pale or whitish. The height is too large for $D$. violacea so that the coral must represent either $D$. coccinea or $D$. nitida, the round branches pointing to a possible identity with the last mentioned species. The available data do not allow of a definite conclusion.

DeHORNE (1920, p. 129) mentions Distichopora coccinea as one of the Stylasterina of the deep sea, probably on account of Gray's notes on the occurrence of his specimens; later data show that the species occurs in rather shallow water.

In the chapter of the present paper dealing with Distichopora violacea, FisHer's (1938) opinion on the supposed conspecifity of $D$. coccinea and $D$. nitida with $D$. violacea has been recorded, while reference was made to Bносн's (1942) detailed description of the various forms. Here it must be noted that the specimens from Aranuka, Gilbert Islands, described by Broch (l. c., pp. 13/14, Pl. 1 fig. 2) as $D$. violacea forma cornuta show all the prominent characters as mentioned in the original description of $D$. coccinea by GRAY (1860): the strongly compressed and often rather acute branchlets, the numerous branchlets emerging from the "anterior" side of the flabellum, and the intense carmine colour. In the chapter referred to further mention was made of the fact that Wells (1954) followed Fisher and Вrосн by regarding coccinea as a synonym of violacea.

In a meeting of the "Verein für naturwissenschaftliche Unterhaltung zu Hamburg", SchMELTz (1875) exhibited specimens of "Distichopora violacea M. E." from Ovalau in the Fiji Islands and specimens of "D. coccinea Gray and D. purpurea Ltk." from the Marshall Archipelago, without mentioning data on the specific characters of these corals. Attempts to find the name Distichopora purpurea Lütken in other papers dealing with Stylasterina were unsuccessful (Boschma, 1953, p. 172), and in a list of species of the group (Boschma, 1957, p. 46) only the scanty data of Schmeltz could be mentioned. Some time 
ago Dr. F. Jensenius MAdsen sent to me a number of Stylasterina from the Copenhagen Museum among which there is a colony labelled with the museum name Distichopora purpurea Lütken. The coral came from the Museum Godeffroy at Hamburg, it bears as date of accession September 9, 1871, and as locality "Sydhavet" (Pacific Ocean). LüTKEN apparently never published the name, accordingly on the base of the existing literature the coral might be named "Distichopora purpurea Schmeltz, 1875, nomen nudum." The coral proved to be a fine specimen of Distichopora coccinea Gray, 1860, which makes the specific name purpurea a synonym of coccinea.

In the literature dealing with Distichopora coccinea very little attention has been paid to the peculiarities of the rows of pores. In BRoch's (1942) description of specimens of $D$. coccinea from the Gilbert Islands ("D. violacea forma cornuta Broch") no mention was made of the pore-rows, but the fact that these corals together with the forma typica (correct name $D$. nitida Verrill) were included in the species named by BRoch $D$. violacea proves that in his specimens the sulci are not very pronounced, the characters in $D$. violacea sensu Broch being: "sulcus very shallow, in larger branches commonly effaced" (l. c., p. 8). In many specimens of $D$. coccinea the pore-rows on the lateral margins of the branches indeed are very similar to those of $D$. nitida, without a distinct sulcus. In other specimens, however, there is a distinct, though not very deep sulcus, especially in the terminal parts of the branches; then as a rule the sulcus becomes far less apparent on older branches of the colony. In connexion with the comparatively little developed sulcus the walls of the dactylopores are very little pronounced, only on the terminal branches rising slightly over the surface, thereby giving these parts sometimes a feebly serrate contour in flabellar view.

\section{Specimens examined}

Amsterdam Museum: Distichopora coccinea, Japan, 2 fragments, 137 by $73 \mathrm{~mm}$ (Pl. III fig. 4) and 50 by $70 \mathrm{~mm}$. The specimens are parts of colonies with rather slender branches, strongly flattened anteroposteriorly. On the anterior surface the small branchlets in the middle of the larger branches are more numerous and larger than on the posterior surface; some of these branchlets are forked, one has grown out to a small divided branch. Sometimes a shallow lateral sulcus occurs on the tops of the smaller branchlets, on older parts of the branches the pores open at the surface; the gastropores are comparatively small, even those on the small branchlets are often not much wider than $0.1-0.15 \mathrm{~mm}$ (Pl. IX fig. 1). The female ampullae (Pl. X fig. 3) occur close together on many of the smaller branchlets, they are low hemispherical, their borders being determined by a circular row of pits. The surface of the ampullae is granular like that of the branches. The colour of the two fragments is light crimson, the tops of the branches are paler, often whitish. The locality "Japan" is obviously erroneous.

Australian Museum, Sydney: Distichopora rosea, Marshall Islands (?), reg. no. G 6247 (partim), 2 fragments, 51 by $43 \mathrm{~mm}$ and 56 by $24 \mathrm{~mm}$. The two specimens are distinctly compressed branches, being in lateral aspect about half as broad as in flabellar view. There are numerous tubercles in the middle of the anterior surface of the larger branches, only a few much smaller ones on the posterior surface. The two fragments bear male ampullae, usually densely together in small patches, sometimes isolated and showing a circular form. The colour of the two fragments is crimson, some regenerating branchlets are whitish.

Australian Museum, Sydney: Distichopora coccinea, Marshall Islands (?), purchased from Mr. Bondin, reg. no. G 263 (partim), 1 fragment, 61 by $48 \mathrm{~mm}$ (Pl. II fig. 9, Pl. VII fig. 3). The fragment is a slender branch with rather narrow side branchlets. On the anterior surface there are a number of incipient branches growing more or less perpendicular to the main plane, one of these has developed into a fairly large complex of some four branchlets, the largest having a length of $15 \mathrm{~mm}$. The colony has male ampullae, usually in groups, sometimes isolated. The colour is crimson, the tips of the branchlets are whitish.

British Museum (Natural History): Distichopora coccinea, Types, New Caledonia, 60. 5. 16. 1, 2 (Gray, 1860, Pl. 17 lower figure), 3 (Gray, 1860, Pl. 17 upper figure), and 6. The two figured specimens measure 101 by $111 \mathrm{~mm}$ (cf. text-fig. 2) and 98 by $107 \mathrm{~mm}$ (cf. text-fig. 3).

British Museum (Natural History): Distichopora coccinea, Australia, 58.12. 13. 5, 6, 2 colonies, 95 by $122 \mathrm{~mm}$ and 63 by $85 \mathrm{~mm}$. The colonies show the typical characters of $D$. coccinea, they differ in that one has the branches stronger developed (broader) than the other.

Copenhagen Museum: Distichopora purpurea Lütken MS., Sydhavet, Mus. Godeffroy, 9. IX. 1871, 2 branches of one colony, 157 by $73 \mathrm{~mm}$ and 90 by $62 \mathrm{~mm}$ (Pl. VIII). The basal part of the larger branch is overgrown with foreign matter, the main stem of this branch next to the dead part is about $20 \mathrm{~mm}$ 
broad. Towards the top the main stem divides into three large branches with a breadth of about $10 \mathrm{~mm}$. - The flattened branches and side branchlets fill almost completely the space occupied by the flabellum. On one (the anterior) surface (Pl. VIII fig. 1) there are not only many tubercles with incipient pore-rows, but quite a number of these have grown out into small branches, often over $10 \mathrm{~mm}$ high, which in their turn already have some side branchlets. The other (the posterior) surface (Pl. VIII fig. 2) has smaller tubercles or very short pointed undivided branchlets. The surface is finely granular as usual in the species. A shallow sulcus occurs on the small branches only, in the older parts of the colony the pores open at the surface of the sides of the branches. On both the flabellar surfaces there are numerous patches of female ampullae. The colour is carmine, the tops of the branches are whitish. - The smaller branch has a shape similar to that of the three branches of the larger fragment. Here again the anterior surface (Pl. VIII fig. 3 ) bears numerous small branchlets, some of which are forked, while on the posterior surface (Pl. VIII fig. 4) they remain smaller. In this branch most of the ampullae are to be found on the posterior surface.

Copenhagen Museum: Distichopora sanguinea Lütken MS., legit MörCH, 1 fragment, 52 by $22 \mathrm{~mm}$. The fragment consists of the terminal part of a branch with several side branchlets. The thickness in the lateral direction is about twice that in the anteroposterior direction, the edges are distinctly shelving, the pore-rows occur on the lateral ridges of the branches, in a shallow sulcus or flush with the surface. On both the flabellar surfaces there are some small tubercles with incipient pore-rows. The colour is a dirty dull red. - LüTKEN's manuscript name "sanguinea" is a synonym of his manuscript name "purpurea", as already noted on a label accompanying the fragment. As remarked on a previous page, the name purpurea is a synonym of coccinea, the specimens presenting the typical characters of this species.

Leiden Museum: Distichopora coccinea, Kingsmill Islands (Gilbert Islands), H. A. WARD, 1 colony, 75 by $122 \mathrm{~mm}$. The colony (Pl. VII fig. 2) forms a broad mass of thick branches arising from a large common basal plate, the branches chiefly in one plane (one or two next to and parallel with the rest), leaving very little space between them. Towards their tops the branches divide into smaller branches, the whole of the colony, however, remaining very compact. The branches are half as thick in antero-posterior diameter as in lateral expansion, while the top branchlets are still more strongly flattened. There are tubercles with small pore-rows in the middle of most of the larger branches, on the anterior as well as on the posterior surface. The coenosteum has a finely granular surface; there are no lateral sulci, the pores opening on the surface of the margins of the branches. Numerous groups of ampullae are present on the anterior surface of the colony (Pl. X fig. 2); they are almost absent on the posterior surface. The ampullae occur closely joined, more or less circular rows of five or six pits showing the margins of the individual ampullae. The surface of the (female) ampullae is finely granulated, like the branches. The colour of the colony is a light yellowish orange. - In its form of growth the colony differs from the other specimens of $D$. coccinea examined. The branches are very robust, little divided into side branches, and are rather short in comparison to their thickness. The colony gives the impression of representing a comparatively juvenile stage of growth, notwithstanding its fairly large size. It differs, moreover, from other specimens of $D$. coccinea by its exceptionally light colour.

Manchester Museum: Distichopora sulcata, West Indies, 1 colony, 71 by $90 \mathrm{~mm}$. The colony has slender branches with a great many side branchlets. In the middle of the larger branches there are rows of tubercles with short pore-rows, in greater number on the anterior than on the posterior surface. The female ampullae ( $\mathrm{Pl}$. X fig. 4) often show rather distinct ridges giving them a more or less stellate appearance. The coral is light carmine red, the tips of the branches are often almost white (Pl. X fig. 4). The original identification and the locality are erroneous.

Paris Museum: Distichopora miniacea Michelin, Iles Sandwich, coll. Michelin, 1868 (in this year the Michelin collection became the property of the Museum), 1 colony, 122 by $100 \mathrm{~mm}$; Iles Sandwich, 1862, basal part of colony, 92 by $65 \mathrm{~mm}$; Iles Sandwich, Ballieu, 1876, 1 colony, 115 by $40 \mathrm{~mm}$; Iles Sandwich, Balliev, 1879, 1 fragment, 80 by $25 \mathrm{~mm}$; Iles Sandwich, 1 colony, 155 by $140 \mathrm{~mm}$ (Pl. VII fig. 1), 4 fragments, 70 by $46 \mathrm{~mm}, 58$ by $59 \mathrm{~mm}$, 45 by $35 \mathrm{~mm}$, and 68 by $67 \mathrm{~mm}$. The collection of corals labelled with the name Distichopora miniacea Michelin forms a rather homogeneous lot though the specimens differ in shape: some colonies have rather robust, broad branches, with their side branchlets filling almost the whole space of the flabellum, others have slenderer branches that are of a more spreading growth. To avoid repetition of data the form of growth of the largest colony (Pl. VII fig. 1) is here 
briefly described, while details of the finer structures are noted of the fragment of 80 by $25 \mathrm{~mm}$. - Of the colony of 115 by $140 \mathrm{~mm}$ a large part of the basal region has become overgrown with foreign matter (this part omitted in the figure). Next to the dead region there are four or five large branches spreading fan-wise in the main plane. The coral is not as flat as generally in the species for several smaller branches are slightly extending anteriorly or posteriorly of the main plane. The branches are strongly compressed antero-posteriorly; in the middle of the larger branches there are rows of tubercles with short pore-rows, which often have grown out as small branchlets extending perpendicular to the main plane of the colony; these incipient branchlets occur on both surfaces, being of larger size and of more plentiful occurrence on the anterior surface. Patches of female ampullae are present on several branchlets on both sides of the colony. - An enlarged view of a part of the anterior surface of the fragment of 80 by $25 \mathrm{~mm}$ (Pl. X fig. 1) shows the finely granular surface of the coenosteum and a row of tubercles each with two or three gastropores surrounded by some dactylopores. The figure further shows female ampullae, arranged in rows or small groups; they are low hemispherical, of circular shape (diameter about $0.8 \mathrm{~mm}$ ), and have a finely granulated surface similar to that of the branch. A small branchlet in side view (Pl. IX fig. 2) shows a shallow sulcus with a row of gastropores of fairly large size (up to $0.28 \mathrm{~mm}$, which is large in comparison to those of Pl. IX fig. 1), at each side flanked by a row of small dactylopores each surrounded by a minute ridge. Next to the pore-rows there is at each side a row of ampullae. On older branches (PI. IX fig. 3) the sulcus has disappeared, the pores opening at the surface of the side of the branch; next to the pore-rows there are a few ampullae. In the figured part the gastropores have about the same diameter as those of the young branchlet. - The colour of the specimens is crimson of varying intensity, the differences in colour possibly caused by fading. The tops of the branches are often of a much paler colour, from pink to white. - The specific name miniacea, very appropriately based on the colour of the corals here dealt with, to all appearances is a museum name that up to now has not been published. Though all the corals of this lot have "Iles Sandwich" (Hawaiian Islands) as indication of the locality this record remains uncertain. It may, however, be observed that the present data do not constitute the first reference to specimens of the genus from Hawaii, for Hickson (in Hickson \& ENGLAND, 1909, p. 347) already mentioned "beautiful rose-coloured Distichoporas from Hawaii"; these may have been specimens of $D$. coccinea.

\section{Geographical distribution}

Ceram and Banda Islands (doubtful record, RuMPHIUs, 1750); New Caledonia (Gray, 1860; present paper); East coast of Australia (Tenison-Woons, $1879 \mathrm{~b}$ ); Australia (present paper); Marshall Islands (Schmeltz, 1875; Wright, 1882; Pax, 1928; present paper); Gilbert Islands (WARD, 1892; ВRосн, 1942; present paper); Samoa (Pax, 1928); Tahiti (FISHER, 1938); Hawaiian Islands (doubtful record, present paper).

\section{DISTICHOPORA FULVACEA MICHELIN, 1862}

Distichopora fulvacea Michelin in Maillard, 1862, Annexe B; Michelin in Maillard, 1863, Annexe B.

In the collection of the Paris Museum there is a small cardboard box containing three fragments of Distichopora with a number of broken off branches. Two of the larger fragments, 35 by 45 and 35 by $42 \mathrm{~mm}$, are of a similar shape, and in all probability belong to Distichopora nitida, having a smooth surface and a reddish orange colour. The other larger fragment is the basal part of a colony, all the larger branches having broken off near the base, so that now the height of the fragment is $22 \mathrm{~mm}$, the breadth $44 \mathrm{~mm}$; the colour of this specimen is ochraceous; the structure of the surface and the condition of the pore-rows point to an identity with Distichopora violacea.

The box further contains two labels, the one reading "Distichopora fulvacea, Michelin, Océanie", to which, in another hand, later was added "B Bourbon Q"; on the other label is noted "Distichopora coccinea, Gray, Il. Sandgwick".

When examining these specimens during a visit to the Paris Museum in 1954, I was not aware of the existence of the name Distichopora fulvacea in the literature, and presumed that this name was an unpublished museum name as often occurring in old museum collections. One of the two labels undoubtedly belongs with the two fragments with a height 
of $35 \mathrm{~mm}$, which show among each other such a striking resemblance that they may be fragments of one colony, the other label then belongs with the fragment with a height of $22 \mathrm{~mm}$. As the fragments with a height of $35 \mathrm{~mm}$ are very similar to a larger specimen in the Paris Museum (48 by $54 \mathrm{~mm}$ ) reported to come from the Sandwich Islands (Hawaii), undoubtedly to be identified with Distichopora ni$t i d a$, it is altogether probable that the label "Distichopora coccinea, Gray, Il. Sandgwick" belongs with these fragments; then the specimen with a height of $22 \mathrm{~mm}$ must be the coral labelled "Distichopora fulvacea Michelin".

Some time ago Dr. L. B. Holruuls drew my attention to the publications of Malllard $(1862,1863)$ containing some notes on corals, including a description of the species Distichopora fulvacea Michelin. In the first edition of MaIlxaro's work (1862) there is an "Annexe B" treating of Cnidiaires, with the following note:

“[Distichopora] fulvacea, Michelin. Cette nouvelle espèce, trouvée par M. Maillard sur les bancs de coraux qui entourent l'île de Bourbon, a beaucoup d'analogie avec le $D$. violacea, Atlas du règ. anim., de Cuvier, Zoophytes, pl. 85, fig. 4, et porte comme lui des paquets de petites verrues sur les faces imperforées, et rougeâtres. Ce nouveau zoophyte est remarquable par ses petits rameaux ornés de deux rangs latéraux de pores se réunissant aux extrémités, par les points jaunes qui entourent les verrues ou par la couleur fauve des grosses branches.

Hauteur de 3 à 4 centimètres."

The author of "Annexe B" is Michelin, as appears from a note in the second edition of MarLLARD's work (1863, Zoologie, p. 26): “Un individu de ce groupe [Coralliens] a déjà été décrit par $M$. Michelin dans l'Annexe B." This last remark apparently also indicates that Michelin had but one colony at his disposal when describing his new species; if this inference is correct it stands to reason that the fragment that at present has a height of $22 \mathrm{~mm}$ is the original specimen from the island Réunion (Bourbon), and consequently is the type specimen of Distichopora fulvacea Michelin. The description of the species by Mrchelin does not give any indication of useful specific characters, noting only the similarity to $D$. violacea, the presence of ampullae and rows of pores at the sides of the branches, and the orange-red colour.
As there is reason to believe that the specimen of 22 by $44 \mathrm{~mm}$ came from the island Réunion and represents the type specimen of Distichopora fulva$c e a$, the coral may be here described in some detail.

The colony is irregularly flabellar, some of the branches growing out on the anterior and posterior surfaces (Pl. I figs. 12 and 13). The branches have a diameter of 3 to $4 \mathrm{~mm}$, together they form a rather crowded compact mass. The colour is ochre-yellow, probably the specimen is rather faded, the colour originally having been of a more reddish (fulvous) tint. The rows of pores are not confined to the lateral margins of the branches, for on many branches there are short or fairly long pore-rows on the flabellar surface. The sulcus is distinct, the gastropores are of comparatively large size. The surface of the coenosteum shows the small flat-topped, roundish tubercles as they are peculiar to $D$. violacea. Some of the branches show patches of male ampullae, in confluent masses, already partly covered with calcareous matter. In the present state of the colony the ampullae do not differ in colour from the general ochraceous tint.

In its general appearance the colony here dealt with shows a certain likeness to the specimens of D. violacea from Torres Straits (cf. Hickson, 1892), corresponding with these, moreover, in the tendency to have pore-rows on the flabellar surfaces of the branches. It is a remarkable fact that among the corals from Torres Straits examined by Hickson (1892) there were also specimens of an orange colour. In a later paper Hickson (in Hickson \& ENGLAND, 1909 , p. 347) remarked of $D$. violacea that "in the Indian Ocean we also find white, yellow, orange, violet, and purple varieties." If the colony here dealt with really is the type specimen of Distichopora fulvacea (the available data point in this direction) the name fulvacea becomes a synonym of violacea.

\section{Geographical distribution}

The species was described after a specimen from Réunion in the Western Indian Ocean; if the coral dealt with above is the type specimen, the name fulvacea becomes a synonym of violacea, the distribution of which is noted on a previous page.

\section{DISTICHOPORA NITIDA VERRILL, 1864}

Distichopora nitida Verrill, 1864, p. 46; Tenison-Woods, I879b, p. 56; Moseley, 1879, p. 482; Moseley, 1880, p. 85; Wright, 1882, p. 74; Quelch, 1884a, p. 115; Wright, 1884, p.218; Quelch, 1884b, p. 267; Quelch, 1885, p. 18; Ward, 1892, p. 53; Fisher, 1938, p. 544; Boschma, 1951, p. 459; Boschma, 1953, p. 167; Wells, 1954, p. 476; Boschma; 
1956a, p. 140; Boschma, 1957, p. 45; Boschma, 1959, p. 247.

Distichopora brasseyi Wright, 1882, p. 75; Quelch, 1884 a, p. 116; Wright, 1884, p. 218; Boschma, 1951, p. 462.

Distichopora allnutti Wright, 1882, p. 76; Quelch, 1884 a, p. 116; Wright, 1884, p. 218; Boschma, 1951, p. 462; Boschma, 1953, p. 167; Boschma, 1957, p. 40.

Distichopora breviserialis Quelch, 1884a, p. 113; Quelch, 1885 , p. 18; Boschma, 1957, p. 41.

Distichopora ochracea Quelch, 1885, p. 19; Boschma, 1953, p. 167; Boschma, 1957, p. 45.

Distichopora violacea forma typica Broch, 1942, p. 9; Boschma, 1953, p. 167.

Distichopora brasseyae Boschma, 1951, p. 459; Boschma, 1953, p. 167; Boschma, 1957 , p. 41.

Distichopora violacea Wells, 1954, p. 476.

Distichopora Hickson, 1924, fig. 71.

Verrill (1864, p. 46) described the species Distichopora nitida as follows:

"Corallum flabelliform, branching dichotomously in a plane. Branches round or flattened transversely; the branchlets obtuse, often compressed at the tips; surface very minutely granular, appearing almost smooth, with scattered patches of rounded verrucae, having rudimentary septa and pits surrounding them, and therefore probably corresponding to the enlarged columellae of cells without solid walls. Three rows of minute pits are arranged closely in regular series along the edges of the branches; those of the central, larger row are circular and often have a slender columella in the centre. The lateral ones are much smaller, and generally irregular in form; a transverse section shows that the central pits correspond to the central open space in the cells of Stylaster while the lateral ones are interseptal chambers, the greater part of which have been obliterated by the thickening of the septa; in some of the cells, twelve septa may be traced. Color bright red, with the tips of the branches yellowish white; other specimens are light orange. - Ebon Islands; $\mathbf{A}$. Garret."

With the exception of the attempts to find Madreporarian characters in the structure of the ampullae and the gastropores, this description clearly denotes the distinctive peculiarities of the form of growth and the smooth condition of the surface, the shiny appearance of the coral having given occasion to the specific name nitida.

An excellent diagnosis of the species was given by QUELCH (1885, Pp. 18/19):

" $D$. nitida is distinguished by its large regularly flabelliform habit; by its rounded branches, somewhat compressed at the base; by its rounded obtuse branchlets, expanded at the tips during division; by its extremely variable coloration, ranging from bright red to light orange; by its minutely granular surface, becoming almost smooth at the basal parts; by its obsolete or very shallow lateral furrows, the partitions between the gastropores being generally raised to the surrounding surface; by the unequal large gastropores; by the minute superficial dactylopores; and by the scattered or grouped raised granulated ampullae, in which the pores communicating with the central cavity are arranged in a circle around the base, the septiform partitions between them passing off to the surrounding coenenchyma or to neighbouring ampullae."

In this diagnosis there is but one statement that needs correction. In $D$. nitida the gastropores are not large, but small in comparison to those of $D$. violacea.

Notes by Wricht and QUELCH on the corals indicated with the specific names brasseyi and allnutti (synonyms of nitida) are referred to below.

Hickson's (1924, p. 152) figure of a Distichopora without indication of a specific name, a side view of a large branch, undoubtedly represents $D$. nitida. The branch is round and has an entirely smooth surface, the pores are not contained in a sulcus, and the cluster of ampullae next to the pore-row corresponds completely with those of $D$. nitida figured in the present paper (Pl. IX fig. 7); around the ampullae there are a number of pits giving the ampullae themselves a more or less stellate contour.

Fisher's attempts to place Distichopora nitida and $D$. coccinea in the synonymy of $D$. violacea have already been dealt with in the chapter of the present paper dealing with $D$. violacea. BRосн (1942), who accepted Fisher's views concerning this supposed synonymy, described at some length specimens named by him Distichopora violacea forma typica, the correct name of which is $D$. nitida Verrill. Вroch's excellent description and distinct figures (l. c., pp. 9-13, Pl. 1 fig. 1, text-fig. 1) leave no doubt to the identity of his specimens with $D$. nitida, the growth form of the figured colony, the smooth surface, and the very feebly developed lateral sulcus definitely pointing to this conclusion. ВRосн mentions a long list of specimens belonging to his $D$. violacea forma typica, generally from shallow water, one small colony from 50 to 100 fathoms (91 to $183 \mathrm{~m}$ ) in San Bernardino Strait in the Philippine Islands, apparently collected together with the specimens of $D$. serpens Broch. No further peculiarities of this colony from deep water are mentioned in the text. As corals of a more or less aberrant shape ВRосн mentions small colonies from a depth of three feet from Eimeo in Tahiti, of low, broad, and irregular growth, and of an extraordinarily dark purplish blue colour. These peculiarities point to a possible identity with $D$. violacea as defined in the present paper, but if they belonged to this species they would have had rather deep sulci, and then Broch would have united them with his $D$. fisheri, representing the true $D$. violacea.

WeLLS (1954) adhered to Broch's views, and ac- 
cordingly used the name Distichopora violacea for specimens not having a distinct sulcus, representing the species $D$. nitida Verrill. Wells mentions specimens of various colours: rich-salmon, pale vermilion with crimson patches, and purple. The figure (1. c., Pl. 185 fig. 3) shows a coral with the growth form of $D$. nitida; the branches are, however, extremely slender for the species. Wells places $D$. nitida, $D$. coccinea, and $D$. granulosa in the synonymy of " $D$. violacea".

In the list at the beginning of the present chapter the species Distichopora brasseyi Wright, D. allnutti Wright, D. breviserialis Quelch, and D. ochracea Quelch are placed in the synonymy of $D$. nitida Verrill. The reasons for this procedure are mentioned below.

In his description of Distichopora brasseyi, WRIGHT (1882, p. 75) noted the colour as "a deep red, tinted or slightly mottled with orange at the extremities of the stems and adult branches, paling off into white and pale orange-yellow", while the form of growth was described as follows: "branches long and erect, slightly tortuous, not so curved or foliaceous as in most of the other species, rounded but slightly compressed in the plane of the flabellum; termination of main branches bilobed and occasionally trilobed; lateral branchlets not frondose, but chiefly elongate and obtusely pointed or clavate, moderately distant from each other; main stems closely set together." The surface of the coenosteum is "very minutely and tortuously canaliculated." The notes on the porerows and the ampullae do not contain important data pointing to specific characters. The coral is remarkable in the first place by its enormous size, the height of the colony being 16 inches $(40 \mathrm{~cm})$, the width 26 inches $(66 \mathrm{~cm})$. The colony apparently was spreading fan-wise from a compact base, the main stems closely together, radiating from the centre in a manner to leave very little space for side branches, the growth being principally upwards (cf. Wright, 1882, Pl. 2). An isolated branch (1. c., Pl. 4 fig. 3) again shows that the tendency for growth was chiefly upwards, the side branchlets remaining small and poorly developed.

The colour of Distichopora allnutti Wright (1882, p. 75) was described as "fuscous orange-red, paling towards the extremities", the form of growth as "infundibuliform, the branches ramifying from a massive solid stem; base very compact; branches stout, bulbiform, nearly circular, moderately ramose, with the extremities flattened, obtusely furcate; the younger and lateral branchlets more acutely pointed; main branches closely packed, giving a very stout ap- pearance to the entire coral", the surface of the coenosteum as "more coarsely canaliculated and granulate than in $D$. brasseyi". The notes on the pore-rows and on the ampullae again do not contain positive details for specific characters. The height of the colony is $4 \frac{1}{2}$ inches $\left(11 \frac{1 / 2}{\mathrm{~cm}}\right.$, apparently measured perpendicular to the base), the longest axis (width) is 9 inches $(23 \mathrm{~cm}$ ), the shortest axis 8 inches $(20 \mathrm{~cm})$. The colony (l. c., Pl. 3 figs. 1 and 2) is more or less funnel-shaped, the closely arranged branches extending in a slanting position around a solid base. The figure of an isolated branch (1. c., Pl. 4 fig. 5) demonstrates the tendency for upward growth, the side branchlets remaining small and insignificant.

In a rather derisive manner, QUELCH (1884 a) criticized the description of the two species by WRIGHT, concluding that they belong to the species $D$. nitida Verrill. The controversy between the two authors gave rise to some further discussion (WRIGHT, 1884; QUELCH, 1884 b), but to all appearances QuELCH was right in his specific determination of the corals here dealt with.

In 1957, when examining various Stylasterina in the collection of the British Museum, the available time did not allow of a study of the whole collection, so that I did not make notes on the specific characters of the two species described by Wright. There is, however, in the collection of the Leiden Museum a coral showing all the characters of Distichopora brasseyi Wright (cf. Boschma, 1951). This coral has a height of about $28 \mathrm{~cm}$ (originally it was much larger as a fragment of at least $10 \mathrm{~cm}$ length has broken off from the topmost part) and a breadth of about $26 \mathrm{~cm}$; the height accordingly corresponds closely with that of the type specimen of $D$. brasseyi. Also in its manner of branching the coral in the Leiden Museum shows a strong resemblance to $D$. brasseyi and D. allnutti (cf. Boschмa, 1951, fig. 1), the thick round branches running close together, leaving very little space for development of side branchlets, so that only at the sides of the coral there are several smaller branches extending sideways and developing in the typical manner of $D$. nitida. The colour of the coral in the Leiden Museum was described as "brick red, the smaller branches often being of a lighter colour, sometimes towards their tips changing into a yellowish grey (l. c., p. 459). This coral came from the Gilbert Islands, like those described by Wrugrt. The surface of the coenosteum is finely granulated, the sulcus of the pore-rows is very feebly developed on some of the terminal branchlets but is altogether absent on the larger stems and branches. The identity of the coral with 
D. nitida Verrill appears to be firmly established. In the cited paper the species was indicated with the name $D$. brasseyae because the specific name was given in honour of Lady BrASSEY.

The colour and the form of growth of Distichopora breviserialis were described by QueLch (1884 a, p. 113) as follows:

"Coenosteum of a rather deep flesh-red or pale aurorared colour, branched, very compact, irregularly flabellate, with the surface granulated, roughened, and minutely canaliculated; branches often coalescent, rather short, thick, uneven, often twisted, almost round above, but much compressed, at the base especially, where three or four branches arise together in the same plane; branchlets very short, thick, and obtuse, of a deeper colour than the rest of the coenosteum."

The type specimen in the collection of the British Museum is a single branch in which some of the side branches are growing more or less perpendicular to the main plane. The surface of the coenosteum is finely granular, on some of the branchlets the porerows occur in a shallow sulcus, as already mentioned by QUELCH. The manner of growth and the condition of the surface point to an identity with $D$. nitida Verrill; QUELCH remarks that the species shows some resemblance to $D$. rosea Kent; the structure of the surface in the last mentioned species indicates, however, an affinity with $D$. violacea (Pallas) or with D. gracilis Dana. Quelch further observes that the notes on $D$. rosea by Tenison-Woods (1879 b, p. 161) in all probability refer to his new species $D$. breviserialis: Tenison-Woods, however, states that in $D$. rosea the margins of the furrows are very prominent and that the surface is much more hispid than any other species of the genus, characters pointing to an identity with $D$. violacea or $D$. gracilis.

The following is the first part of the description of Distichopora ochracea by QuELCH $(1885$, p. 19):

"Coenosteum branching in a plane, of a dull ochreyellow colour, sometimes becoming white at the tips; branches thick, rounded, or slightly flattened; branchlets short and rather thick, rounded, obtuse, expanded at the time before division takes place. Coenenchyma rather firm; surface minutely granular at the basal parts of the branchlets, becoming more granulated at the extremities, with crowded, very obtusely conical eminences, between which are scattered pores. Cyclosystems regularly arranged in continuous, wide, shallow lateral furrows."

QuELCH further notes some peculiarities of the pores and the ampullae, and adds that the new species is most closely related to $D$. nitida Verrill. The type specimen in the collection of the British Museum, a small fragment from the top of a colony (Quelch, 1885, Pl. 1 fig. 2) resembles in its growth form $D$. nitida, corresponds with this species by having a finely granulated surface, but has lateral sulci which are rather deeper than generally in $D$. nitida. Notwithstanding this the species to all appearances is a slightly aberrant form of $D$. nitida.

\section{Specimens examined}

Amsterdam Museum: Distichopora coccinea, Südsee, Heinr. Platow Hamburg Naturalienhandlung, 2 colonies, 139 by $215 \mathrm{~mm}$ (Pl. XI) and 243 by 183 $\mathrm{mm}$. The figured specimen consists of three or four large branches with numerous side branches extending in widely different angles from a common basal part. Some of the smaller branches are growing out next to the general plane. The measurements of this colony have been taken more or less arbitrarily, the distance from the base to the top of the middle branch being recorded as the height, the dimension perpendicular to this height representing the breadth, more or less corresponding with the larger diameter of the colony. The branches with their side branches form a regular flabellum except where branches have been broken off. The terminal parts of the branches are curved to one side, the coral thereby presenting a concave (anterior) and a convex (posterior) surface. The surface of the branches, including the topmost parts of the branchlets, is finely granular, giving a more or less shiny appearance to the colony. In the small branchlets the pore-rows may occur in a shallow sulcus, in the larger branches the pores open at the surface of the lateral margins (Pl. IX figs. 5 and 6). On some of the smaller branches there are patches of male ampullae in dense clusters (Pl. XIII fig. 4), the granulation of their surface completely corresponding with that of the branches. The colour of the colony is a light reddish purple, the tips of the branchlets are paler, often whitish. - The other colony ( 243 by $183 \mathrm{~mm}$ ) has an altogether similar form of growth, consisting of a small number of large branches extending from a common basal part, which here is overgrown with foreign matter encroaching on the lower part of the branches. The larger branches have a diameter of 12 to $15 \mathrm{~mm}$ at their lower parts that still were living when the colony was collected. In this coral again one of the surfaces is concave, the other convex, the first to be considered the anterior surface. At this surface of the flabellum there are a few side branches that have developed into small flabellar growths perpendicular to the general plane. The finer structures and the colour correspond in every respect with those in the other colony. It has male ampullae like those of the other specimen.

Australian Museum, Sydney: Distichopora nitida, 
Marshall Islands, J. R. ETHEHidge, reg. no. G 6235 (partim), 1 fragment, 51 by $28 \mathrm{~mm}$ (Pl. I fig. 1). The specimen is a branch with some side branches, which show a strong tendency to grow out at an angle with the flabellar plane. The branches are distinctly compressed antero-posteriorly, they have blunt to pointed tops. The surface of the coenosteum is finely granulated, not showing the small tubercles as found in $D$. violacea. Most of the pore-rows lie at the surface of the lateral margins of the branches; in some of the smaller branchlets, however, the pores are contained in a distinct sulcus. There are a few patches of male ampullae. The colour of the colony is ochre-yellow. On account of the occurrence of lateral sulci the identification of the specimen with $D$. nitida is not altogether certain. In its form of growth the coral shows some resemblance to Distichopora breviserialis Quelch, here regarded as belonging to the species D. nitida (see notes on a previous page).

British Museum (Natural History): Distichopora breviserialis, Type, 62.7.4.31, 1 fragment, 64 by $58 \mathrm{~mm}$. See notes on a previous page.

British Museum (Natural History): Distichopora ochracea, Type, Solomon Islands, H. B. Guppy, Esq., 85. 5. 4. 1, 1 fragment, 26 by $18 \mathrm{~mm}$ (QueLCH, 1885, Pl. 1 fig. 2). See notes on a previous page.

Leiden Museum: Distichopora nitida, Kingsmill Islands (Gilbert Islands), H. A. WARD, 1 colony, 60 by $103 \mathrm{~mm}$. In its manner of growth the colony shows a strong likeness to the specimen figured by Broch (1942, Pl. 1 fig. 1, indicated with the name Distichopora violacea forma typica); it is, however, a more complete colony consisting of several large branches growing from a common basal part. The colony is rather concave anteriorly, convex posteriorly. On the flabellar surfaces there are a few irregular pore-rows. The colour of this colony is a pale reddish orange, the tops of the branches having a lighter shade of the same tint.

Leiden Museum: Kingsmill Islands (Gilbert Islands), Serrurier dedit, May 12, 1895 (identified with Distichopora brasseyae Wright, Bosckma, 1951), 2 colonies (or parts of one large colony), 278 by 162 $\mathrm{mm}$ (Pl. XII) and 272 by $98 \mathrm{~mm}$ (in both the top branches broken off), and some fragments. The two specimens (or parts of one colony) form corals of very solid appearance, consisting of a number of thick branches running from the base to the top of the colony in a nearly parallel manner; when dividing the resulting new branches again remain close together, leaving very little space for the development of side branchlets. The main branches are round and thick (diameter about $15 \mathrm{~mm}$ ), the branchlets are flattened antero-posteriorly, especially at their tops, the whole of the structure resulting in a coral of very uneven surface owing to the strong difference in size between the main branches and the laterally extending branchlets. The surface of the coenosteum is smooth to the naked eye, rather shiny. When enlarged it is seen to be densely covered with minute granulations, which often are combined to form short ridges, not unfrequently leading to a pronounced vermiculation of the surface. The pores are not contained in a sulcus, even on the smallest branchlets they open at the surface (Pl. XIII fig. 5, the ridge in the middle of the figure is an incipient branchlet with a pore-row on its top). Instead of being contained in a sulcus the pore-rows often occur on a small ridge slightly extending over the surface; this happens especially on the older branches of the colony. The gastropores are comparatively small, widest (about $0.2 \mathrm{~mm}$ ) in the smaller branchlets, narrower (about $0.15 \mathrm{~mm}$ ) in the larger branches (Pl. IX fig. 7). In the small branchlets the narrow dactylopores are of a more or less circular shape; they have a more or less oval opening in the larger branches, the long axis of the oval being transversely orientated. Dactylotome projections are only feebly developed. The two colonies have numerous ampullae, solely occurring on the smaller branches. On one of the surfaces they occur in greater number than on the other. The ampullae are of low hemispherical shape, at their margins they are surrounded by a circular row of fairly large pits. The ampullae occur in linear rows (Pl. IX fig. 7) or in irregular groups, crowdedly joining, so that the borders between the individual ampullae are chiefly to be determined by the rows of pits (Pl. XIII fig. 5). The surface of the ampullae has a granulation similar to that of the branches. The colour of the two specimens is a light brick-red, the smaller branches often having a paler colour, sometimes towards their tips changing into a yellowish grey. - The specimens here dealt with were described at some length in a previous paper (Bоschma, 1951). The corals being of a form of growth entirely different from the specimens of $D$. nitida at that time known to me, I identified them with $D$. brasseyi Wright (or brasseyae because the specific name was dedicated to Lady Brassey), regarding this form as a well-defined species. The general shape of the branchlets, the structure of the coenosteum, the condition of the pore-rows, and the shape of the ampullae correspond, however, in every detail with those of $D$. nitida; accordingly $D$. brasseyi must be considered conspecific with $D$. nitida though having a tendency for a strongly pronounced upward growth 
and for a development of very large branches, at first sight entirely different from the growth form of typical specimens of $D$. nitida, which also may reach a comparatively large size ( $\mathrm{Pl}$. XI) but are more evenly spreading in all directions. The conclusion that the names $D$. brassey $i$ (and $D$. allnutti) are synonyms of $D$. nitida is not new, for QueLch (1884a) already defended this view.

Manchester Museum: Distichopora coccinea, Marshall Islands, 2 colonies, 146 by $62 \mathrm{~mm}$ and 93 by $92 \mathrm{~mm}$. The colony with a height of $93 \mathrm{~mm}$ has a more or less fan-wise shape, the branches diverging from a common centre. In its form of growth it is similar to the specimen of Pl. XIV fig. 5 , the branches being, however, slightly thicker. In the tops of the branches the pore-rows often occur in a shallow sulcus, on the larger branches the pores open at the surface or on a small ridge extending over the surface. The colony bears female ampullae in short rows or in small groups, these are confined to the anterior (slightly concave) surface. The other colony consists of one large branch with some side branches. In its finer structure it corresponds altogether with the other specimen. Female ampullae are to be found on both the flabellar surfaces, especially on the smaller branches. There are a few short pore-rows on the posterior side of some of the branches. The colour of the two colonies is a light orange red, the tops of the branches often have a lighter colour, light yellowish or almost white. - Three figures are here given to illustrate details of the structure. One of these (Pl. IX fig. 4) shows a pore-row on the lateral margin of a branch with a diameter of about $7 \mathrm{~mm}$. The gastropores are about $0.24 \mathrm{~mm}$ wide, the oval openings of the dactylopores are arranged with their long axis perpendicular to the line connecting the gastropores. The second figure (Pl. XIII fig. 2) shows the top of a branch with some small groups of female ampullae, which are not as crowdedly joined as usual in the species, showing a more or less circular shape; the pits surrounding the ampullae have a white colour, being filled up with some calcareous matter. Here the surface of the ampullae is even more finely granular than that of the branch. The third figure (Pl. XIII fig. 3) represents the top of another branch of the same colony, with dense patches of ampullae showing about the same kind of granulation as the surface of the branch.

Manchester Museum: Distichopora sulcata, West Indies, 1 colony, 88 by $66 \mathrm{~mm}$. The colony is of a rather irregular shape. It consists of two main stems growing out from a common base, the one having a diameter of $10 \mathrm{~mm}$, the other of $7 \mathrm{~mm}$. Both stems have side branches, which often do not remain in the flabellar plane but are forming a rather wide angle with the anterior or the posterior surface. The porerows of the smaller branchlets are contained in a shallow sulcus; in the larger branches the pores are flush with the surface. Many of the smaller branches bear patches of female ampullae, usually with an evenly granulated surface, sometimes possessing feebly developed ridges, giving them a more or less stellate appearance ( $\mathrm{Pl}$. X fig. 4). The colour is a light vermilion red, the tops of the branchlets are often whitish for a distance of 5 to $8 \mathrm{~mm}$ from the top. - The locality (West Indies) is erroneous, as is the original identification with the West Indian coral D. sulcata, which has a whitish colour (Pourtalès, 1871, p. 38).

Paris Museum: Distichopora, Iles Sandwich, BALLIEU, 1876, 1 fragment, 48 by $54 \mathrm{~mm}$; 1 fragment, 70 by $45 \mathrm{~mm}$. The fragment with a height of $70 \mathrm{~mm}$ is the basal part of a colony with the lower parts of some thick branches having a diameter of 8 to $10 \mathrm{~mm}$ at the place of fracture. The other fragment is a part of a branch with a diameter of about $8 \mathrm{~mm}$, bearing a side branch and a few branchlets. The specimens show the typical characters of $D$. nitida; in their form of growth they bear a certain likeness to the specimens to which the name $D$. brasseyi was given; the branchlets are, however, not as stunted as they are in the specimens referred to. The colour of the two fragments is orange-yellow.

Paris Museum: without indication of locality, 1 colony, 86 by $60 \mathrm{~mm}$ (PI. XIV fig. 5). The colony is spreading in one plane, it consists of a main stem with a thickness of about $10 \mathrm{~mm}$, which towards the top of the colony is gradually dividing into a number of smaller branches with somewhat pointed or rather blunt tops. The colony differs from most of the other specimens of $D$. nitida by having the surface of the coenosteum of the branchlets much more coarsely granulated, the granulations occurring in a similar coarse shape on the female ampullae (Pl. XIII fig. 1); the larger branches and the main stem have the fine granulation that is characteristic of the species. In some of the branchlets the pores occur in a shallow sulcus; on the larger branches the pores invariably open at the surface. Besides the regular pore-rows on the lateral margins of the branches there are a few short or longer pore-rows on the flabellar surfaces. The colour of the colony is reddish orange, the tops of the branches are often whitish.

University of Queensland, Dept. of Zoology: Distichopora violacea, Great Barrier Reef, identified by J. W. WeLls, 1 colony, 110 by $122 \mathrm{~mm}$. The colony 
has rather thick branches (diameter of the largest branch $10 \mathrm{~mm}$ at the base) spreading fan-wise in one plane. It has the shape and the manner of branching of D. nitida; it also has the fine granulation of the surface as it is characteristic of the species, even the smallest branchlets not having the flat-topped tubercles as they occur in $D$. violacea. In the branchlets the pores are contained in a shallow sulcus, which even often remains in the larger branches. The larger branches are here and there distinctly compressed in a lateral direction, thereby giving the coral some resemblance to the specimen from the Brussels $\mathrm{Mu}$ seum that is here tentatively identified with D. livida; the constrictions of the branches occur, however, in their middle region, not in the anterior half only as in the specimen of the Brussels Museum. On the posterior (slightly convex) surface of the coral there are several female ampullae, which are not as regularly hemispherical as usual in the species, but often have small irregular, sometimes more or less radially arranged ridges. The colour of the colony is reddish orange. - The identification of the specimen with $D$. nitida is not altogether certain, the coral showing some resemblance to " $D$. livida." The fine granulation points to the probability that it belongs to $D$. nitida. The coral was identified with $D$. violacea by WeLLs, who based himself on BrocH's (1942) data. Owing to Broch's definition of the various forms the coral should receive the name $D$. violacea forma typica, this form representing the species that has to bear the name $D$. nitida.

\section{Geographical distribution}

Great Barrier Reef (Wells, 1954; present paper); Solomon Islands (Quelch, 1885); Philippine Islands (doubtful record, specimen from 50-100 fathoms, BROCH, 1942); Marshall Islands (VerRILL, 1864; Brock, 1942; present paper); Gilbert Islands (WRIGHT, 1882; BRoch, 1942; present paper); Tahiti (doubtful record, specimens of irregular growth, Ввосн, 1942); Hawaiian Islands (doubtful record, present paper).

\section{DISTICHOPORA IRREGULARIS MOSELEY, 1879}

Distichopora irregularis Moseley, 1879, p. 502; Moseley, 1880 , p. 85 ; Wright, 1882 , p. 74; Kirkpatrick, 1890, p. 12; Hickson, 1892, p. 502; Delage \& Hérouard, 1901, fig. 247; Broch, 1942, p. 24; Boschma, 1953, p. 167; Boschma, 1956 b, p. F 100; Boschma, 1957, p. 44.

Dystichopora irregularis Dawydoff, 1952, p. 56.

The species Distichopora irregularis was described as follows (Moseley, 1880, pp. 80/81):

"Coenosteum of a light pinkish colour, branching irregularly, flabelliform; branches rounded but moderately flattened in the plane of the flabellum, more compressed towards their tips. Surface of the coenosteum finely granular in texture. Lines of pores sometimes placed on the flabellar edges of the branches, sometimes absent from these, and coursing irregularly in curved lines over the faces of the branches, often joining one another at various angles. Pore rows consisting of a median row of nearly circular-mouthed gastropores, with very deeply-seated styles, and placed somewhat widely with an interval of about their own width between them; and of a row of elongate-mouthed dactylopores also sparsely disposed on either side. The lines of the pore rows are slightly channelled out in the surface of the coenosteum.

Extreme height of the single specimen, $40 \mathrm{~mm}$. Extreme breadth of the branches, $4 \mathrm{~mm}$. In the pore rows about eight gastropores occur in the length of $3 \mathrm{~mm}$.

Off Samboangan, Philippine Islands. 10 fathoms."

The type specimen in the collection of the British Museum has a height of $40 \mathrm{~mm}$ and a breadth of $28 \mathrm{~mm}$ (cf. Moseley, 1880, Pl. 12 fig. 8). The sur- face of the coenosteum is smooth, presenting a fine granulation only, as also appears from the figure representing an enlarged view of the top of a branch (l. c., Pl. 12 fig. $8 \mathrm{a}$ ). This figure is further interesting as it shows that at least in this part of the colony the pores occur in a distinct sulcus, which often obtains a depth corresponding with that found in many specimens of $D$. violacea.

After having examined specimens of Distichopora violacea from Murray Island (Torres Straits) and Lembeh Island (near North Celebes), in which the pore-rows were not confined to the lateral margins of the branches but often occurred on the flabellar surfaces, Hickson (1892, p. 503) remarked that he was "inclined to think that Moseley's species $D$. irregularis may, after all, be but a younger stage of $D$. violacea or $D$. coccinea." It is, however, much more justified to conclude that the typical characters of $D$. irregularis, the irregular pore-rows, may present themselves as an exception in specimens of $D$. violacea. As a matter of fact small pore-rows also occur on the flabellar surface of some specimens of $D$. nitida and of $D$. borealis (cf. Frsher, 1938, p. 543), while in $D$. coccinea besides the pore-rows on the sides of the branches there are always small porerows on the incipient branchlets in the middle of the larger branches. 
Kinkpatrick (1890) reported the species Distichopora irregularis from Garvan Reef in the China Sea, depth 2 fathoms. As only the name of the coral was mentioned this record remains doubtful.

Вroch (1942, pp. 24-27) examined three fragments of Distichopora irregularis from off Jolo, in the Philippine Islands, depth about 25 fathoms $(45 \mathrm{~m})$, the locality being comparatively little distant from that of the type specimen. The largest fragment (Broch, 1942, Pl. 2 fig. 4) is somewhat less spreading than the type specimen, but corresponds with it in the shape of the branches, which are cylindrical, not flattened. The pore-rows of the two specimens occur in an entirely similar manner. As in the type specimen, the surface of the coenosteum is smooth, showing in BROcH's specimen a finely vermiculated structure. The corals from off Jolo differ from the type specimen in that the sulcus is very shallow or even absent. In his key to the species (l. c., pp. 8/9), BRосн even uses this peculiarity as a character of the species ("sulci lacking or at most barely indicated"). As remarked above, Moseley's figure of a terminal branch (1880, Pl. 12 fig. 8 a) shows very distinct sulci, the presence or absence of these grooves therefore is not constant in the species.

According to BROCH (1942, pp. 26/27) the occurrence of pore-rows on the flabellar surface of the specimens from Torres Straits described and figured by Hickson (1892) makes it questionable that these corals belong to $D$. violacea; possibly they should be identified with $D$. irregularis. Having had occasion to study specimens from Torres Straits in the collection of the Manchester Museum, apparently originally belonging to the lot studied by Hickson, I must defend the view that they certainly do not belong to D. irregularis. In a very pronounced manner the structure of the surface shows the small circular tubercles, which are characteristic of $D$. violacea. The specimens undoubtedly are $D$. violacea with aberrant pore-rows.

\section{Geographical distribution}

Philippine Islands (Moseley, 1879; ВRосн, 1942), Garvan Reef, China Sea (doubtful record, KIRKPATricK, 1890).

\section{DISTICHOPORA LIVIDA TENISON-WOODS, 1879}

Distichopora livida Tenison-Woods, 1879a, p. 301; Tenison-Woods, 1879b, p. 62; Quelch, 1884a, p. 115; Wright, 1884 , p. 218; Quelch, 1884b, p. 268; Von Lendenfeld, 1885 , p. 615 ; Von Lendenfeld, 1887, p. 46; Kirkpatrick, 1902, p. 54; Boschma, 1953, p. 167; Boschma, 1957, p. 45.

The original description of Distichopora livida (TENIson-Woods, 1879 a, pp. $301 / 302$ ) reads:

"Corallum, in stout, solid tufts, three or four inches high, flabellate or twisted, and gnarled like the branches of a tree, not always spreading in the same plane, very solid and compact, livid, tips of branches sometimes yellow or white, lateral furrows and tips of smaller branches bright red or orange. Branches almost cylindrical, stout, rugose, very finely vermiculate, many projecting branchlets, the central stem often disproportionately thicker than the branches and smooth. Lateral furrows conspicuous from their color. Gastropores large, irregular. Dactylopores small, situate on a moderately projecting, broad margin. Style very long and spinous. Ampullae in slightly swollen, pale, livid masses, in which the separate cells are not easily distinguished."

The species was further characterized as being larger and stouter than D. coccinea, it was stated to have been collected in the Solomon Islands, in the Penrhyn Islands, and in the Marshall group (based on "second hand information, in general vague and indefinite").
In another publication (TeNison-Woods, $1879 \mathrm{~b}$, p. 62) there is again a description of the coral, with slight unimportant differences in wording, while the distribution of the species is noted as "Solomon Islands; New Hebrides; New Guinea." This publication contains figures of the external appearance of the species with a slightly enlarged lateral view of a branchlet, a section of a gastropore showing the gastrostyle and small spines on the inner wall, the top of a gastrostyle much enlarged (these figures copied in fig. $4 \mathrm{a}-\mathrm{c}$ of the present paper), a transverse section of a gastrostyle much enlarged, a longitudinal section of the top of a branch, and a transverse section of a terminal branch showing the canal system strongly enlarged. In a key to the Pacific species of the genus Distichopora (D. nitida omitted), Tenison-Woons $(1879 \mathrm{~b}$, p. 63$)$ divides them in those which have the branches nearly cylindrical (violacea, rosea, and livida) and those which have the branches compressed (coccinea and gracilis). The first group comprises two species with the marginal furrows much raised (violacea, rosea) and one with the margins slightly raised (livida). As far as concerns Tenison-Woods's opinion on the branches of $D$. gracilis being compressed it may be here noted that DANA (1848) in the description of the species does not mention this 

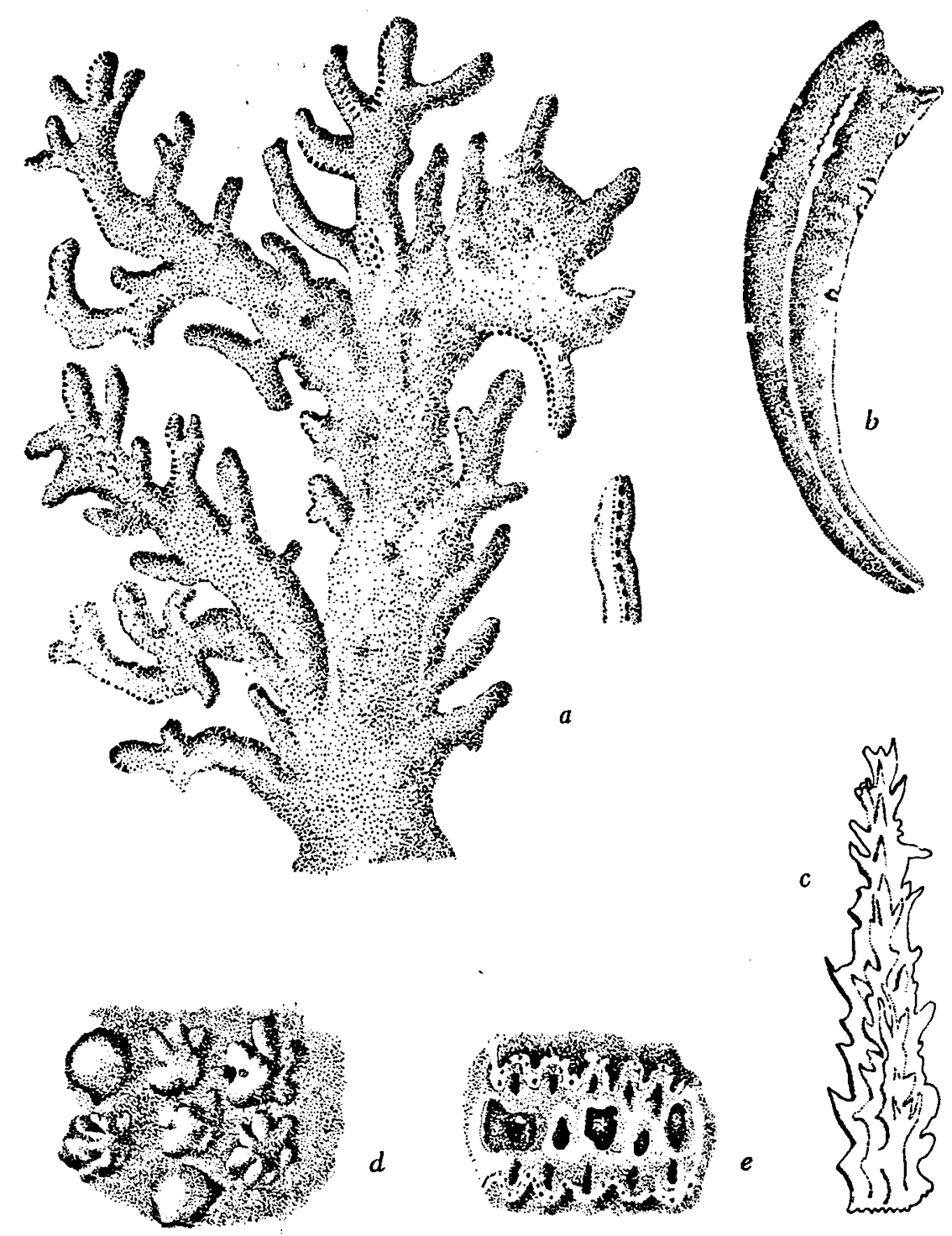

Fig. 4. a-c, Distichopora livida Tenison-Woods; a, colony and lateral view of a branchlet; $b$, section of a gastropore with gastrostyle and spines on inner wall; c, top of a gastrostyle. d, e, Distichopora violacea (Pallas); d, ampullae; e, part of a pore-row. After TENison-Woods $(1879 \mathrm{~b}, \mathrm{Pl}$. 1). Original size; the colony natural size, the other figures enlarged on different scales.

peculiarity, though the very young colony (l. c., Pl. 60 fig. 5) seems to have one branch with a flattened top, apparently showing the beginning of a dichotomical division.

In his notes on Distichopora livida, Quelch (1884 a) remarks that in specimens in the British Museum collection from unknown locality, which seem to belong to this species, "the colour varies considerably from dull or pale purplish red to dull reddish or brownish orange, having the extremities, as given in the description of the species, white, yellow, or orange, and the lateral furrows and incipient branchlets bright red or orange." (l. c., p. 115). QuELCH adds that, if this identification is correct, the species proves to be closely related to $D$. nitida Verrill, if indeed it is distinct from this species, and remarks (1. c.): "If, however, the strict meaning of lividus was intended, i.e. bluish or black and blue, then this 
species presents a most remarkable variation in colour, and certainly would seem to be distinct from any yet described."

In the collection of the Brussels Museum there is a fairly large colony of a Distichopora from the Fiji Islands ( 85 by $60 \mathrm{~mm}$ ), which possibly might be identified with $D$. livida, presenting peculiarities corresponding in many respects with those mentioned in the description of the species by Tenison-Woods. The colony (Pl. XIV figs. 1 and 2) shows a strong resemblance to the figure of TeNISON-Woods (cf. fig. $4 \mathrm{a}$ in the present paper) as it consists of a stout, erect main stem with several side branches. The colour of the specimen in the Brussels Museum is a dark greyish violet, a tint not much differing from "livid", which in the Concise Oxford Dictionary is explained as "of a bluish leaden colour." In this colony, however, the colour is uniform all over the surface, the pore-rows having the same tint, not being bright red or orange as stated for the type specimen. The identification with $D$. livida, therefore, remains altogether uncertain.

To a certain degree the colony in the Brussels Museum combines characters of $D$. violacea and of $D$. nitida. The colour is more like that of many specimens of $D$. violacea than the more or less reddish or orange tint generally to be observed in $D$. nitida. The smaller branches have the typical characters of $D$. violacea by presenting a rough surface, divided into numerous flat-topped roundish papillae, which in this specimen often unite as small ridges or vermiculations (Pl. VI fig. 3), while the lateral sulcus is well developed, with large gastropores and dactylopores with distinctly projecting walls (PI. IV fig. 5). On the other hand the main stem shows the typical characters of $D$. nitida, the surface being finely granular, and the rows of pores, consisting of distinctly smaller gastropores and dactylopores, not being contained in a sulcus but opening on the surface (Pl. IV fig. 4).

The colony presents a remarkable peculiarity in the shape of the stem and the larger branches. In posterior view (PI. XIV fig. 2) these parts are evenly rounded, giving the colony a robust appearance; in anterior view (Pl. XIV fig. 1) they show a broad median ridge, the lateral parts next to this ridge being more or less hollowed out, giving the branches a somewhat trapezoid shape in cross section. It is interesting to note that one of the specimens from the Australian Museum, which in the present paper is identified with D. violacea (PI. XIV figs. 3 and 4), in its shape closely corresponds with the top part of the colony in the Brussels Museum, though differing by its vermilion colour. This specimen has an altogether similar shape of the larger branches, which are irregularly trapezoid in cross section, the lateral sides of the figure then being concave, the parallel sides (the anterior and posterior surfaces of the colony) being convex.

If the specimen here dealt with really represents the form described by Tenison-Woons as Distichopora livida, this species is nothing else but an aberrant form of $D$. violacea, growing to a much larger size and having a much more pronounced main stem than generally in the species. It remains interesting to note that in this manner $D$. violacea may obtain some of the characters of $D$. nitida.

As I did not have the opportunity to examine specimens that without any doubt belong to the species Distichopora livida, the supposed identity of the specimen in the Brussels Museum with this species remains a conjecture only. For the present $D$. livida must be considered a species dubia.

\section{Geographical distribution}

Tenison-Woods (1879a) records the distribution of D. livida ("according to second hand information, in general vague and indefinite") as: Solomon Islands; Penrhyn Island (Tongarewa, $09^{\circ} 12^{\prime} \mathrm{S}, 154^{\circ} 35^{\prime} \mathrm{W}$ ); Marshall Islands; in another paper (1879b) as: Solomon Islands; New Hebrides; New Guinea. The coral here tentatively identified with $D$. livida came from the Fiji Islands.

\section{DISTICHOPORA PROFUNDA HICKSON \& ENGLAND, 1909}

Distichopora profunda Hickson \& England, 1909, p. 348; Boschma, 1957, p. 46.

Hickson \& England (1909, p. 348) gave the following account of Distichopora profunda, based on two specimens obtained at a depth of 219 to $274 \mathrm{~m}$ (references to figures, notes on soft parts, and remarks of comparison to other genera omitted):
"As far as can be ascertained from one of the small colonies obtained, the growth is flabellate, the branches being very stout, obtuse, and flattened in the plane of the flabellum. The thickest branch is $10 \mathrm{~mm}$. $\times 4 \mathrm{~mm}$. in diameter, while the base of the main stem is $7 \times 4 \mathrm{~mm}$. The colony is not old enough for it to be ascertained whether the method of growth is dichotomous or anastomosing. The colour is brownish white, the surface is very rugose, recalling the structure of Sporadopora dichotoma, but as the pits and furrows of the coenenchym- 
canals are much deeper and larger they can be easily seen without magnification. The pores are confined chiefly to the lateral sides of the branches, where there is generally a double row of gastropores bordered by a single row of dactylopores on each side $(.4 \times .2 \mathrm{~mm}$. in diam.). The latter are usually horseshoe-shaped, the outer edge slightly raised above the surface of the coral, the "open" end of the horseshoe being turned towards the row of gastropores.... Sometimes the line of pores is continued on to either of the surfaces of the coral; there may also occasionally be a few isolated pores, a gastropore with one or more dactylopores near it upon the surface. The gastropores vary in size; the larger ones are $0.5 \mathrm{~mm}$. in diameter. In $D$. violacea they are rarely more than $0.3 \mathrm{~mm}$. in diameter. The arrangement of the gastropore-cavities is fan-shaped, as in $D$. violacea. The long gastrostyle is brush-like at the tip. One important feature of this species is that tabulae are common in the gastropores. The tabulae do not occur in very young (that is to say, shallow) gastropores, but more than one may be present in the older pores .... On re-examining Distichopora violacea we have found that they do occur in the older gastropores of that species. In many of these there are several incomplete tabulae-that is to say, excrescences-from the wall of the pore that may or may not reach the gastrostyle. These incipient tabulae sometimes are seen in $D$. profunda."

The authors further note the following differences of $D$. profunda from D. violacea (1. c., p. 349):
"The branches are much bigger than in $D$. violacea and the surface of the coenosteum is much rougher and coarser. The gastropores are decidedly larger. The gastropores are in many places arranged in two alternating rows on the edges of the branches, a condition which is very rare indeed in $D$. violacea. The lips of the dactylopores project in the form of horseshoe-shaped collars from the surface of the coenosteum, much more definitely than in $D$. violacea. The tabulae in the gastropores are more frequent and definite than they are in $D$. violacea."

In the collection of the British Museum there is a specimen labelled "Distichopora profunda, Type, off Salomon Atoll, Chagos Archipelago, 120-150 fms., Percy Sladen Trust Exp., Prof. S. J. Hickson Coll., 1957. 2. 18. 1." The figure (Hickson \& ENGLAND, 1909 , Pl. 44 fig. 4) represents the specimen in natural size, the measurements being 33 by $28 \mathrm{~mm}$. The differences from $D$. violacea (the coarser structure of the surface, the greater breadth of the branches, and the much larger gastropores) have already been mentioned by the cited authors.

\section{Geographical distribution}

The species is known from one locality only: off Salomon Atoll, Chagos Archipelago, Western Indian Ocean (Hickson \& England, 1909).

\section{DISTICHOPORA PROVIDENTIAE (HICKSON \& ENGLAND, 1909)}

Sporadopora providentiae Hickson \& England, 1909, p. 349; Broch, 1942, p. 27; Boschma, 1953, p. 167; Boschma, 1957, p. 61.

Distichopora irregularis Broch, 1942, p. 27.

The type specimens of the species described by Hickson \& England (1909, pp. 349/350) under the name Sporadopora providentiae came from off Providence Island in the Western Indian Ocean, depth 125 fathoms $(228 \mathrm{~m})$. They were collected by the Percy Sladen Trust Expedition. The chief peculiarities of the species are as follows (quoted from the original description, references to figures omitted):

"The habit of growth of this new species is flabelliform and dichotomous.... The colour is yellowish white; the surface is slightly granular in appearance, but smoother than in S. dichotoma, in which Moseley likens the texture to that of loaf-sugar. The zooid-pores are very numerous round the edges of the branches, but a few may be scattered on either surface. There is a nearer approach to arrangement in cyclosystems than in Moseley's species. Yet the system of pores recalls still more strongly the condition common in Distichopora, most of the gastropores lying in an irregular double or single row at the edge of the branches and the dactylopores arranged either in irregular lateral rows or more irregularly scattered. The lip of the gastropore projects slightly above the surface of the coenosteum and the aperture is about $2.75 \mathrm{~mm}$. in diameter. The gastropore is deep and curved down the branch; it bears a long gastrostyle, similar to that of Distichopora but not quite so slender, tapering to a point near the gastropore .... The apertures of the dactylopores are either round or top-shaped and are usually provided with a horseshoe-shaped lip, very similar to that of Distichopora profunda.... The female ampullae are visible from the exterior in Sporadopora providentiae as slight swellings; they occur on both surfaces.... The species differs from Sporadopora dichotoma, which was obtained by the "Challenger' in $600 \mathrm{fms}$. off Rio de la Plata and which is the only other species of the genus known to science, in being more slender in structure, in having the greater number of the pores on the edges of the branches and arranged there in rows as in Distichopora, and in the absence of a cavity in the dactylozooids. In all these characters it shows affinities with the genus Distichopora and more particularly with the species $D$. profunda. It is of some interest that in the series beginning with $D$. violacea from shallow water, $D$. profunda from 120-150 fathoms, S. providentiae from the same depth, and S. dichotoma from 600 fathoms we have a series connecting the two genera."

The diameter of the pores is apparently $0.275 \mathrm{~mm}$, not $2.75 \mathrm{~mm}$ as noted in the description. When mentioning S. dichotoma as the only other species of 
the genus, the authors overlooked the description of Sporadopora marginata Tenison-Woods (1880), a fossil form from the Chatham Islands, rather summarily described. Tenison-Woods (1. c., p. 22) mentions that in S. marginata the pores have a raised margin, which constitutes a specific difference from $S$. dichotoma.

The figures of Sporadopora providentiae (Hrckson \& ENGLAND, 1909, Pl. 44 figs. 1-3) are very instructive. Fig. 2 of the cited paper shows a very regular row of gastropores from the side of a branch, surrounded by numerous dactylopores, which are somewhat loosely arranged over the surface; the condition of the pore-row is rather similar to that in the species of Distichopora. The other figured pore-row from the side of a branch (l. c., fig. 3) is much more irregular in that the gastropores do not occur in a straight line, but often in pairs next to each other; here the gastropores are surrounded by dactylopores which do not form longitudinal rows as in the other figure. The illustration of a branch in flabellar view (l.c., fig. 1) shows one long line of gastropores with surrounding dactylopores, the line being broken up into more or less separated cyclosystems. Besides this row of pores the figure shows a number of cyclosystems or very short rows of pores each occurring in a more or less isolated position on the surface.

As in the genus Sporadopora the gastropores and dactylopores are not arranged in cyclosystems, the pores being more or less regularly distributed over the surface of the corallum, the species providentiae does not present the characters of the genus. Apparently its affinities are more closely with the genus Distichopora, although it but rarely shows the typical characters of this genus, viz., pores consisting of a long row of gastropores flanked at each side by a row of dactylopores. For the present the correct name of the species seems to be Distichopora providentiae (Hickson \& ENGLAND).

Broch (1942, p. 27) also discussed the systematic position of Sporadopora providentiae Hickson \& England. He correctly concludes that the species does not belong in the genus Sporadopora, but gives as his opinion that it is identical with Distichopora irregularis Moseley. Here ВROCH is decidedly wrong; though the irregularly distributed pore-rows may be reminiscent of those of $D$. irregularis, the pore-rows themselves, with their widely scattered dactylopores, are quite unlike those of $D$. irregularis.

In the collection of the Manchester Museum there is a branch of Distichopora providentiae forming part of the type specimens, the locality Providence Island and the depth of 125 fathoms being indicated on the label. The branch (Pl. XV figs. 1-3) has a length of $26 \mathrm{~mm}$, the greatest breadth is $7 \mathrm{~mm}$, the thickness $3 \mathrm{~mm}$. The top of the branch shows the initial stage of division into three smaller branches. The surface of the coenosteum is rather coarsely granular, the granules often uniting into ridges forming a vermiculated structure. At one of the margins (Pl. XV figs. 1 and 2) the pores are arranged in rows as they occur in the other species of Distichopora, though not as regularly, the greater part of the gastropores being placed in a longitudinal row, with a few beside this row; the dactylopores are here grouped in a similar manner as usual in the genus. On the other margin (Pl. XV fig. 3) the pores are more irregularly distributed, the gastropores often occurring in a double row, the dactylopores being placed more or less around each singular gastropore. There are also numerous gastropores on the flabellar surfaces of the branch (Pl. XV fig. 2); here a tendency is to be observed for a linear arrangement, but on the whole the gastropores are rather widely scattered, while the dactylopores occur especially near the margins of the gastropores turning towards the base of the branch. The gastropores have a width of $0.25-0.33 \mathrm{~mm}$ (corresponding with the value of $0.275 \mathrm{~mm}$ as noted by Hickson \& ENGLAND). The opening of the gastropores is surrounded by a ridge of very little elevation. The slit-like small dactylopores have a wall of slightly more pronounced shape, often being higher on the side turned away from the gastropore, comparable to dactylopore projections as occurring in other species of Distichopora. The ampullae occur as slight swellings on both of the flabellar surfaces, they are rather deeply imbedded in the coenosteum, the part protruding over the surface having a diameter of only $0.5 \mathrm{~mm}$.

As remarked by Hickson \& ENGLAND, the species is more or less intermediate between the genera Distichopora and Sporadopora. Because of the tendency to form pore-rows similar to those of Distichopora the species should be placed in this genus, not in Sporadopora, which is characterized by having rather regularly scattered pores without a tendency to form cyclosystems.

\section{Geographical distribution}

The species is known from one locality only: off Providence Island, Western Indian Ocean (HIckson \& ENGLAND, 1909). 


\section{DISTICHOPORA BOREALIS FISHER, 1938}

Distichopora borealis Fisher, 1938, p. 543; Broch, 1942, p. 20; Boschma, 1953, p. 167; Boschma, 1957, p. 41.

Distichopora borealis forma japonica Broch, 1942, p. 20; Boschma, 1953, p. 167.

Distichopora sp. Eguchi, 1941, p. 1187.

Fisher (1938, p. 543) gives the following diagnosis of Distichopora borealis:

"Resembling D. sulcata Pourtalès but differing in having the marginal sulcus about twice as broad, larger gastropores, still more prominent dactylopore projections, and much more strongly corrugated ampullae; surface of coenosteum minutely spiculated rather than uneven and glossy."

From the description of the species the following parts may be here quoted:

"The colony branches mostly in one plane after the habit of typical Distichopora, but the branches are sometimes twisted or bent.... The gastropores lie close together in a well-defined sulcus, the raised, rough borders of which are occupied by a series of tilted, slitlike dactylopores (or dactylotomes) oriented transversely or oblique-transversely to long axis of branch. Each dactylopore forms the aperture of a gouge-shaped projecting lip, these projections becoming more and more prominent on the distal portion of branchlets. Here the margins of branchlets in profile are strongly dentate on account of the dactylopore processes. The dactylotomes are about half as long as width of gastropore (varying one-third to two-thirds). Gastropores (from 0.25 to $0.425 \mathrm{~mm}$ in width) are spaced usually one-half to their own diameter apart. The spacing of dactylotomes is irregular, but there is frequently one on either side opposite a septum between two gastropores; and one, or occasionally two, on either side, corresponding to the gastropore. There are no dactylostyles. The gastropores are very deep, slightly curved, and descend at a sharp angle to long axis of branch. Most of them end at center of branch, being separated from the series of opposite side only by a thin septum. The walls are beset by crowded short irregular spicules. The gastrostyle is very slender, usually long, and bristling with oblique sharp delicate spicules. The tip may be seen in a cleaned specimen by looking into the gastropore on the axis of its slant. Of sporadic occurrence on the front and back of larger stems are primitive cyclosystems consisting of a gastropore (sometimes 2 or 3 of unequal size) surrounded by upward of 10 dactylopore projections, with the dactylotomes turned toward the gastropore. These are usually on a slight convexity and are the first appearance of new branchlets .... The male ampullae are superficial, convex, with a ridged or corrugated surface. Diameter of ampulla about $0.5 \mathrm{~mm}$; dorsal wall thin; inner surface compact. The female ampullae are strongly convex, the surface traversed by prominent, interrupted or continuous, often sharp ridges or crests; or the surface is irregularly corrugated with occasional tubercles. Diameter of ampulla 1 to $1.25 \mathrm{~mm}$ or about twice that of the male ampullae; dorsal wall thicker than in male; inner surface fenestrated, often with irregular branched spicules, which anastomose into a wide-meshed spongy superstructure on the wall proper.... On the main branches the coenosteum is firmer, but the surface is not smooth to the touch, nor is there any of the slight gloss or "finish" that is found in D. sulcata. The lighter bands of the vermiculation apparent in plates 72 and 73 are due in part to the more porous structure of the surface layer and in part to microscopic spicules. These are more obvious (under high magnification) on the dactylotome projections and on the ridges traversing the ampullae. Color of dried specimens: Cartridge buff, warm buff, capucine buff; Ridgway's nomenclature."

Brock (1942, p. 20) identified specimens from Japan with Distichopora borealis Fisher; as they showed certain differences from the original description he established the forma japonica for these corals. The data of the locality, etc., are: "Dr. TH. Mortensen's Pacific Expedition 1914-16, June 11, 1914, Okinose, Sagami Sea, depth 60 fathoms, hard bottom, three specimens." The material consisted of a branch of a larger colony of 55 by $35 \mathrm{~mm}$, a colony of 34 by $47 \mathrm{~mm}$, and a colony with a height of 35 $\mathrm{mm}$, an erect stem with only one small branch near its upper end. The specimens are dichotomously or subdichotomously branched, a little irregularly flabellate; in one specimen the fan has a tendency to curve in to one (the anterior) side, so that the flabellum here is a little concave. The figured specimen (l. c., Pl. 2 fig. 5) is a rather spreadingly divided branch.

The description of the forma japonica runs as follows (Ввосн, 1942, pp. 20-22, references to figures omitted):

"Owing to the development of tooth-shaped dactylotomeprojections at the outer side of the dactylopores, the side contours of the branches are finely serrate. The branches are in transverse section anterior-posteriorly strongly compressed, and the pore-rows are strictly confined to the narrow, lateral sides. The surface of the coenosteum is roughened by small rounded warts or papillae which, however, in many places fuse into a vermiform reticulation. In the distal parts the branches are also longitudinally veined; but neither here nor elsewhere are pores observed under the lens. No microscopic spicules could be observed on the surface of the coenosteum. Specimens preserved in alcohol have a light yellow color, whereas dried specimens are almost white, in most parts with a distinct lilac hue.

The sulcus is astonishingly broad and distinctly limited. Owing to its great width (generally $0.7-0.8 \mathrm{~mm}$ ) one might at first sight judge it as rather shallow; but in comparison with most other species the sulcus must in the present species be designated as comparatively fairly deep. The gastropores attain at the opening a diameter of about $0.53 \mathrm{~mm}$, and are thus much narrower than the sulcus. The inner wall of the gastropore is furnished with scattered small, needle-shaped spicules which are especially numerous near the opening, and which here generally form a 
girdle of spines, evidently serving as a kind of sifting apparatus against smaller bodies (detritus) which are thus prevented from penetrating into the interior of the gastropore. - The gastrostyle is long and slender, needle-shaped, and armed with extraordinarily long, bristling spicules.

The dactylopores are usually separated from the sulcus by a low wall. Indications of a dactylotome have only been observed in a few cases. The bordering wall of the sulcus is slightly elevated at each side of the dactylopore as a distinct, though rather blunt point, and between these two denticles the outer wall of the dactylopore aperture is feebly carved out, so that the mouth part of the dactylopore in side view projects a little like a two-topped tooth on the contour of the branch.

No ampullae could be found in the present specimens."

Since Broch described the specimens from Japan some more corals from the same locality have come to light in the collections of the Copenhagen $\mathrm{Mu}$ seum, labelled: "Dr. Th. Mortensen's Pacific Expedition 1914-16, Okinose, Sagami Sea, depth $115 \mathrm{~m}$, hard bottom, 11. VI. 1914." These data correspond almost completely with those recorded by Вrосн for his specimens, the only difference being the depth (115 $\mathrm{m}$ for the present specimens, 60 fathoms or 110 $\mathrm{m}$ for the specimens examined by Ввосн); if they were not collected in the same haul the corals of the two lots came at least from approximately the same locality. The corals here dealt with consist of two fairly large colonies and some fragments, the measurements of the large colonies are 106 by $69 \mathrm{~mm}$ and 102 by $87 \mathrm{~mm}$. The specimens, which have a white colour, are in good condition though partly overgrown with sponges (removed by cleaning) and Bryozoa or other foreign organisms. Without any doubt they belong to the species Distichopora borealis Fisher.

The colony with a height of $106 \mathrm{~mm}$ (Pl. XVI fig. 1) consists of a main stem (thickness at the base about $6 \mathrm{~mm}$ ), which at half the length of the coral divides into three branches, two of which are spreading in one plane, the third (the middle branch) extending somewhat anteriorly from the two other branches. The tops of the two large side branches are somewhat curved, giving the anterior surface a more or less concave appearance. The larger branches are more or less cylindrical, the terminal branchlets are flattened antero-posteriorly. The pore-rows are confined to the lateral margins of the branches. There are many female ampullae, in longitudinal rows or in small groups, on the anterior as well as on the posterior surface of the colony. The colony with a height of $102 \mathrm{~mm}$ (Pl. XVI fig. 2) has a very short main stem with a thickness of about $8 \mathrm{~mm}$, which at the base divides into some branches that with their side branches form a rather regularly flabellar colony.
Here again the tops of the branches are somewhat curved leading to a rather concave anterior surface. Pore-rows and female ampullae occur in a manner similar to that in the other colony.

The shape of the two colonies bears a strong likeness to that of the type specimens of Distichopora borealis (cf. Fisher, 1938, PI. 71), though the branches grow less densely next to each other. On the other hand the colony figured by Brocr (1942, Pl. 2 fig. 5) has a much more spreading form of growth, the branches more widely diverging.

On the larger branches the surface of the coenosteum is finely granular; sometimes this granulation remains on the smaller branches (e.g., in the lower half of Pl. XV fig. 11); as a rule, however, the granules in the topmost parts of the branchlets have a tendency to form longitudinal ridges, which deviate sideways to end at the lateral margins (Pl. XVI figs. 3-6). In a fragment of a male colony from the type lot of $D$. borealis (PI. XV figs. 6-9) the greater part of the surface is finely granular, on the topmost parts only the granules being united to longitudinal ridges. The enlarged view of a male colony in Fisher (1938, Pl. 73) shows an altogether similar structure, finely granular on the larger part of the branches, sideways deviating longitudinal ridges on the tops of the branches. In the enlarged figure of a female colony in the same publication (1. c., Pl. 72) there are among the fine granules on the larger part of the branches several spinules, which towards the tops of the branches unite to often pronounced longitudinal ridges, leading to a somewhat coarser structure of the surface. Broch $(1942$, p. 21) describes for his specimens a structure of a similar kind, referring to rounded warts or papillae, which often fuse into a vermiform reticulation, and remarks that the distal parts of the branches are longitudinally veined; spinules were not to be found on the surface of his specimens. There are a few widely scattered spinules on the main branches of the large colonies from the Sagami Sea represented in figs. 1 and 2 of Pl. XVI.

In the specimens of Distichopora borealis from the Sagami Sea the lateral sulcus is not deeper than that of many specimens of $D$. violacea; it is, however, distinctly wider. The distance between the outer rims of two opposite dactylopores varies in $D$. violacea from 0.8 to $1.0 \mathrm{~mm}$ (exceptionally $0.6 \mathrm{~mm}$ ), in the specimens of $D$. borealis from the Sagami Sea this distance varies from 1.0 to $1.2 \mathrm{~mm}$ (Pl. XV figs. 4, 5 , and 10), while the same comparatively high values occur in the small fragment from the type lot (Pl. XV figs. 7 and 8). In Fisher's figure of the lateral margin of a branch (1938, Pl. 70 fig. 3) the distance between 
the outer margins of two opposite dactylopores is $1.5 \mathrm{~mm}$, even larger than in the specimens here dealt with; Broch (1942, text-fig. 5 b) has a drawing of a similar part of a Japanese specimen of $D$. borealis in which the distance here concerned is about $1.15 \mathrm{~mm}$, corresponding with the data of specimens from the same locality described in the present paper.

The gastropores of the specimens of Distichopora borealis from the Sagami Sea show a peculiarity not mentioned by Fisher (1938) and by Broch (1942). They form rather narrow tubes (width $0.25-0.35$ $\mathrm{mm}$ ), which become more or less funnel-shaped at their opening at the surface, the funnel-shaped part having a diameter of $0.4-0.8 \mathrm{~mm}$. Sometimes the funnel-shaped part becomes very distinct because of its margin being elevated as a small ridge (Pl. XV fig. 5); generally the funnel-shaped part is less clearly marked (Pl. XV figs. 4 and 10). The funnel-shaped part is also present in the fragment from the type lot of D. borealis ( $\mathrm{Pl}$. XV figs. 7 and 8), though not as distinct as in some branches of the specimens from the Sagami Sea. Fisher (1938, p. 543) gives as width of the gastropores 0.25 to $0.425 \mathrm{~mm}$; ВRосн (1942, p. 21) remarks that the gastropores attain at the opening a diameter of about $0.53 \mathrm{~mm}$; undoubtedly these measurements were at least partly based on the diameter of the funnel-shaped distal parts of the gastropores.

Part of a median section of a branch (easily to be obtained by splitting the branch into two halves with the point of a knife) is shown in text-fig. $5 \mathrm{a}$. The figure represents two gastropores, the one with a rather young gastrostyle, the other with the top of a larger gastrostyle. The inner walls of the gastropores are rather closely beset with spinules, especially in the region of the tops of the gastrostyles. Text-fig. $5 \mathrm{~b}$ and $\mathrm{c}$ represent the top of a gastrostyle and a more proximal part of another. In their spinulation the gastrostyles do not differ noticeably from those of other species of Distichopora, though the spines are somewhat larger than generally. FisHer (1938, p. 543) when describing the gastropores of $D$. borealis remarks: "The walls are beset with crowded short irregular spicules. The gastrostyle is very slender, usually long, and bristling with oblique sharp delicate spicules." Brосн $(1942$, p. 21) in his description of $D$. borealis forma japonica notes: "The inner wall of the gastropore is furnished with scattered small, needle-shaped spicules which are especially numerous near the opening, and which here generally form a girdle of spines... The gastrostyle is long and slender, needle-shaped, and armed with extraordinarily long, bristling spicules." The data presented here among each other do not show striking differences, being apparently based on slight individual variation.

In the specimens from the Sagami Sea the dactylopores sometimes have a dactylotome connecting their opening with the region of the gastropore; more

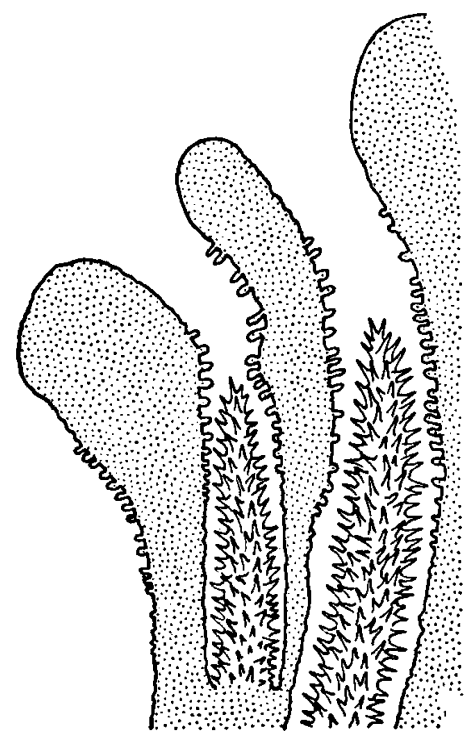

a

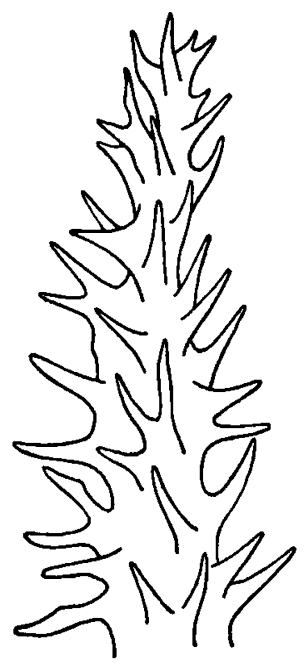

b

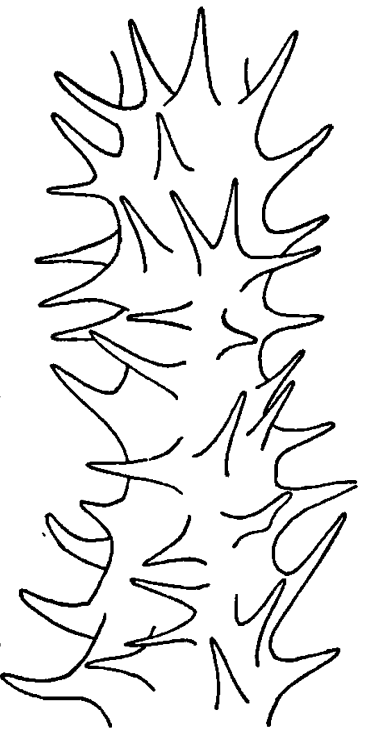

c

Fig. 5. Distichopora borealis Fisher, specimen from the Sagami Sea. a, longitudinal section of two gastropores with the gastrostyles; $b, c$, parts of gastrostyles. $a, \times 45 ; b, c$, $\times 190$. 
often, however, each dactylopore is completely surrounded by an elevated rim; this last condition is the rule in the parts shown in figs. 4, 5, and 10 of Pl. XV. In the fragment from the type lot of $D$. borealis (Pl. XV figs. 7 and 8 ) the dactylopores as a rule also show a complete elevated rim, while in the figure of FISHER (1938, Pl. 70 fig. 3 ) the outer margin of the dactylopores appears to be much higher than the inner margin, the dactylopores having more or less pronounced dactylotomes. Ввосн (1942, fig. 5 b) has a figure in which the inner margin of several dactylopores has united into a ridge, a situation described as follows (1. c., p. 22): "The dactylopores are usually separated from the sulcus by a low wall. Indications of a dactylotome have only been observed in a few cases."

The prominent dactylotome projections give the margins of the branches a more or less serrate appearance in flabellar view, this being especially pronounced in the younger branchlets (Pl. XV fig. 11, Pl. XVI fig. 3). When the young branchlets have a great number of ridges, these also end into spines at the margins of the branchlets, the serrate appearance of these branchlets is then partly due to the dactylotome projections, partly to the spinous ends of the ridges (PI. XVI figs. 4-6). In the fragment from the type lot of $D$. borealis (Pl. XV figs. 6 and 8 ) the serrated appearance of the margins is chiefly caused by the dactylotome projections. Fisher (1938, p. 543) also remarks that in $D$. borealis the margins of branchlets in profile are strongly dentate on account of the dactylopore processes.

The two large colonies and many of the fragments of $D$. borealis from the Sagami Sea bear numerous female ampullae, arranged in longitudinal rows or in small groups on the flabellar surfaces of the branches; the frequency of occurrence appears to be almost the same on the anterior and the posterior surfaces. The ampullae are hemispherical bodies with a diameter of 1.0-1.35 mm (Pl. XV fig. 10, Pl. XVI figs. 3-6); they are of somewhat indefinite shape and seem to be overgrown with a layer of calcareous matter. Faintly they show spines and ridges as described by Fisher (1938) for the type specimens of $D$. borealis, but they are not as sharply delimited from the rest of the surface as in Fisher's specimens (1. c., Pls. 71 and 72). One of the figures (Pl. XVI fig. 4) shows a broken ampulla (the topmost one of the row) clearly proving that some calcareous matter has been deposited on the lower floor, giving an additional argument for the opinion that the indistinct shape of the unbroken ampullae is caused by a layer of calcareous matter. The ampullae in the lower half of figs. 4 and 5 of PI. XVI have a different aspect from those in the upper half of the same figures by forming closely united groups in which the individual ampullae rise very little over the surface, the margins between the ampullae being indicated by pits in a similar manner as in the specimens of $D$. coccinea of Pl. X figs. 2 and 3, while the surface of the ampullae in these parts has a somewhat rougher granulation. It seems not too far-fetched to suppose that the more or less indefinite state of the ampullae in the parts here dealt with again is a sign of degeneration owing to their being covered with a layer of calcareous matter. The size of the ampullae of the specimens from the Sagami Sea $(1.0-1.35 \mathrm{~mm})$ differs but little from the measurements as given by FisHER (1938) for the ampullae of specimens from the Aleutian Islands $(1.0-1.25 \mathrm{~mm})$. BROCH's specimens from the Sagami Sea did not bear ampullae.

The shape of the colonies from the Sagami Sea and the structure of their finer parts closely correspond with the type specimens of Distichopora borealis as described by Fisher (1938); there does not seem to be a well-founded reason to distinguish the specimens from the Sagami Sea as a separate forma japonica as established by Вносн (1942).

Eguch (1941, p. 1187) mentioned a Distichopora spec. obtained at two stations of the Sititô-maru (Sta. 2, $33^{\circ} 57^{\prime} 36^{\prime \prime} \mathrm{N}, 138^{\circ} 50^{\prime} 48^{\prime \prime} \mathrm{E}$, depth $80 \mathrm{~m}$; Sta. $8,34^{\circ} 08^{\prime} 00^{\prime \prime} \mathrm{N}, 138^{\circ} 52^{\prime} \mathrm{E}$, depth $126 \mathrm{~m}$ ). The here mentioned localities are at a comparatively short distance from the Sagami Sea, and the depth is of the same order as that of the specimens dealt with in the present paper; accordingly it seems safe to conclude that the specimens mentioned by EGUCH belonged to the species Distichopora borealis Fisher.

\section{Specimens examined}

Copenhagen Museum: Dr. Th. Mortensen's Pacific Expedition 1914-16, Okinose, Sagami Sea, depth 115 $\mathrm{m}$, hard bottom, 11. VI. 1914, 2 colonies and some fragments, measurements of the large colonies 106 by $69 \mathrm{~mm}$ and 102 by $87 \mathrm{~mm}$. See description on previous pages (Pl. XV figs. 4, 5, 10, and 11; Pl. XVI).

United States National Museum: Distichopora borealis Fisher, "Albatross", Sta. 3480, Amukta Pass, Aleutian Islands, $52^{\circ} 06^{\prime} \mathrm{N}, 171^{\circ} 45^{\prime} \mathrm{W}, 283$ fathoms; fragment from type lot, identified by W. K. Fisher, length $15 \mathrm{~mm}$ (PI. XV figs. 6-9).

\section{Geographical distribution}

Aleutian Islands (Fisher, 1938; present paper); Sagami Bay, Japan (Broch, 1942; present paper); Pacific Ocean near Sagami Bay (EGuchr, 1941). 


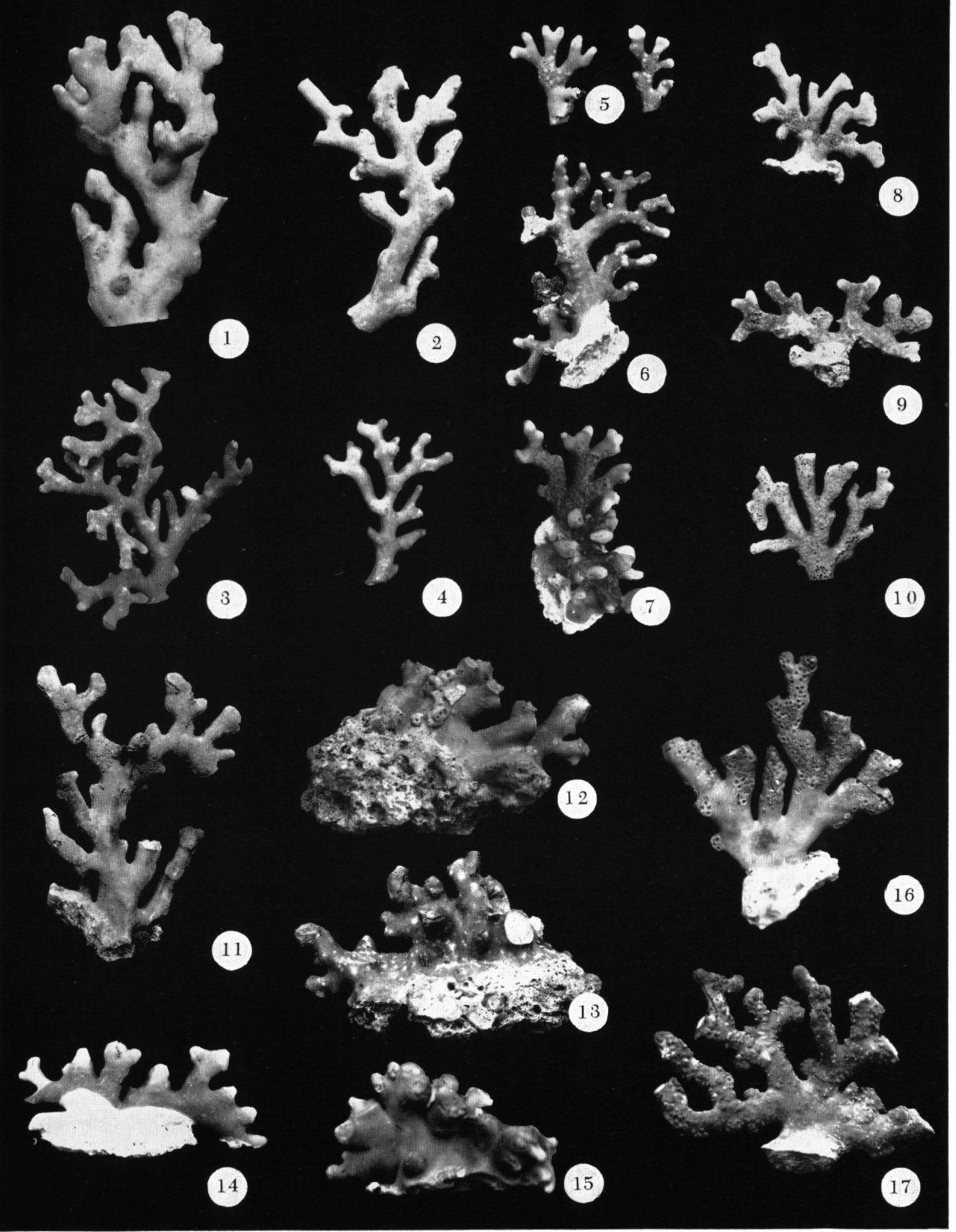

PLATE I

Fig. 1. D. nitida, Marshall Islands, Etheridge leg.; Australian Museum. Fig. 2. D. violacea, Kangitiki River, New Zealand; Manchester Museum. Figs. 3 and 4. D. violacea, two specimens, Gilbert Islands; Australian Museum. Fig. 5. D. violacea, two specimens, Snellius Expedition, Bone Tamboeng near Macassar; Leiden Museum. Fig. 6. D. violacea, Snellius Expedition, Binongko; Leiden Museum. Fig. 7. D. violacea, Gulf of Suez, Gohar leg.; Leiden Museum. Figs. 8-10. D. violacea, three specimens, Red Sea, Ruyssenaers leg.; Leiden Museum. Fig. 11. D. violacea, Timor, PéroN \& Lesueur leg., 1801; Paris Museum. Figs. 12 and 13. D. violacea, Réunion, probably the type of $D$. fulvacea Michelin, posterior and anterior view; Paris Museum. Figs. 14 and 15. D. violacea, two specimens, Tahiti, Ranson leg.; Paris Museum.

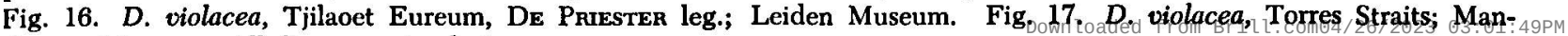
chester Museum. All figures natural size. 


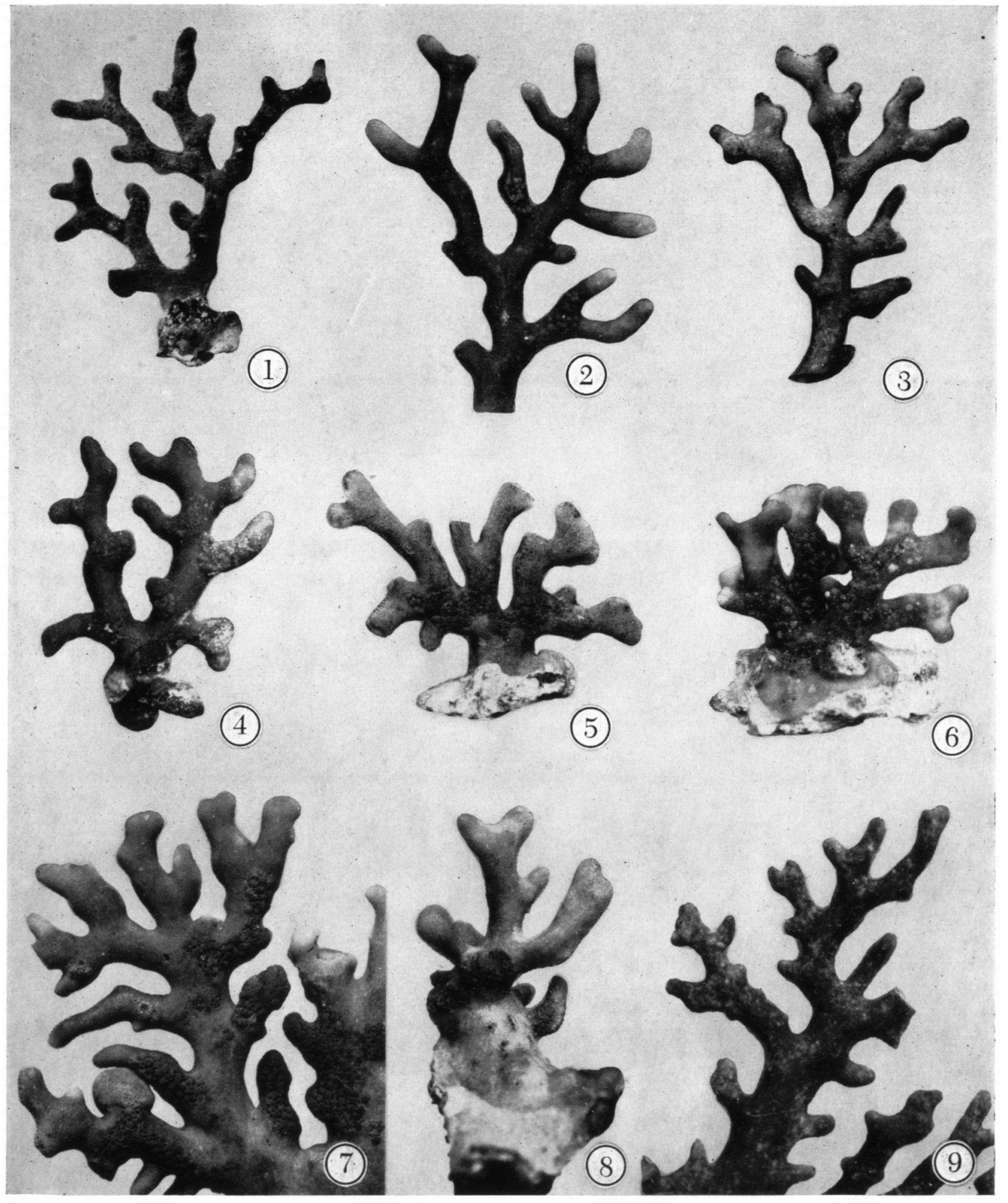

PLATE II

Fig. 1. D. gracilis, type specimen of D. milesii Quelch; British Museum. Fig. 2. D. gracilis, Passe du Hao, Tuamotu Islands, Seurat leg.; Paris Museum. Fig. 3. D. violacea, Gilbert Islands; Australian Museum. Fig. 4. D. violacea, Storm Island, Fiji Islands, Boscrma leg.; Leiden Museum. Fig. 5. D. violacea, Red. Sea, Ruyssenaers leg.; Leiden Museum. Fig. 6. D. violacea, Gulf of Suez, Gohar leg.; Leiden Museum. Fig. 7. D. violacea, Red Sea; Paris Museum. Fig. 8. D. violacea, Marshall Islands (?); Australian Museum. Fig. 9. D. coccinea, Marshall Islands (?); Australian Museum. All figures twice natural size. 


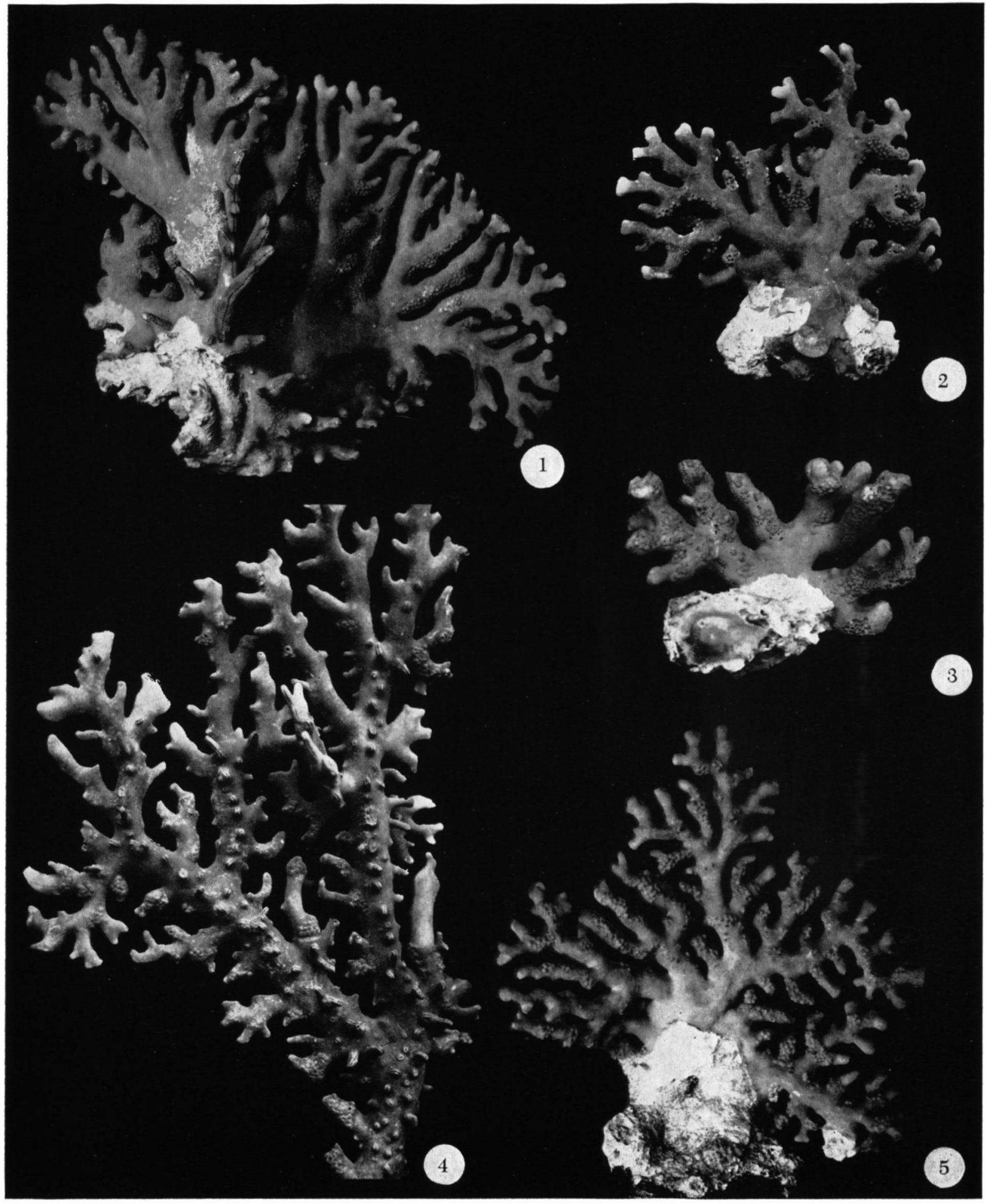

PLATE III

Fig. 1. D. violacea forma tenella, Red Sea, large colony; Paris Museum. Fig. 2. D. violacea forma tenella, Red Sea, colony of ordinary size; Paris Museum. Fig. 3. D. violacea forma violacea s. s., Red Sea; Paris Museum. Fig. 4. D. coccinea, "Japan"; Amsterdam Museum. Fig. 5. D. gracilis, Gambier Islands, Seurat leg.; Paris Museum. All figures natural size. 

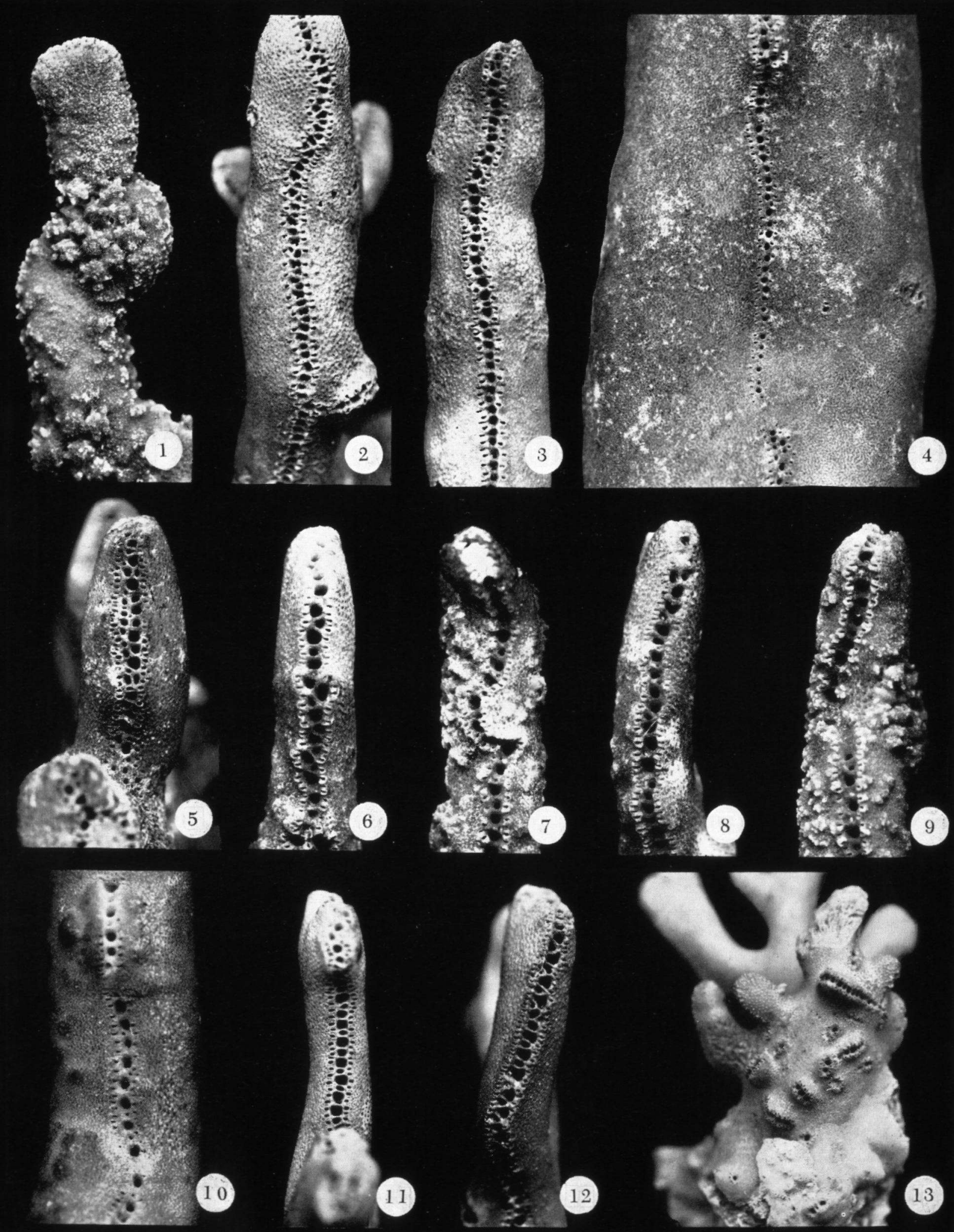

PLATE IV

Fig. 1. D. violacea, Torres Straits, top of a branch in flabellar view, with spiny, stellate female ampullae; Manchester Museum. Figs. 2 and 3. D. violacea, Timor, Péron \& Lesceur leg., 1801, pore-rows in the tops of branches; Paris Museum. Fig. 4. "D. livida", Fiji Islands, lateral view of the main stem (diameter about $12 \mathrm{~mm}$ ), showing pores of small size; Brussels Museum. Fig. 5. "D. livida", Fiji Islands, top of a branch with pores of large size; Brussels Museum. Figs. 6-9. D. violacea, Torres Straits, tops of branches in lateral view, showing pore-rows and (in 7 and 9 ) female ampullae; Manchester Museum. Fig. 10. D. violacea, Rangitiki River, New Zealand, lateral view of a branch of a thickness of about 5 mm; Manchester Museum. Fig. 11. D. violacea, Red Sea, RuYssensers leg., lateral view of the top of a branch; Leiden Museum. Fig. 12. D. violacea, Marshall Islands (?), lateral view of the top of a branch; Australian Museum. Fig. 13.

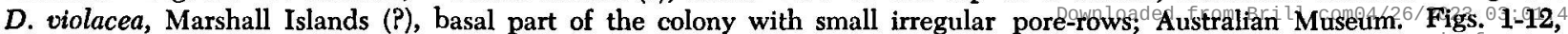
$\times 5 ; 13, \times 3$. 

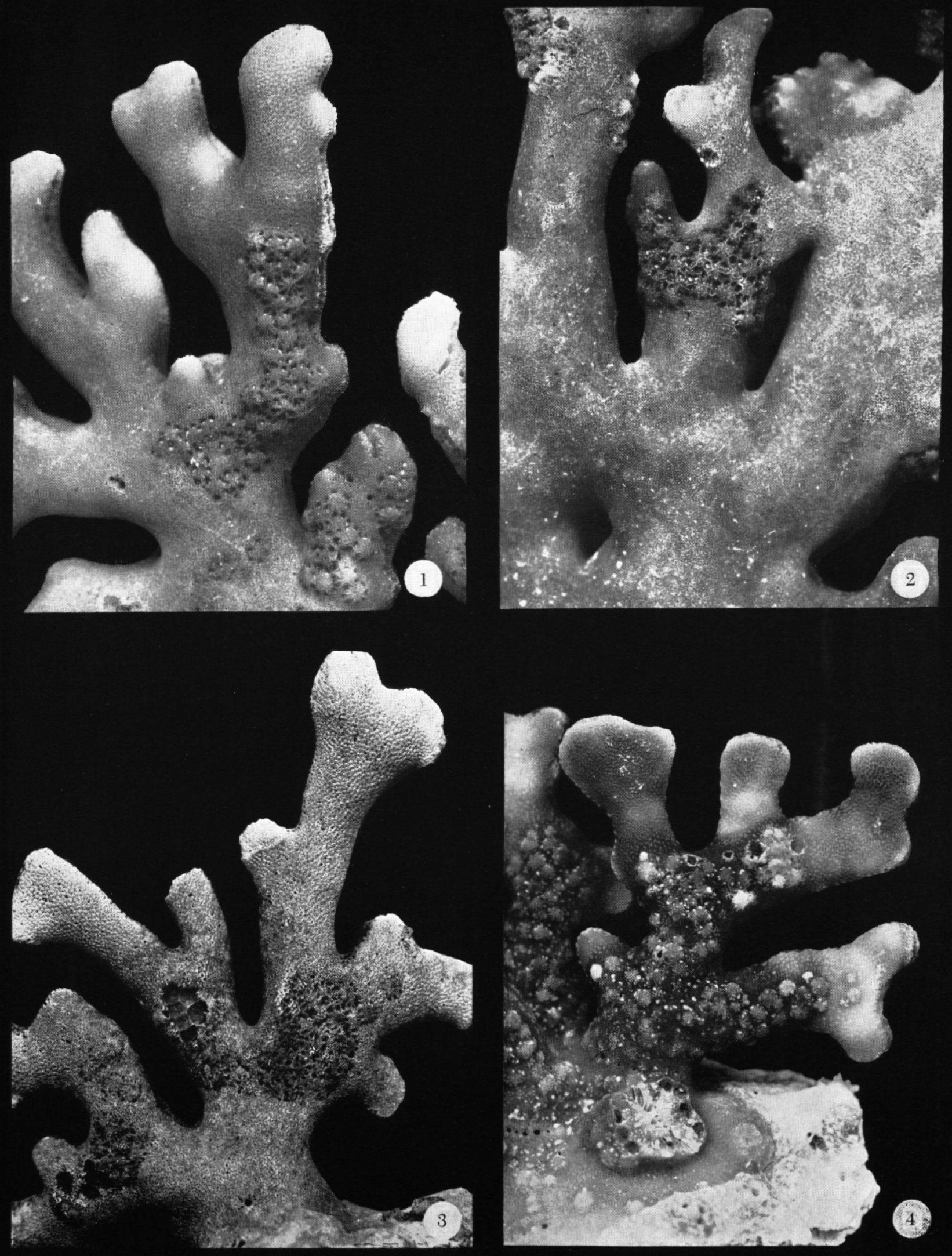

PLATE V

Fig. 1. D. violacea, Red Sea, female ampullae with a comparatively smooth surface; Paris Museum. Fig. 2. D. violacea, Red Sea, female ampullae with rather coarse granulation and stellate appearance; Paris Museum. Fig. 3. D. violacea, Red Sea, Ruyssenaers leg., female ampullae of stellate appearance, surface of coenosteum very rough; Leiden Museum. Fig. 4. D. violacea, Gulf of Suez, Gohap leg., female ampullae of flat shape and with fine granulation; Leiden Museum. All figures $\times 5$. 


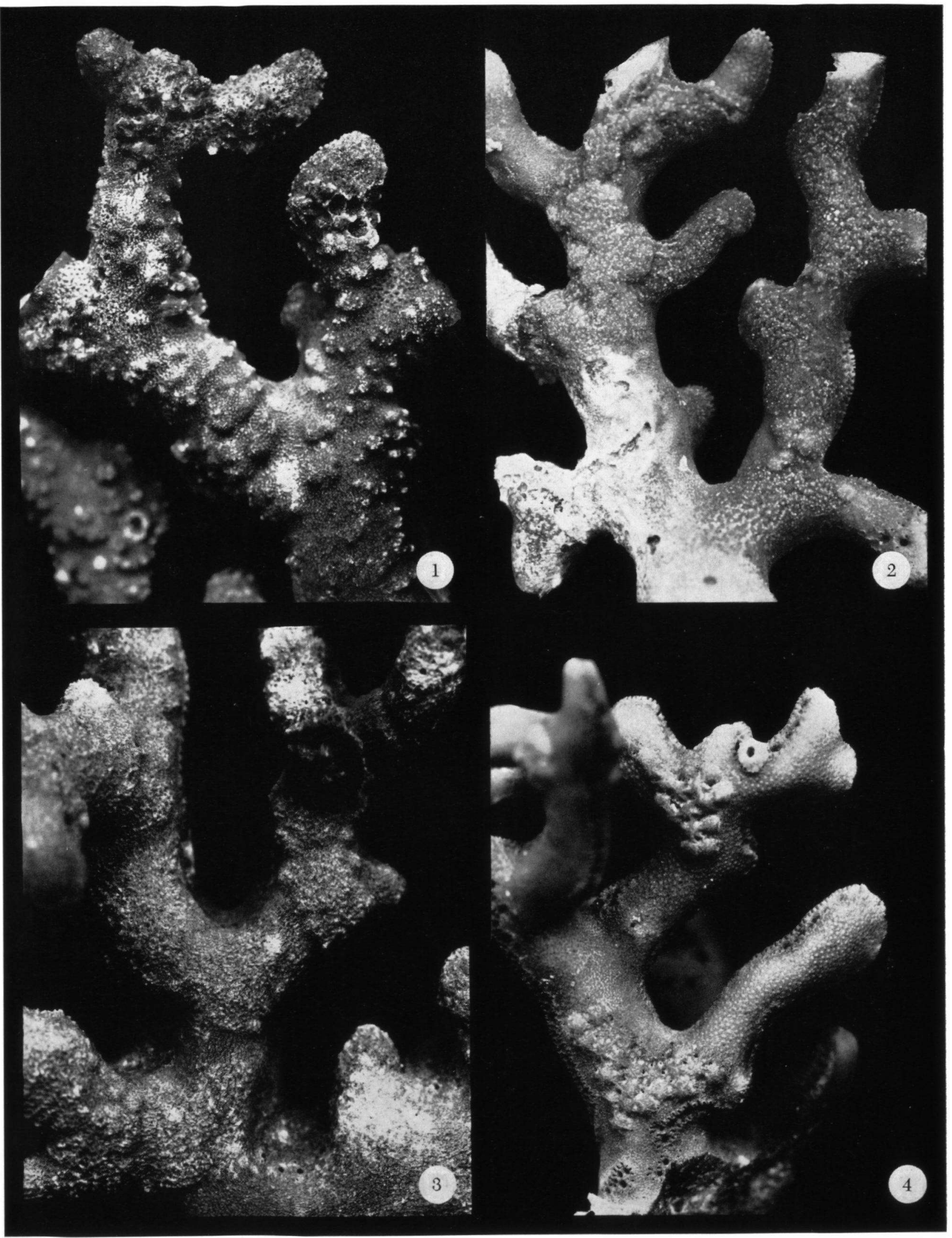

PLATE VI

Fig. 1. D. violacea, Torres Straits, female ampullae with spines and thick ridges, often stellate; Manchester Museum. Fig. 2. D. violacea, Storm Island, Fiji Islands, Boschмa leg., male ampullae; Leiden Museum. Fig. 3. "D. livida", Fiji Islands, female ampullae covered with a calcareous layer, surface of coenosteum rough; Brussels Museum. Fig. 4. D. violacea, Suva reef, Fiji Islands, Boschma leg., female ampullae of rather stellate shape, some irregular pore-rows on flabellar surface; Leiden Museum. All figures $\times 5$. 


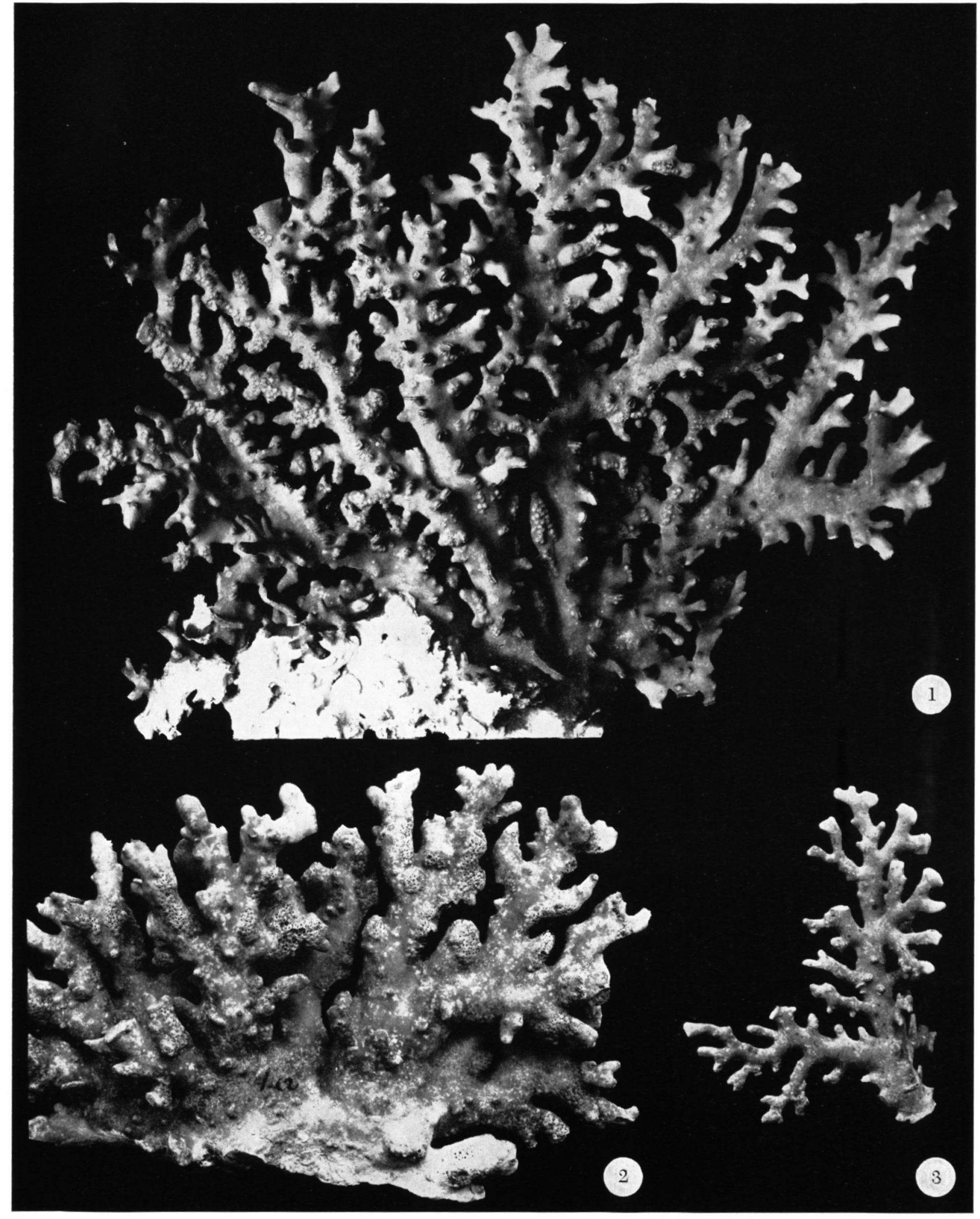

PLATE VII

Fig. 1. D. coccinea, labelled D. miniacea Michelin, Hawaiian Islands, anterior view; Paris Museum. Fig. 2. D. coccinea, Gilbert Islands, from WARD, anterior view; Leiden Museum. Fig. 3. D. coccinea, Marshall Islands (?), anterior view; Australian Museum. All figures natural size. 


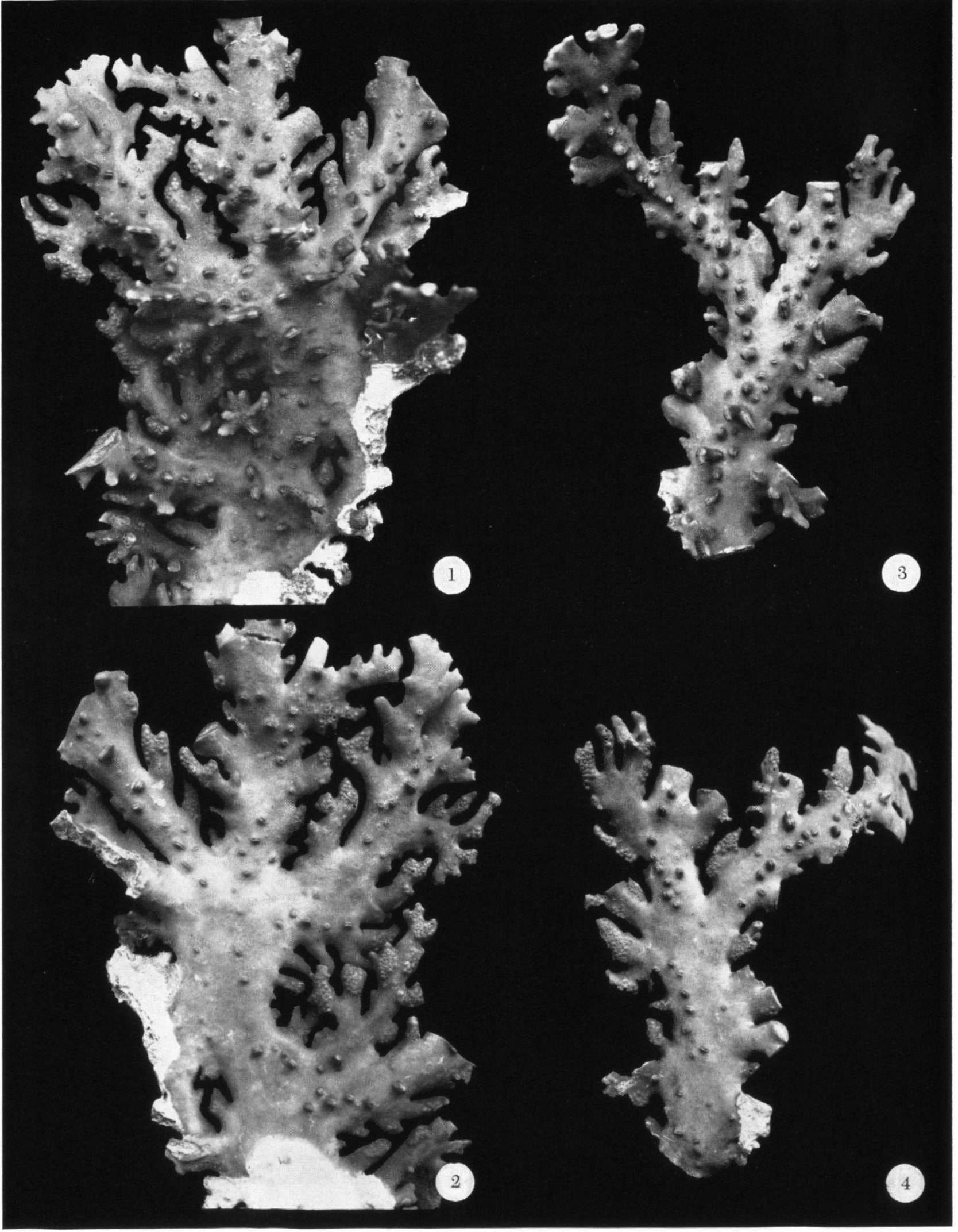

PLATE VIII

D. coccinea, type specimen of D. purpurea Lütken MS.; Copenhagen Museum. Fig. 1. Anterior view of the larger branch Fig. 2. Posterior view of the larger branch. Fig. 3. Anterior view of the smaller branch. Fig. 4. Posterior view of the smalle1 branch. All figures natural size. 


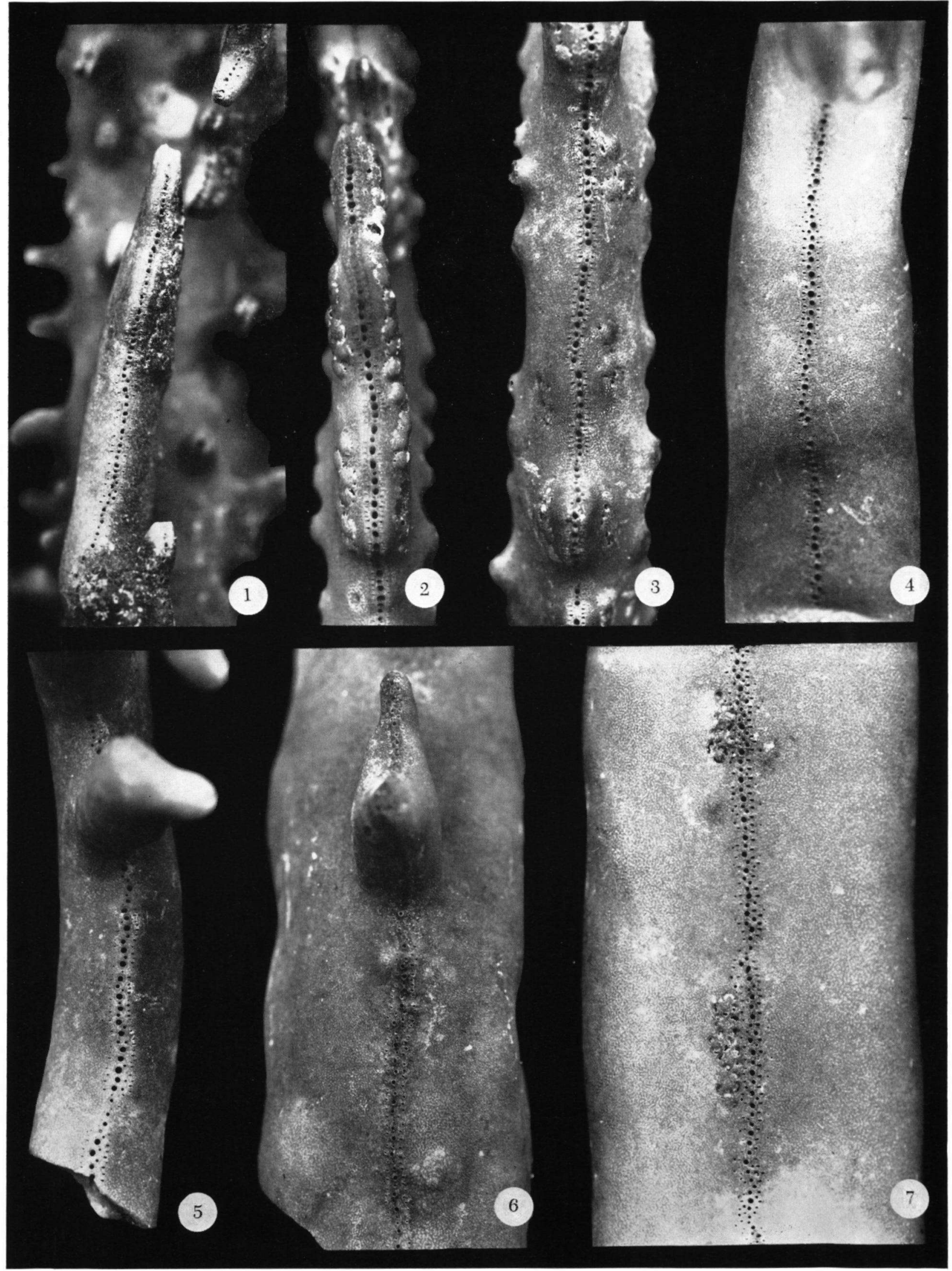

\section{PLATE IX}

Fig. 1. D. coccinea, "Japan", lateral view of a side branchlet with comparatively small pores; Amsterdam Museum. Figs. 2 and 3. D. coccinea, labelled D. miniacea Michelin, lateral view of branches with comparatively large pores and some female ampullae in rows next to the pore-rows; Paris Museum. Fig. 4. D. nitida, Marshall Islands, lateral view of a branch; Manchester Museum. Figs. 5 and 6. D. nitida, "Südsee", from Platow, Lateral view of two branches, the one with rather large pores, the other with very small pores; Amsterdam Museum. Fig. 7. D. nitida, Gilbert Islands, Serrurien don., formerly identified with $D$. brasseyae, hateral view of a thick branch (diameter about 12 mm), showing a pore-row 2 and $a$ few $9 \mathrm{PM}$ female ampullae; Leiden Museum. All figures $\times 5$. 

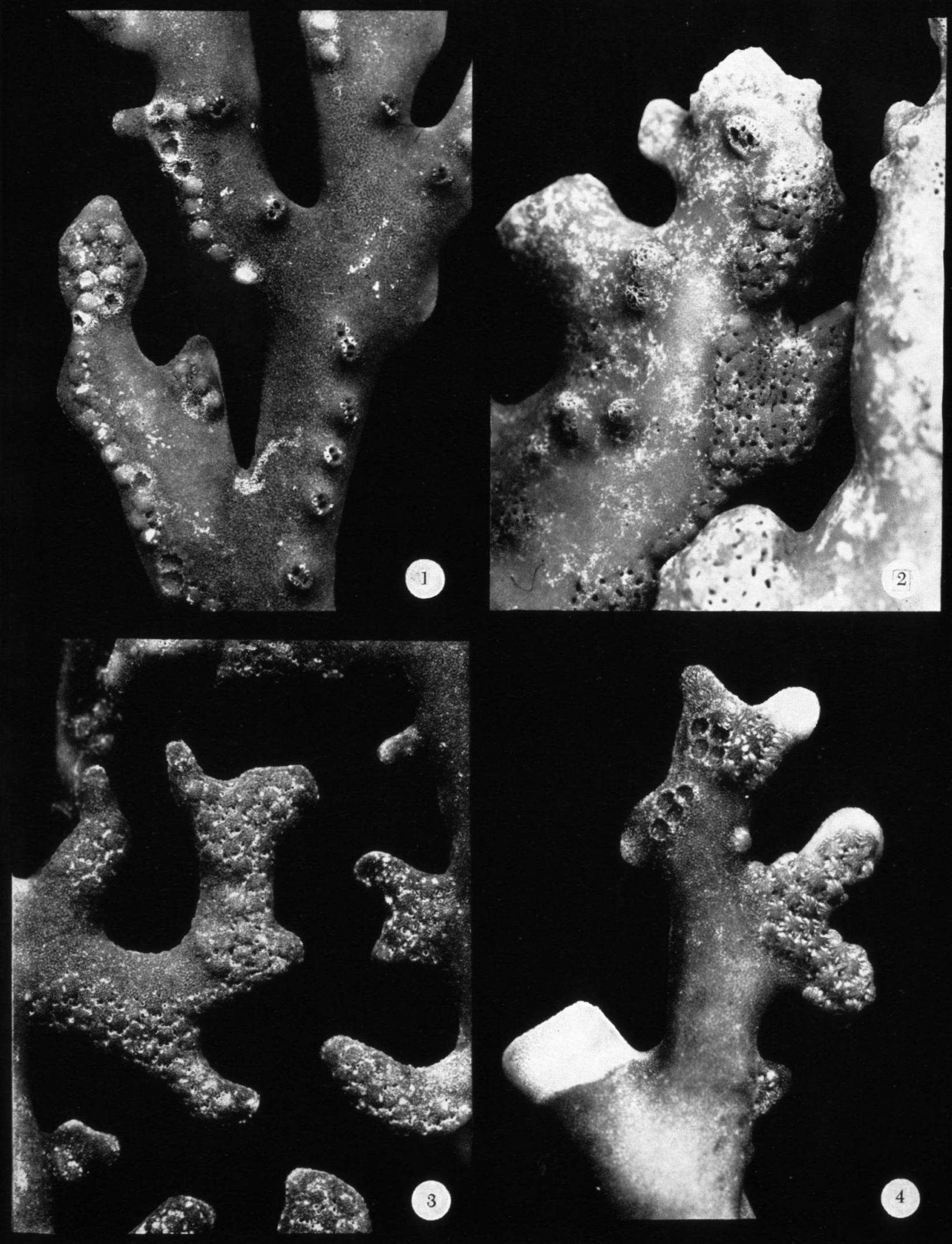

\section{PLATE X}

Fig. 1. D. coccinea, labelled D. miniacea Michelin, anterior view of a branch with small tubercles with short pore-rows, and rows or small groups of female ampullae; Paris Museum. Fig. 2. D. coccinea, Gilbert Islands, from WARD, anterior view of a branch with small tubercles with short pore-rows, and groups of female ampullae; Leiden Museum. Fig. 3. D. coccinea, "Japan", groups of female ampullae with rather coarse granulation; Amsterdam Museum. Fig. 4. D. nitida, labelled "D. sulcata, West Indies", groups of female ampullae with ridges giving them a slightly stellate shape; Manchester Museum. All figures $\times 5$. 


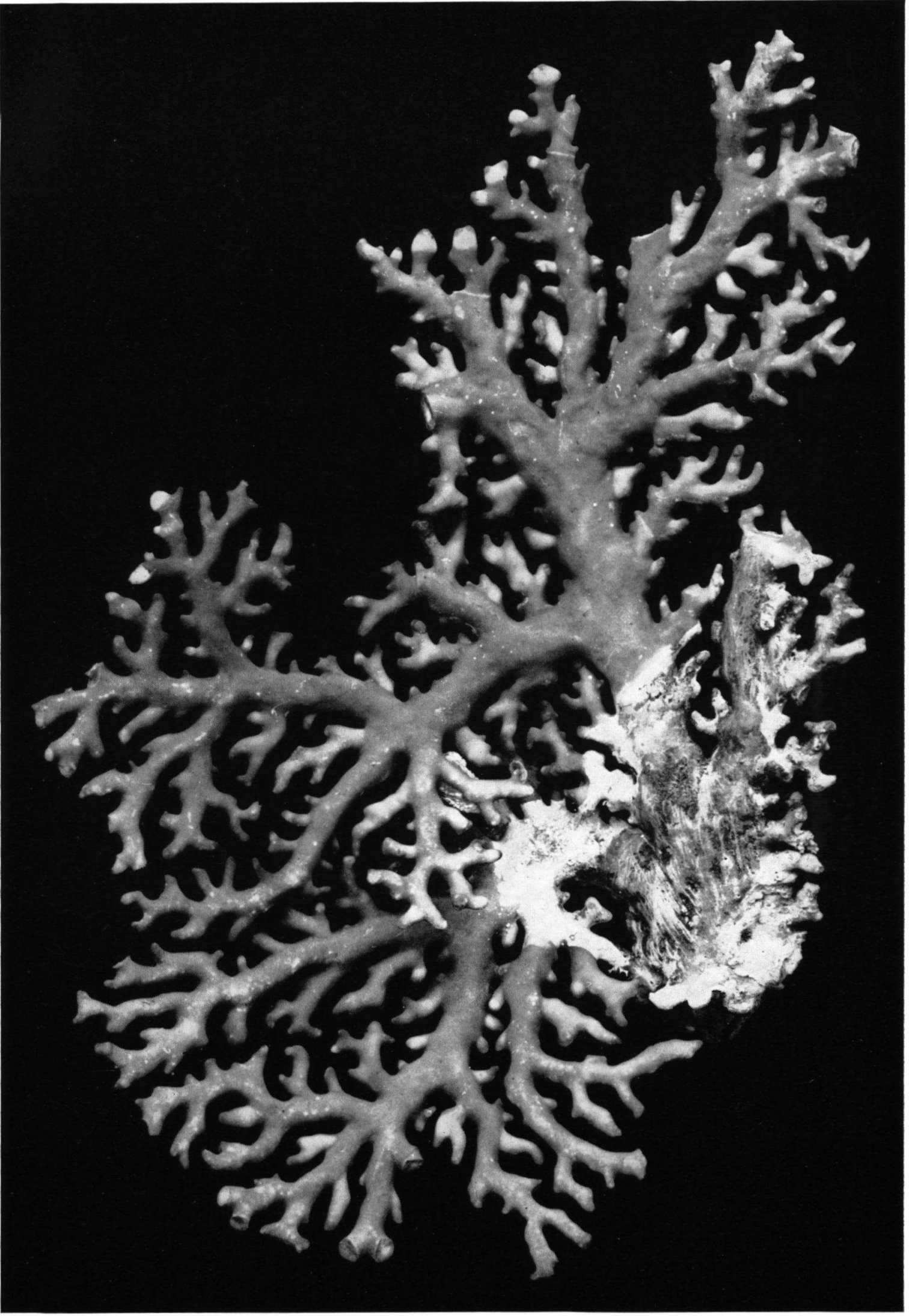

PLATE XI

D. nitida, "Südsee", from Platow; Amsterdam Museum. Natural size. 


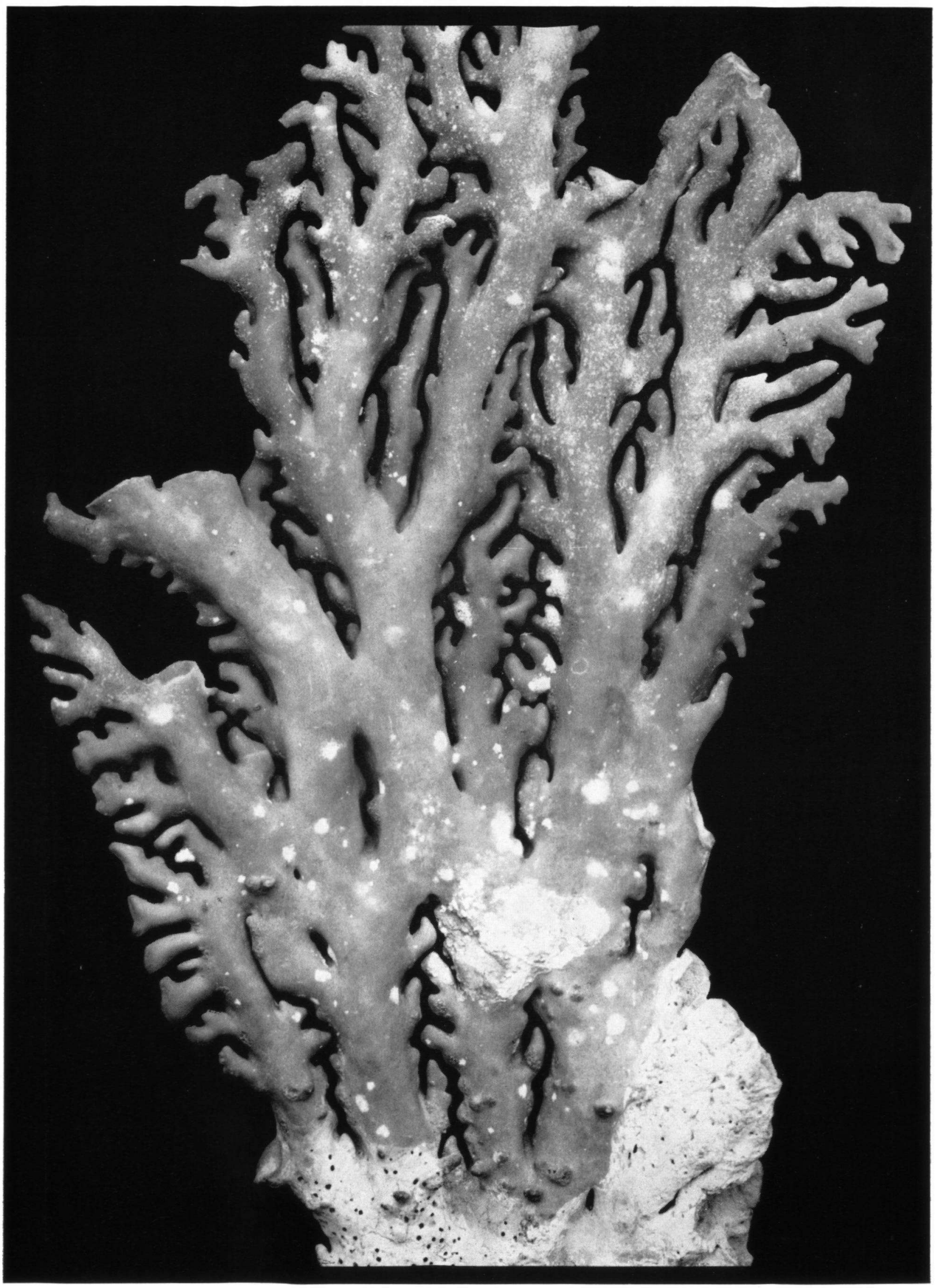

PLATE XII

D. nitida, Gilbert Islands, SerrunIER don., formerly identified with $D$. brasseyae; Leiden Museum. Natural size. 


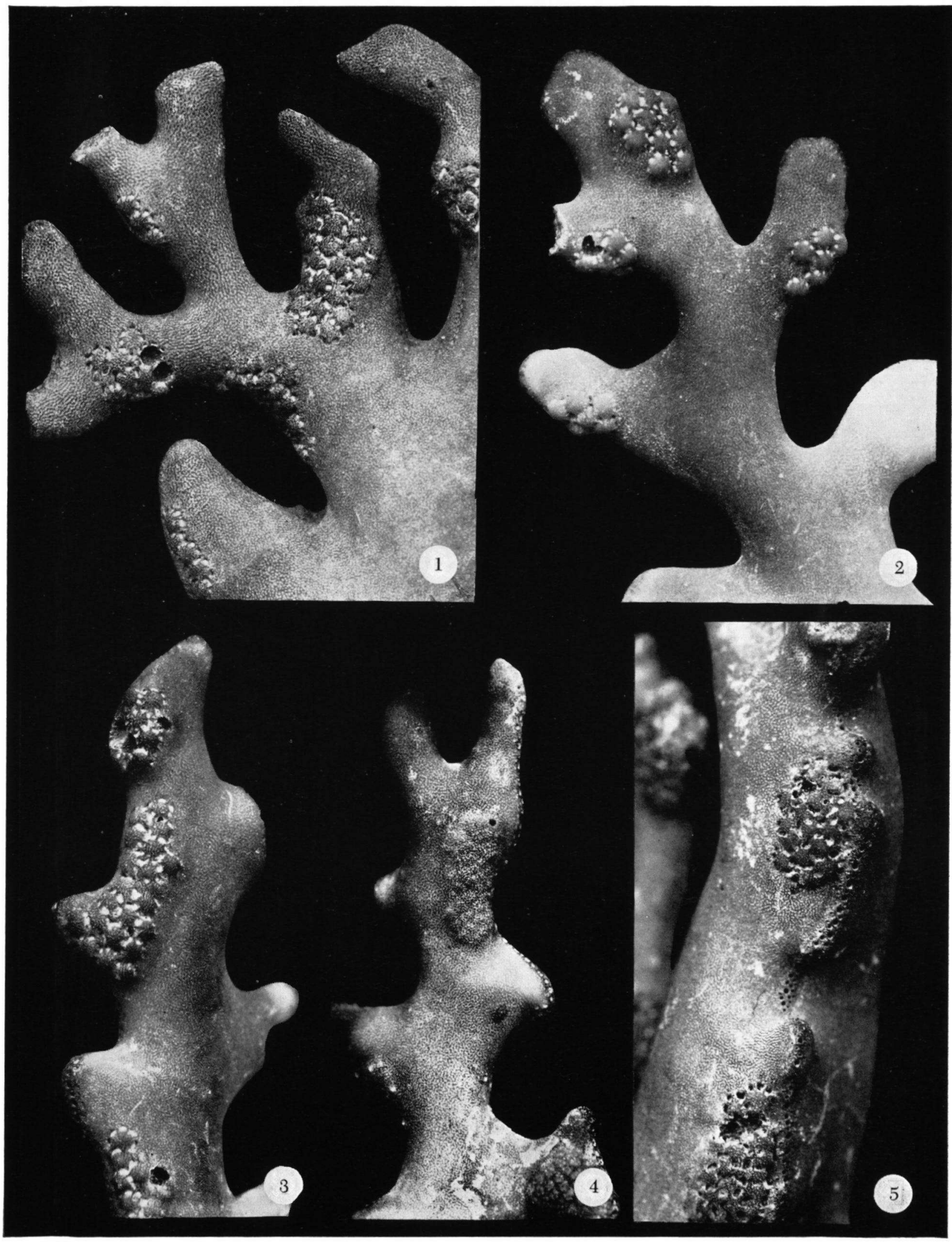

PLATE XIII

Fig. 1. D. nitida, Hawaiian Islands, BaLlieu don., branch with female ampullae, surface of coenosteum and of ampullae rather coarse; Paris Museum. Figs. 2 and 3. D. nitida, labelled $D$. coccinea, Marshall Islands, branches with female ampullae, surface of coenosteum and of ampullae rather finely granulated; Manchester Museum. Fig. 4. D. nitida, "Südsee", from Platow, branchlet with male ampullae; Amsterdam Museum. Fig. 5. D. nitida, Gilbert Islands, SERruruen don., formerly identified with $D$. brasseyae, lateral view of a branch with female ampullae and pore-rows, some of these on ridges forming incipient side branchlets; Leiden Museum. All figures $\times 5$. 

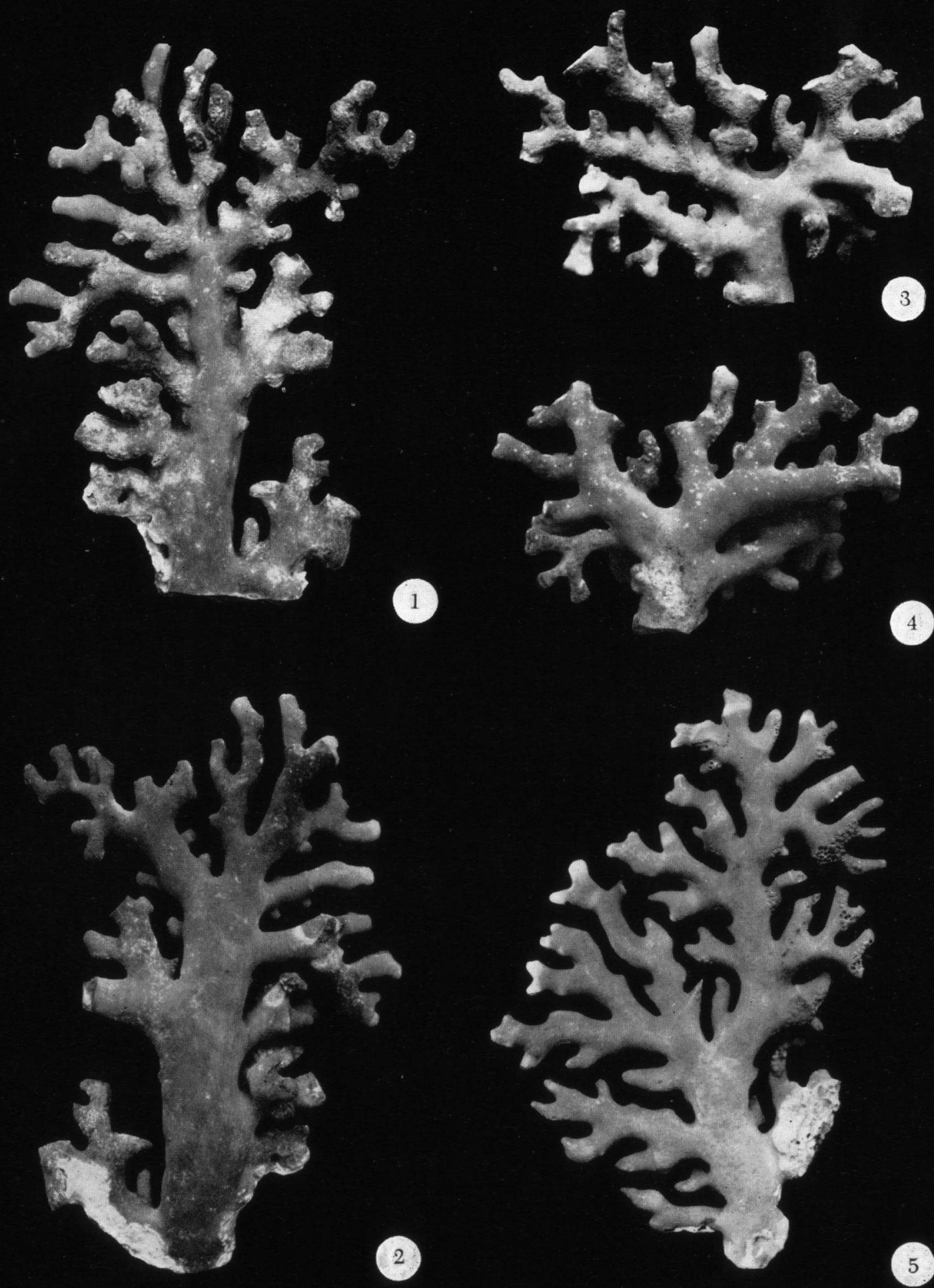

\section{PLATE XIV}

Fig. 1. "D. livida", Fiji Islands, anterior view; Brussels Museum. Fig. 2. "D. livida", Fiji Islands, posterior view; Brussels Museum. Fig. 3. D. violacea, labelled D. rosea, Bougainville Strait, New Hebrides, BraIthwarte leg., anterior view; Australian Museum. Fig. 4. D. violacea, labelled D. rosea, Bougainville Strait, New Hebrides, Brarthwarre leg., posterior view; Australian Museum. Fig. 5. D. nitida, locality unknown, posterior view; Paris Museum. All figures natural size. 


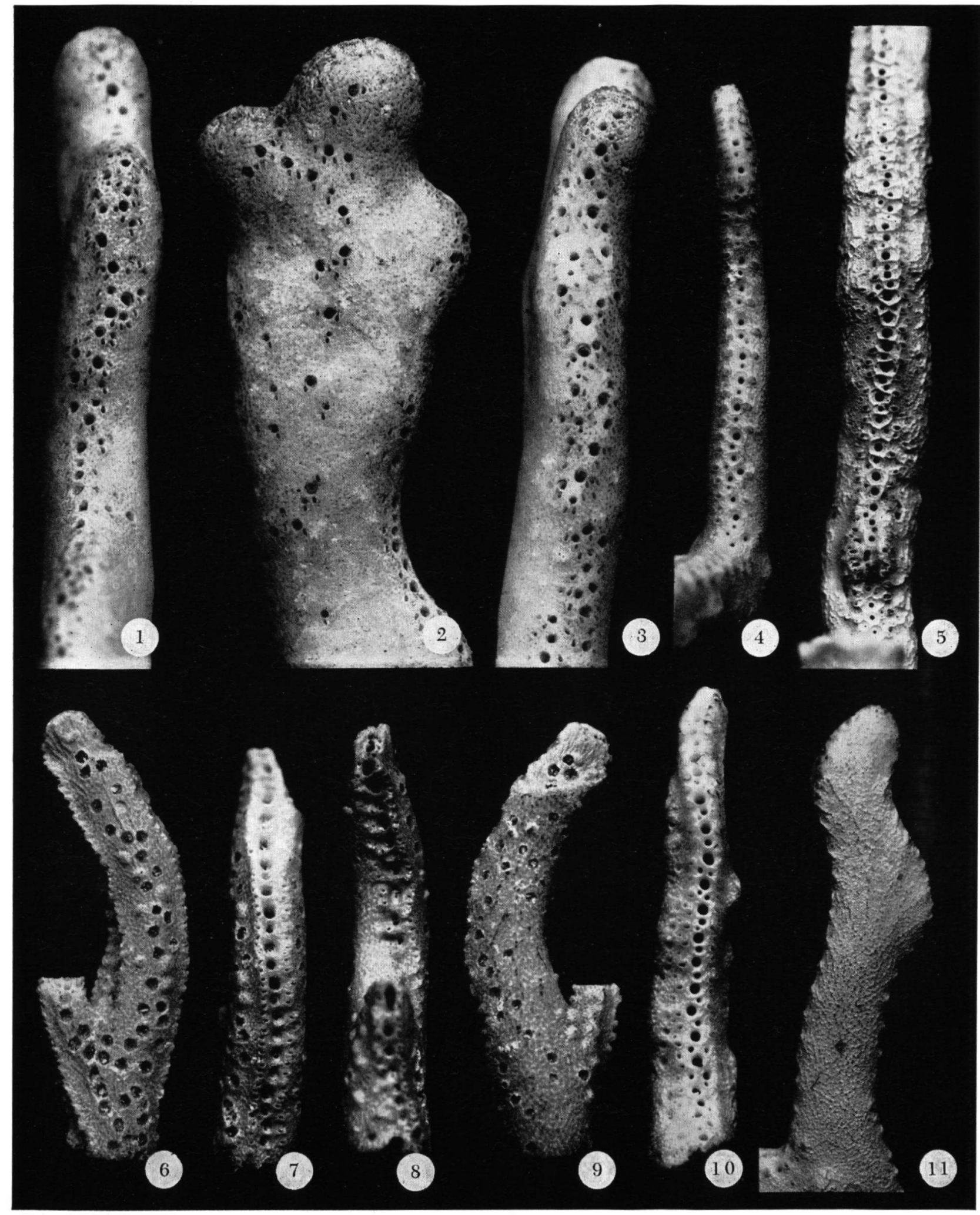

PLATE XV

Figs. 1-3. D. providentiae, off Providence Island, Western Indian Ocean, top of a branch in lateral view, in flabellar view, and in the other lateral view; Manchester Museum. Figs. 4 and 5. D. borealis, Okinose, Sagami Sea, branches in lateral view; Copenhagen Museum. Figs. 6-9. D. borealis, Amukta Pass, Aleutian Islands, top of branchlet of male colony from the type lot, from four sides; United States National Museum. Fig. 10. D. borealis, Okinose, Sagami Sea, top of a branch in lateral view; Copenhagen Museum. Fig. 11. D. borealis, Okinose, Sagami Sea, top of a branch in flabellar view; Copenhagen Museum. Figs. 1-3, $\times 6 ; 4-11, \times 5$. 


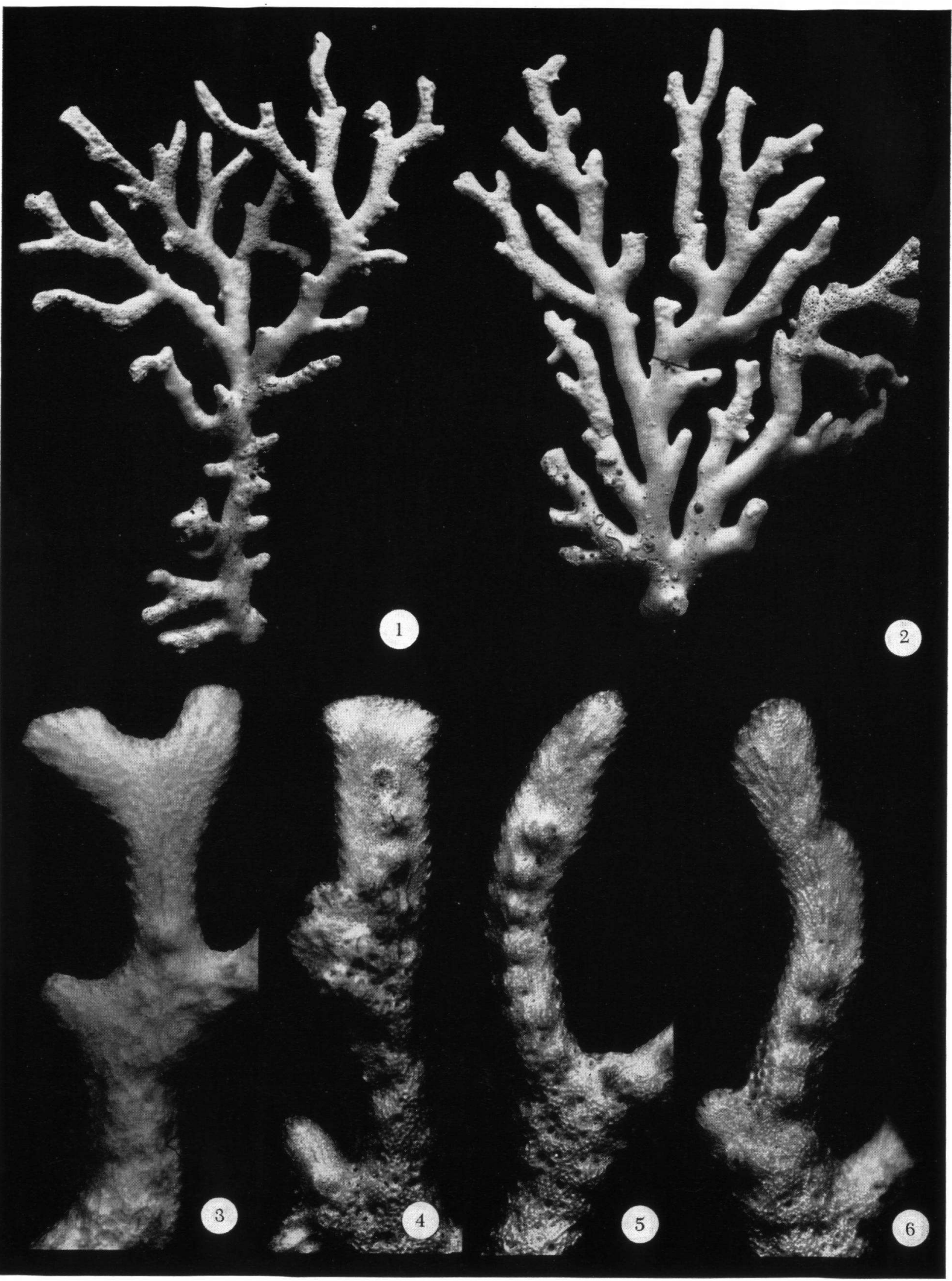

\section{PLATE XVI}

D. borealis, Okinose, Sagami Sea; Copenhagen Museum. Fig. 1. One of the large colonies in anterior view. Fig. 2. The other large colony in posterior view. Figs. 3-6. Tops of branches in flabellar view, with female ampullae. Figs. 1 and 2 , natural size; $3-6, \times 5$. 


\section{DISTICHOPORA SERPENS BROCH, 1942}

Distichopora serpens Broch, 1942, p. 16; Boschma, 1953, p. 167; Boschma, 1956a, p. 142; Boschma, 1956b, p. F 100; Boschma, 1957, p. 46.

Broch (1942, pp. 16-18) gives the following description of the species (notes on the soft parts and references to figures omitted):

"The specimens display a distinctly dichotomic ramification, and larger colonies evidently do not show pronounced differences of main stem and branches. The branches and the terminal branchlets are rather strongly compressed and have their pore-rows along the narrower, lateral margins. Owing to the dentiform projections at the outer side of the dactylopores, the branchlets under the lens show a serrate contour in anterior and posterior aspect. The gastropores are seated in a comparatively deep and regular sulcus. The surface of the coenosteum is distinctly and rather coarsely warty, but no pores are seen between the warts at lower, magnifications, and neither vermiculation nor veins have been observed. The color (in alcohol) is a yellowish orange.

The gastropores attain a diameter at the opening of $0.25-0.30 \mathrm{~mm}$ and have a comparatively short, feebly conical gastrostyle. In the deeper parts of the gastropore the walls especially in older pores carry rather numerous, small and irregularly warty protuberances, but no spicules are present.

The dactylopores are arranged at somewhat irregular intervals and show no distinct relation to the gastropores. A dactylotome connects the inner part of the oval dactylopore with the sulcus, whereas the side walls, and especially the outer wall of the pore opening, are elevated to form a low tooth which is more prominent on the terminal part of the branchlet.

The female ampullae are rather superficially placed on the flattened sides of the branches, and protrude like somewhat larger globe segments. Their surface is rather coarsely warty, and in most cases they are radially grooved, especially in their peripheral parts. The ampullae may occur singly, but in most cases they appear in small groups. They do not influence the regular configuration of the pore-rows.

The coenosteum of the present species is rather densely constructed with narrow coenenchym canals. It is on the other hand not copiously developed, and the colonies are accordingly rather slender, and slender in comparison with other species of Distichopora."

Seven fragments and quite small colonies (the type specimen, cf. Broch, 1942, Pl. 2 fig. 8, having a height of $24 \mathrm{~mm}$ and a breadth of $17 \mathrm{~mm}$ ) were collected in San Bernardino Strait, Philippine Islands, at a depth of 50 to 100 fathoms (91 to $183 \mathrm{~m}$ ).

In its general appearance the type specimen of $D$. serpens bears a strong resemblance to the specimens of $D$. gracilis from the Tuamotu Islands. The fact that the branches and the terminal branchlets are strongly compressed points already to a distinct specific difference, the branches of $D$. gracilis being approximately round. Moreover the gastrostyles of $D$. serpens are entirely different from those of all other species of the genus by being short and feebly conical, not elongated as in the other species. Especially on account of the last-mentioned character $D$. serpens occupies an isolated position in the genus.

The side view of a branch of Distichopora serpens, showing details of the pore-row (BRoch, 1942, fig. 3 b) was copied by Boschma (1956 b, p. F 102).

\section{Geographical distribution}

The species is known from one locality only: San Bernardino Strait, Philippine Islands (Ввосн, 1942).

\section{EXPLANATION OF THE PLATES}

The photographs were made in the Leiden Museum, with the exception of PI. II fig. I (British Museum) and of
PI. III figs. 1 and 5 and Pl. VII fig. 1 (Mr. L. Le Charles, Paris).

\section{REFERENCES}

Blainville, H. M. D. DE, 1830: Zoophytes. Dict. Sc. Nat., vol. 60. Strasbourg \& Paris.

Blannville, H. M. D. DE, 1834: Manuel d'Actinologie ou de Zoophytologie. Paris.

Bondaert, P., 1768: Lyst der Plant-Dieren, bevattende de algemeene Schetzen der Geslachten en korte Beschryvingen der bekende Zoorten. Utrecht.

Boddaert, P., 1798: Natuurlyke Historie der Plant-Dieren, bevattende de algemeene Schetzen der Geslachten en korte Beschryvingen der bekende Zoorten. Amsterdam.

Bosc, L. A. G., 1802 [an X]: Histoire naturelle des Vers, contenant leur description et leurs moeurs, vol. 2. Paris.

Boschma, H., 1951: On a Specimen of Distichopora brasseyae Wright (Hydrocorallia, Stylasterina). Proc. Kon. Ned. Akad. Wetensch. Amsterdam (C), vol. 54.

Boschma, H., 1953: The Stylasterina of the Pacific. Zool. Meded. Mus. Leiden, vol. 32 no. 16.

Boschma, H., 1956a: Stylasterina in the Collection of the 
Paris Museum I. Distichopora gracilis Dana. Proc. Kon. Ned. Akad. Wetensch. Amsterdam (C), vol. 59.

Boschмa, H., 1956b: Milleporina and Stylasterina. Treatise on Invertebrate Paleontology, part F, Coelenterata.

Boschma, H., 1957: List of the described Species of the Order Stylasterina. Zool. Verh. Mus. Leiden, no. 33.

Boschma, H., 1959: The Species Problem in Corals. Proc. XVth Intern. Congr. Zool. London.

BRocH, HJ., 1942: Investigations on Stylasteridae (Hydrocorals). Skr. Norske Vidensk.-Akad. Oslo, matem.-naturv. Kl. 1942 no. 3.

Broch, HJ., 1950: Stylasteridae (Hydrocorals) from Southern Seas. Discovery Repts., vol. 26.

Crossland, C., 1928: Coral Reefs of Tahiti, Moorea, and Rarotonga. Journ. Linn. Soc. London, Zool., vol. 36.

Cuvier, G., 1830. Le Règne animal, distribué d'après son organisation, 2nd ed., vol. 3. Paris.

Cuvier, G., 1836: Idem, 3rd ed., vol. 3. Bruxelles.

DanA, J. D., 1846-1849: Zoophytes. United States Exploring Expedition during the Years 1838, 1839, 1840, 1841,1842 , under the Command of Charles Wilkes, U. S. N., vol. 7 .

DANA, J. D., 1859: Synopsis of the Report on Zoophytes of the U. S. Exploring Expedition. New Haven.

DAwydoff, C., 1952: Contribution à l'étude des Invertébrés de la faune marine benthique de l'Indochine. Bull. Biol. France Belgique, suppl. 37.

Defrance, J. L. M., 1826: Distichopore. Dict. Sc. Nat., vol. 42. Strasbourg \& Paris.

Dehorne, Y., 1920. Les Stromatoporoïdés des terrains secondaires. Mém. pour servir à l'explication de la Carte géol. détaillée de la France. Paris.

Delage, Y. \& E. Hérouard, 1901: Traité de Zoologie concrète, vol. 2 pt. 2. Les Coelentérés. Paris.

Deshayes, G. P. \& H. Milne Edwards, 1836: Histoire naturelle des animaux sans vertèbres [par J. B. P. A. DE LAMarck], vol. 2. Histoire des Polypes. Paris.

Deslongchamps, E., 1824: Histoire naturelle des Zoophytes, ou Animaux Rayonnés. Encycl. Méthod., vol. 2. Paris.

Edmondson, C. H., 1928: The Ecology of an Hawaiian Coral Reef. Bernice P. Bishop Mus., Bull. 45.

Edmondson, C. H., 1946: Reef and Shore Fauna of Hawaii. Bernice P. Bishop Mus., Spec. Publ. 22 (first printed, 1933). Honolulu.

EGUCHI, M., 1941: Stylasterina from Japanese Seas. Jubilee Publ. Comm. Prof. H. YABE, M. I. A., 60th Birthday, vol. 2.

Ellis, J., \& D. Solander, 1786. The Natural History of many curious and uncommon Zoophytes. London.

ENGLAND, H. M., 1926: Development of Gonophores of the Stylasteridae. Proc. Zool. Soc. London.

Fisher, W. K., 1938: Hydrocorals of the North Pacific Ocean. Proc. U. S. Nat. Mus., vol. 84.

Fowler, G. H., 1900: The Hydromedusae. A Treatise on Zoology (ed. E. Ray Lankester), vol. 2. The Porifera and Coelenterata. London.

Gardiner, J. S., 1936: The Reefs of the Westem Indian Ocean. I, Chagos Archipelago; II, The Mascarene Region. Trans. Linn. Soc. London (2), Zool., vol. 19.

Gmelin, J. F., 1789: Vermes Zoophyta. Caroli a Linné Systema Naturae, ed. XIII, vol, 1 pt. 6. Lugduni.

GrÄFFE, E., 1866: Notizen über die Fauna der Viti-Inseln. Verh. k.-k. zool.-bot. Ges. Wien, Jhrg. 1866.
Gray, J. E., 1860: Description of a new Species of Distichopora from New Caledonia. Proc. Zool. Soc. London.

Grobsen, K., 1917: Lehrbuch der Zoologie [Claus], 3rd ed. Marburg in Hessen.

HaLl, T. S., 1898: Stylasteridae from the Victorian Tertiaries. Proc. Roy. Soc. Victoria, n. s., vol. 10.

Henschel, A. G. E. Th., 1833: Clavis Rumphianae botanica et zoologica accedunt vita G. E. RuMPhI, Plinii Indici, specimenque materiae medicae amboinensis. Vratislaviae.

Herbst, J. F. W., 1789: Von den Würmern. Gemeinnüzzige Naturgeschichte des Thierreichs [Borowski], vol. 10. Berlin \& Stralsund.

Hickson, S. J., 1889: A Naturalist in North Celebes. London.

Hickson, S. J., 1892: Reports on the Zoological Collections made in Torres Straits by Professor A. C. Haddon, 18881889. Notes on a small Collection of Hydrocorallinae. Scient. Proc. Roy. Dublin Soc., n. s., vol. 7.

Hickson, S. J., 1893: The early Stages in the Development of Distichopora violacea, with a short Essay on the Fragmentation of the Nucleus. Quart. Journ. Microsc. Sci., n. s., vol. 35 .

Hickson, S. J., 1898: On the Species of the Genus Millepora: a preliminary Communication. Proc. Zool. Soc. London.

Hickson, S. J., 1924: An Introduction to the Study of Recent Corals. Publ. Univ. Manchester, Biol. Ser., no. 4.

Hickson, S. J., \& H. M. England, 1905: The Stylasterina of the Siboga Expedition. Siboga Exp., monogr. 8.

Hickson, S. J., \& H. M. Encland, 1909: The Stylasterina of the Indian Ocean. Trans. Linn. Soc. (2), Zool,, vol. 12.

KeNT, W. S., 1871: On some new and little-known Species of Madrepores, or Stony Corals, in the British Museum Collection. Proc. Zool. Soc. London.

Kent, W. S., 1893: The Great Barrier Reef of Australia; its Products and Potentialities. London.

Kirkpatrick, R., 1890: Report upon the Hydrozoa and Polyzoa collected by P. W. BAssetr-Smirh, Esq., Surgeon R. N., during the Survey of Tizard and Macclesfield Banks, in the China Sea, by H. M. S. "Rambler", Commander W. U. Moore. Ann. Mag. Nat. Hist. (6), vol. 5.

Kirkpatrick, R., 1902: Hydrozoa. Guide to the Coral Gallery ........ British Museum (Natural History). London.

Klunzinger, C. B., 1879: Die Korallthiere des Rothen Meeres. III, Die Steinkorallen, pt. 2, Die Astraeaceen und Fungiaceen. Berlin.

KNAuER, F., 1887: Handwörterbuch der Zoologie (unter Mitwirkung von Von Dalla TorRe). Stuttgart.

KüнN, O., 1928: Hydrozoa. Fossilium Catalogus, I. Animalia (ed. C. Diener), pt. 36. Berlin.

KüнN, O., 1939: Hydrozoa. Handbuch der Paläozoologie (ed. Schindewolf), vol. 2 A. Berlin.

Lamarck, J. B. P. A. DE, 1816a: Histoire Naturelle des animaux sans vertèbres, vol. 2. Paris.

LAmARCK, J. B. P. A. DE, 1816b: Tableau encyclopédique et méthodique des trois Règnes de la nature. 23me partie, Mollusques et Polypes divers. Paris.

Lamouroux, J., 1821: Exposition méthodique des genres de l'ordre des Polypiers. Paris.

Lendenfeld, R. von, 1885: The Australian Hydromedusae, part 5. Proc. Linn. Soc. New South Wales, vol. 9. 
Lendenfeld, R. von, 1887: Descriptive Catalogue of the Medusae of the Australian Seas. Australian Museum, Sydney.

Ludwig, H., 1886: Dr. Johannes Leunis Synopsis der Thierkunde, 3rd ed., vol. 2. Hannover.

Matllard, L., 1862: Notes sur l'ile de la Réunion (Bourbon). Paris.

Malllard, L., 1863: Idem, 2me éd., vol. 2. Paris.

Martens, E. von, 1902: Die Mollusken (Conchylien) und die übrigen wirbellosen Thiere in RuMPF's Rariteitkamer. RuMPHIUs Gedenkboek. Haarlem.

Michelin, H., 1862: Cnidiaires. Annexe B in Malllard, 1862.

Michel.n, H., 1863: Cnidiaires. Annexe B in Maillard, 1863.

Milne Edwards, H., 1836-1849: Les Zoophytes. Le Règne animal distribué d'après son organisation, ..... par Georges Cuvier. Paris.

Milne Edwards, H., 1860: Histoire Naturelle des Coralliaires ou Polypes proprement dits, vol. 3. Paris.

Milne Edward, H., \& J. Haime, 1850-1854: A Monograph of the British fossil Corals. London.

Moseley, H. N., 1877: Preliminary Note on the Structure of the Stylasteridae, a Group of Stony Corals which, like the Milleporidae, are Hydroids, and not Anthozoans. Proc. Roy. Soc. London, vol. 25.

Moserey, H. N., 1879: On the Structure of the Stylasteridae, a Family of the Hydroid Stony Corals. Phil. Trans. Roy. Soc. London, vol. 169.

Moseley, H. N., 1880: Report on certain Hydroid, Alcyonarian, and Madreporarian Corals procured during the Voyage of H. M. S. Challenger in the Years 18731876. Rep. Sci. Res. Challenger, Zool., vol. 2 pt. 7.

Moseley, H. N., 1892: Notes by a Naturalist. An Account of Observations made during the Voyage of $\mathrm{H}$. M. S. "Challenger" round the World in the Years 1872-1876, new and revised ed. (lst ed., 1879). London.

NARDo, G. D., 1844a: Nota sopra una nuova specie di Distichopora vivente (D. cinabarina Nardo). Atti Ist. Veneto di Scienze, Lettere ed Arte, vol. 3.

NARDo, G. D., 1844b: Nuova specie vivente di Dictichopora, D. cinnabarina Nardo. Atti quinta Unione Scienziati italiani. Lucca.

NARDo, G. D., 1845: Eine neue Classification der Zoophyten. Isis (ed. Oken), Jhrg. 1845.

OxEN, L., 1815: Lehrbuch der Naturgeschichte, vol. 3, Zoologie, pt. 1, Fleischlose Thiere. Leipzig \& Jena.

Ortmann, A., 1892: Die Korallriffe von Dar-es-Salaam und Umgegend. Zool. Jahrb., Syst., vol. 6.

Pallas, P. S., 1766: Elenchus Zoophytorum sistens generum adumbrationes generaliores et specierum cognitarum succinctas descriptiones cum selectis auctorum synonymis. Hagae-Comitum.

PAx, F., 1928: Akori. Die Rohstoffe des Tierreichs, vol. 2, chapter 12, C. Berlin.

Perrier, E., 1881: Les colonies animales et la formation des organismes. Paris.
Pourtalès, L. F. DE, 1871: Deep-sea Corals. Illustrated Catalogue of the Museum of Comparative Zoölogy at Harvard College, IV.

Quelch, J. J., 1884a: On new Stylasteridae, with Remarks on some recently described Forms. Ann. Mag. Nat. Hist. (5), vol. 13.

Quelch, J. J., 1884b: On some Stylasteridae. Ibid. (5), vol. 13.

QUeLCH, J. J., 1885: On some Deep-sea and Shallow-water Hydrozoa. Ibid. (5), vol. 16.

Rumphius, G. E., 1750: Herbarium Amboinense, vol. 12. Amsterdam.

Schmeltz, J. D. E., 1866: Bemerkungen. In GräFFE, 1866.

Schmeltz, J. D. E., 1875: [Distichopora violacea, D. coccinea, D. purpurea]. Verh. Ver. naturw. Unterh. Hamburg, vol. 1.

Schmeltz, J. D. E., 1882: Führer durch das Museum Godeffroy. Hamburg.

Schweigger, A. F., 1819: Anatomisch-physiologische Untersuchungen über Corallen. Beobachtungen auf naturhistorischen Reisen. Berlin.

Schweigger, A. F., 1820: Handbuch der Naturgeschichte der skelettlosen ungegliederten Thiere. Leipzig.

Tenison-Woods, J. E., 1879a: On a new Species of Distichopora. Proc. Linn. Soc. New South Wales, vol. 4.

Tenison-Woons, J. E., 1879b: On the Anatomy of Distichopora - with a Monograph of the Genus. Journ. Proc. Roy. Soc. New South Wales, vol. 13.

Tenison-Woons, J. E., 1880: Corals and Bryozoa of the Neozoic Period in New Zealand. Palaeontology of New Zealand, pt. 4. Wellington.

Toxioxa, T., 1953: Invertebrate Fauna of the Intertidal Zone of the Tokara Islands I. Introductory Notes with the Outline of the Shore and the Fauna. Publ. Seto Marine Biol. Lab., vol. 3 no. 2.

UTINOMI, H., 1956a: Coloured Illustrations of Sea Shore Animals of Japan. Osaka.

UTiNomi, H., 1956b: Invertebrate Fauna of the Intertidal Zone of the Tokara Islands XIV. Stony Corals and Hydrocorals. Publ. Seto Marine Biol. Lab., vol. 5 no. 3.

Verrill, A. E., 1864: List of Polyps and Corals sent by the Museum of Comparative Zoölogy to other Institutions in Exchange, with Annotations. Bull. Mus. Comp. Zoöl. Harvard Coll., vol. 1 no. 3 .

WARD, H. A., 1892: Catalogue of Specimens of Echinodermata, Corals, Gorgonias and Sponges, for sale at WArD's Natural Science Establishment. Rochester, N. Y.

Weiss, J. W., 1954: Recent Corals of the Marshall Islands. Bikini and Nearby Atolls, part 2, Oceanography (Biologic). Geol. Survey Professional Paper 260-1.

Wilkens, C. F., 1787: P. S. Pallas Charakteristik der Thierpflanzen, ed. by J. F. W. Herbst, vol. 1. Nürnberg.

Wrichr, B., 1882: On some new Species of Corals. Ann. Mag. Nat. Hist. (5), vol. 9.

Wright, B., 1884: On new Stylasteridae. Ibid. (5), vol. 13. 